\title{
Recent Advances in the Synthesis of Polymer-Grafted Low-K and High-K Nanoparticles for Dielectric and Electronic Applications
}

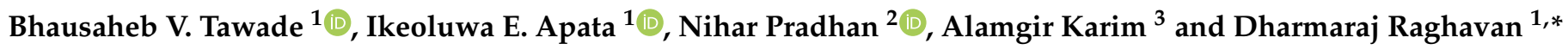 \\ 1 Department of Chemistry, Howard University, Washington, DC 20059, USA; \\ bhausaheb.tawade@howard.edu (B.V.T.); ikeoluwa.apata@bison.howard.edu (I.E.A.) \\ 2 Department of Chemistry, Physics and Atmospheric Science, Jackson State University, \\ Jackson, MS 39217, USA; nihar.r.pradhan@jsums.edu \\ 3 Department of Chemical and Biomolecular Engineering, University of Houston, Houston, TX 77204, USA; \\ akarim3@central.UH.edu \\ * Correspondence: draghavan@howard.edu
}

check for updates

Citation: Tawade, B.V.; Apata, I.E.; Pradhan, N.; Karim, A.; Raghavan, D. Recent Advances in the Synthesis of Polymer-Grafted Low-K and High-K Nanoparticles for Dielectric and Electronic Applications. Molecules 2021, 26, 2942. https://doi.org/ $10.3390 /$ molecules 26102942

Academic Editor: Bhanu P.

S. Chauhan

Received: 14 April 2021

Accepted: 10 May 2021

Published: 15 May 2021

Publisher's Note: MDPI stays neutral with regard to jurisdictional claims in published maps and institutional affiliations.

Copyright: (c) 2021 by the authors. Licensee MDPI, Basel, Switzerland. This article is an open access article distributed under the terms and conditions of the Creative Commons Attribution (CC BY) license (https:// creativecommons.org/licenses/by/ $4.0 /)$.

\begin{abstract}
The synthesis of polymer-grafted nanoparticles (PGNPs) or hairy nanoparticles (HNPs) by tethering of polymer chains to the surface of nanoparticles is an important technique to obtain nanostructured hybrid materials that have been widely used in the formulation of advanced polymer nanocomposites. Ceramic-based polymer nanocomposites integrate key attributes of polymer and ceramic nanomaterial to improve the dielectric properties such as breakdown strength, energy density and dielectric loss. This review describes the "grafting from" and "grafting to" approaches commonly adopted to graft polymer chains on NPs pertaining to nano-dielectrics. The article also covers various surface initiated controlled radical polymerization techniques, along with templated approaches for grafting of polymer chains onto $\mathrm{SiO}_{2}, \mathrm{TiO}_{2}, \mathrm{BaTiO}_{3}$, and $\mathrm{Al}_{2} \mathrm{O}_{3}$ nanomaterials. As a look towards applications, an outlook on high-performance polymer nanocomposite capacitors for the design of high energy density pulsed power thin-film capacitors is also presented.
\end{abstract}

Keywords: polymer-grafted nanoparticles; dielectric properties; energy density; $\mathrm{SiO}_{2} ; \mathrm{TiO}_{2} ; \mathrm{BaTiO}_{3}$; $\mathrm{Al}_{2} \mathrm{O}_{3}$; reversible deactivation radical polymerization; ATRP; RAFT; NMP; click chemistry

\section{Introduction}

The growing demand for power electronics and energy storage serves as an excellent motivation for developing next generation dielectrics and electrical insulation materials [1,2]. Dielectric polymers and polymer nanocomposites stand out as next generation dielectric materials for many electrical insulation and energy storage applications owing to their high dielectric strength, high voltage endurance, low dielectric loss, low equivalent series resistance, a gradual failure mechanism, light weight, low cost and ease of processability [3-10]. The use of polymer-based dielectric capacitors in various sectors is summarized in Figure 1A. As a result of numerous emerging potential applications of polymer-based dielectric materials and capacitors, research on strategies for enhancing capacitive energy storage methods has experienced significant growth. Figure 1B shows the number of yearly publications in the last 25 years on the topic of "dielectric polymer capacitor" as found in the Sci-Finder database. Clearly, over the years the research interest in the field of polymer dielectric capacitors has grown exponentially.

Apart from the use of polymers in nanocomposites, inorganic materials such as ceramics are critical components for nanocomposite capacitors due to their extremely large dielectric constants, often times $>1000$. Despite their high dielectric constants, inorganic materials suffer from a low breakdown strength and non-graceful failure mode. Polymer nanocomposites integrate key attributes of polymer and ceramic nanomaterial to improve the overall dielectric properties [11,12]. 


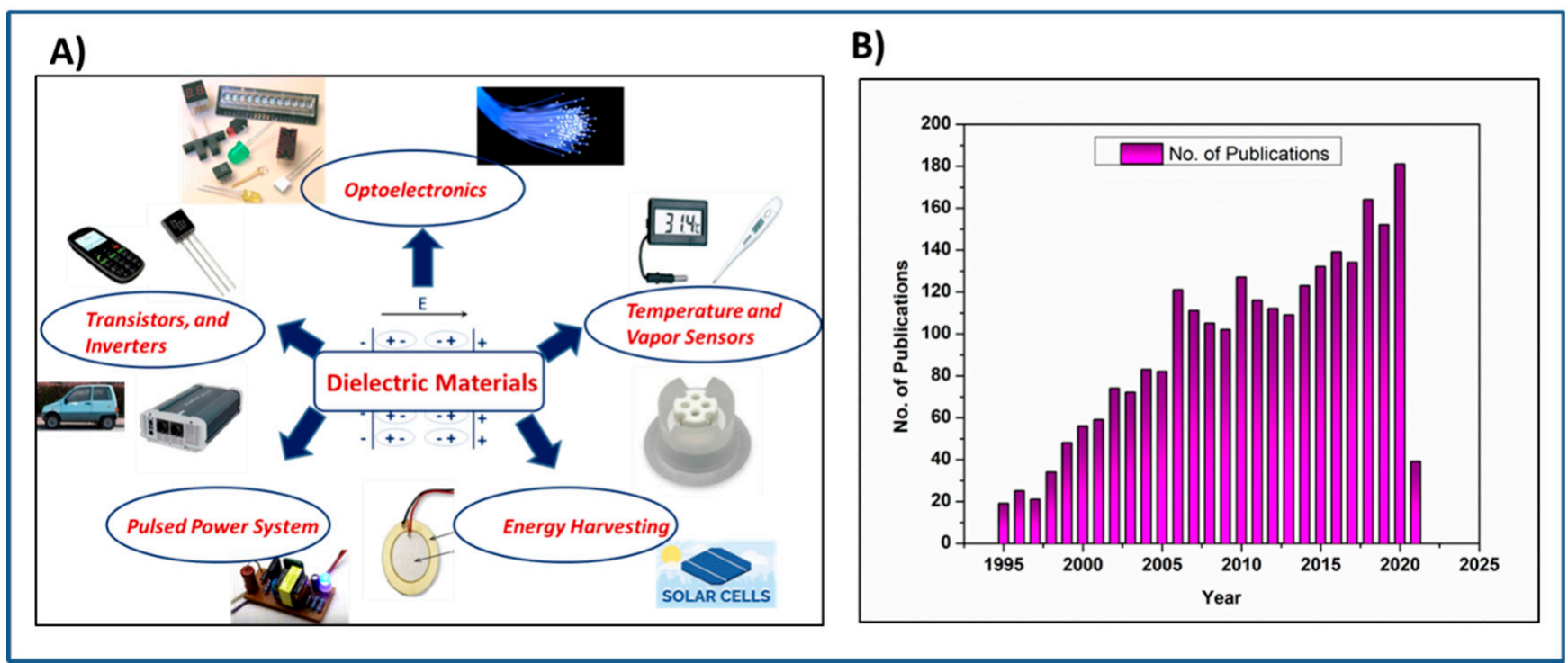

Figure 1. (A) The emerging applications of dielectric capacitors (B) Number of publications on "polymer dielectric capacitor" per year in the last 25 years.

Several comprehensive review articles including a couple of review articles from our group have been published in the field of polymer and polymer nanocomposite dielectrics [13-26]. Our first review article dealt with coverage of the nanoscale strategies in the field of polymeric and polymer nanocomposites for use in emerging dielectric capacitorbased energy storage applications [13]. Some of the strategies to address permittivity contrast between nanofillers and the polymer matrix including potential for developing gradient permittivity structured nanofillers were presented. Additionally, we had described approaches to improve the compatibility of nanofiller with polymer, minimize nanofiller aggregation, and mitigate the permittivity contrast between nanofiller and polymer, In our second review article, we discussed different chemical routes for surface functionalization of ceramic nanoparticles [14]. For instance, the article dealt with the synthesis of low-k and high- $\mathrm{k}$ nanomaterials [19-24] as well as surface functionalization of nanomaterials including treatment with hydrogen peroxide, silane coupling agents, phosphonic acid and dopamine moieties that improved the interaction between nanomaterials and polymer matrix.

In the review article published in Nanotechnology [14], it was pointed out that the selection of the surface modifying coupling agent on the surface of nanoparticles/layer dictate the dielectric properties of the nanocomposites as well as the performance of the bilayer as it relates to gate dielectrics. Although, functionalization of nanomaterials with chemical agents is less cumbersome and less equipment intensive there are several shortcomings to adopting this method viz., (i) the structure of the chemical modifying agent is distinctly different from the long chain of polymer matrix (ii) side reaction of the chemical agent could lead to multilayer formation and (iii) physical adsorption of the modifying agent. Unlike the surface modification of nanoparticles with chemical agents, the polymer grafting of the nanoparticles yield nanoparticles with surface energy which closely matches with that of the polymer matrix. The improved compatibility of polymer-grafted nanoparticles with polymer matrix often yields nanocomposites with superior properties compared to nanocomposites with chemical agent-modified nanoparticles. For instance, maximum energy density and extraction efficiency values for polymethylmethacrylate (PMMA) grafted $\mathrm{BaTiO}_{3}$ filled PMMA nanocomposites was found to be two fold higher than that of coupling agent surface-modified $\mathrm{BaTiO}_{3}$ filled PMMA nanocomposites [27].

There are many approaches to improve the compatibility of the nanoparticles with polymer matrix, the nanoparticles spatial dispersion in the matrix and decrease the permittivity contrast between polymer and nanoparticles. Approaches could be based on 
the use of by external triggers such as a simple control of the film processing conditions (controlling \% loading of filler) [28] or, of the electrostatic repulsion (tuning by change $\mathrm{pH}$ ) [29] or with a magnetic field (tuning based on magnetic field) [30] or an internal trigger such as chemical/polymer grafting approach [31,32]. This article only deals with internal trigger (by synthesis of polymer-grafted nanoparticles) to address the compatibility of nanoparticles and polymer. Several recent reviews have comprehensively covered the topic of polymer grafting of nanoparticles [33-40]. For example, the review by Ameduri et al., [35] dealt primarily with grafting of polymers on high-K NPs $\left(\mathrm{BaTiO}_{3}\right)$ for use in the formulation of high energy storage fluorinated polymer nanocomposites. In the present review, we cover the synthesis of polymer-grafted high- $\mathrm{K}$ and low-K nanoparticles for the fabrication of nanocomposites for electronics and dielectric application. Unlike, Yang et al.'s [38] review which discusses only the synthesis of polymer-grafted high and low K-nanoparticles using surface initiated-polymerization approaches, our review will cover the broad gamut of approaches available to synthesize polymer-grafted silicon dioxide $\left(\mathrm{SiO}_{2}\right)$, titanium dioxide $\left(\mathrm{TiO}_{2}\right)$, barium titanate $\left(\mathrm{BaTiO}_{3}\right)$, and aluminum oxide $\left(\mathrm{Al}_{2} \mathrm{O}_{3}\right)$ nanoparticles and their applications as dielectrics and electronics.

The grafting of polymeric chains to nanoparticles can generally be achieved by four approaches namely (i) "grafting to"; (ii) "grafting from"; (iii) templated and (iv) in situ polymerization or encapsulation. Figure 2 presents pictorially the various approaches commonly adopted to prepare polymer-grafted nanoparticles. All the four approaches yield polymer-grafted nanoparticles of varying shell architecture. The polymer graft conformation on the nanoparticles is a result of the covalent bond formation that compensates for the entropy loss resulting from the polymer chains stretching away from the surface. If the polymer chains on the grafted nanoparticles have molecular weight lower than the entanglement molecular weight, then the harvested nanoparticles are commonly blended with virgin polymer to form polymer nanocomposite. On the other hand, if the molecular weight of the polymer chains on the polymer-grafted nanoparticles is far greater than the entanglement molecular weight, a nanocomposite could be formed without the addition of an external polymer matrix. The former is called multi component system while the latter is called single component system [37,41-43].

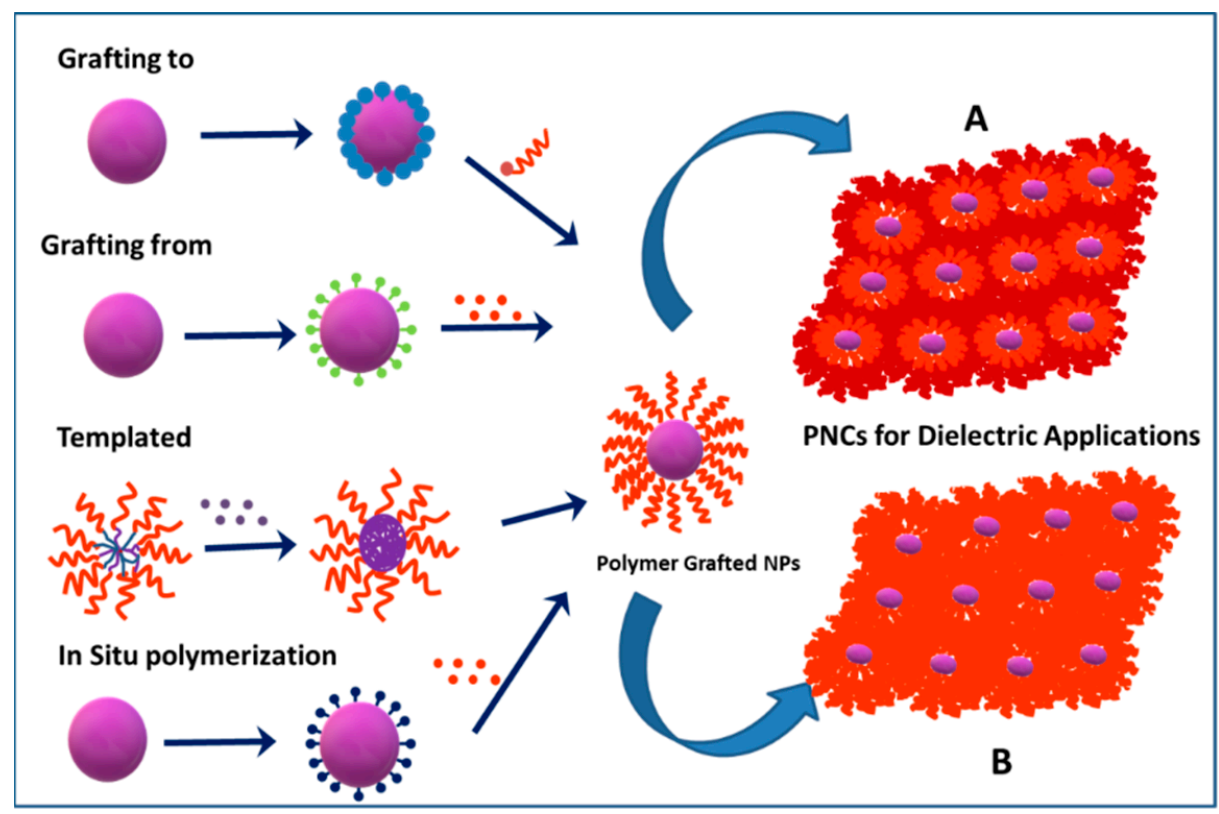

Figure 2. Approaches for grafting polymer chains on the surface of nanomaterials. (A) Polymernanocomposite formed from polymer-grafted NPs and polymer matrix. (B) Polymer nanocomposite formed from only polymer-grafted NPs). 
As represented in Figure 2, encapsulation or in situ polymerization approach is based on monomers being initially adsorbed on the NPs surface, and initiation of polymerization of the adsorbed monomer layer, yielding polymer-coated NPs. Sometimes the encapsulation approach could be termed as in situ grafting through approach because the monomers adsorbed on the NPs undergo polymerization in the presence of initiator in the bulk $[44,45]$. The second approach uses block copolymer-based micelle-template in the synthesis of hairy nanoparticles (HNPs). In this method, a precursor, commonly a metal salt or an organometallic compound, is loaded into the core of polymer micelles based on either multi-molecular block copolymer or unimolecular star block copolymer. The reduction of (complex) metal ions in the micelle core yields core-shell NPs [46,47]. The third approach is based on grafting-to which involves the attachment of end-functionalized polymer chains on the surface of NPs via suitable chemical reactions. A variety of reactions such as esterification, silylation, click reactions including thiol-ene, alkyne-azide cycloaddition, etc. have generally been utilized in the grafting to approach. The fourth approach is based on grafting-from/SI-CRP which consists of growing polymer chains directly from the surface of nanoparticles functionalized with suitable initiator/CTA functionalities. There have been remarkable developments in the surface-initiated controlled radical polymerization (SI-CRP) route for the synthesis of polymer-grafted nanoparticles [33,48-52]. Pioneering work from Matyjaszewski [53], Mueller [54], Benicewicz [55], Takahara [56], Hawker [57] and coworkers have paved the road for progress in SI-CRP methods. SI-CRPs (ATRP, SI-RAFT and SI-NMP) have been successfully employed for the generation of plethora of polymer grafted nanoparticles (PGNPs) because of its tolerance towards various functional groups [48].

Table 1 summarizes the advantages and disadvantages of the four approaches outlined in the synthesis of PGNPs. Among the various approaches, grafting from approach is widely employed in the polymer functionalization of nanoparticles because of its ability to synthesize well-defined polymer architectures of desired composition and molecular weight, and a shell of controlled thickness on the nanoparticle surface. Given the enormous data available on grafting from technique, this article will predominantly cover this approach. Examples of other approaches in the polymer functionalization of ceramic oxide NPs are also covered.

Table 1. Comparison of advantages and disadvantages of polymer grafting methods.

\begin{tabular}{|c|c|c|}
\hline Grafting Methods & Advantages & Disadvantages \\
\hline Grafting to & $\begin{array}{l}\text { A number of coupling reactions and click reaction are } \\
\text { available. } \\
\text { Well-defined end-functionalized polymers can be } \\
\text { obtained from CRPs. } \\
\text { Clean approach, less labor intensive [33] }\end{array}$ & $\begin{array}{l}\text { Due to the steric hindrance high grafting } \\
\text { density could not be achieved. } \\
\text { The approach is limited to polymer grafts } \\
\text { with defined end groups. } \\
\text { The surface of nanoparticles may have } \\
\text { unreacted functionality }\end{array}$ \\
\hline Grafting from & $\begin{array}{l}\text { High grafting density, tuning of thickness with } \\
\text { molecular weight of growing chain is possible [48] }\end{array}$ & $\begin{array}{l}\text { The stringent reaction conditions have to } \\
\text { be maintained. }\end{array}$ \\
\hline Templated & Well-defined size of nanoparticles can be obtained [58] & $\begin{array}{l}\text { Scalability is difficult. } \\
\text { Not cost effective }\end{array}$ \\
\hline In situ polymerizations & $\begin{array}{l}\text { The technique is scalable and similar to conventional } \\
\text { free radical polymerization [59] }\end{array}$ & $\begin{array}{l}\text { Difficulty in controlling grafting density } \\
\text { and molecular weights. } \\
\text { Well defined structures such as block } \\
\text { copolymers cannot be synthesized. }\end{array}$ \\
\hline
\end{tabular}




\section{Grafting from Approach}

Grafting from approach may entail the use of anionic or cationic or free radical polymerization in the functionalization of NPs. SI-anionic and cationic polymerizations are excellent routes in providing polymer grafted nanoparticles (PGNPs) with predetermined molecular weights of narrow dispersity [60-63]. However, the complexity of the experimental techniques limits their broad use [64-67]. Alternatively, initiator immobilized NPs have been subjected to free radical polymerization to yield graft NPs $[68,69]$. Conventional free radical polymerization suffers from poor control of molecular weights, chain-end functionality, and polydispersity [31]. Therefore, surface initiated controlled radical polymerization techniques such as atom transfer radical polymerization (ATRP), reversible addition-fragmentation chain-transfer polymerization (RAFT) and nitroxide mediated polymerization (NMP) have been pursued for the synthesis of well-defined PGNPs. Controlled radical polymerization (CRP) technique involves reversible activation-deactivation equilibrium between active chain propagating species and dormant species which lower the rate of chain propagation than that of conventional free radical polymerization. Thus, CRP polymerization offers a route to synthesize PGNPs with well-defined molecular weights and low dispersity. Figure 3 gives a general scheme for the various SI-CRPs methods. Typically, the synthesis of PGNPs is based on the surface modification of NPs, then anchoring/immobilization of initiator/chain transfer agent attachment on the surface-modified NPs and finally polymerization using the surface initiator attached to NPs to obtain PGNPs. Surface modification of NPs is often accomplished with coupling agents such as silane, phosphonic acids, dopamine, etc. More details about the surface modification of NPs with reagents such as silane agent, phosphonic acid, and dopamine can be found in our recent review article [14]. The second step is introducing initiator functionality on the surface agent modified NPs. Alternatively, initiator functionality and coupling agent are pre-reacted to form initiator functionalized coupling agent which is then subsequently reacted with NPs [70]. The merits and demerits of various surface initiated controlled radical polymerization techniques have been presented in Table 2 .

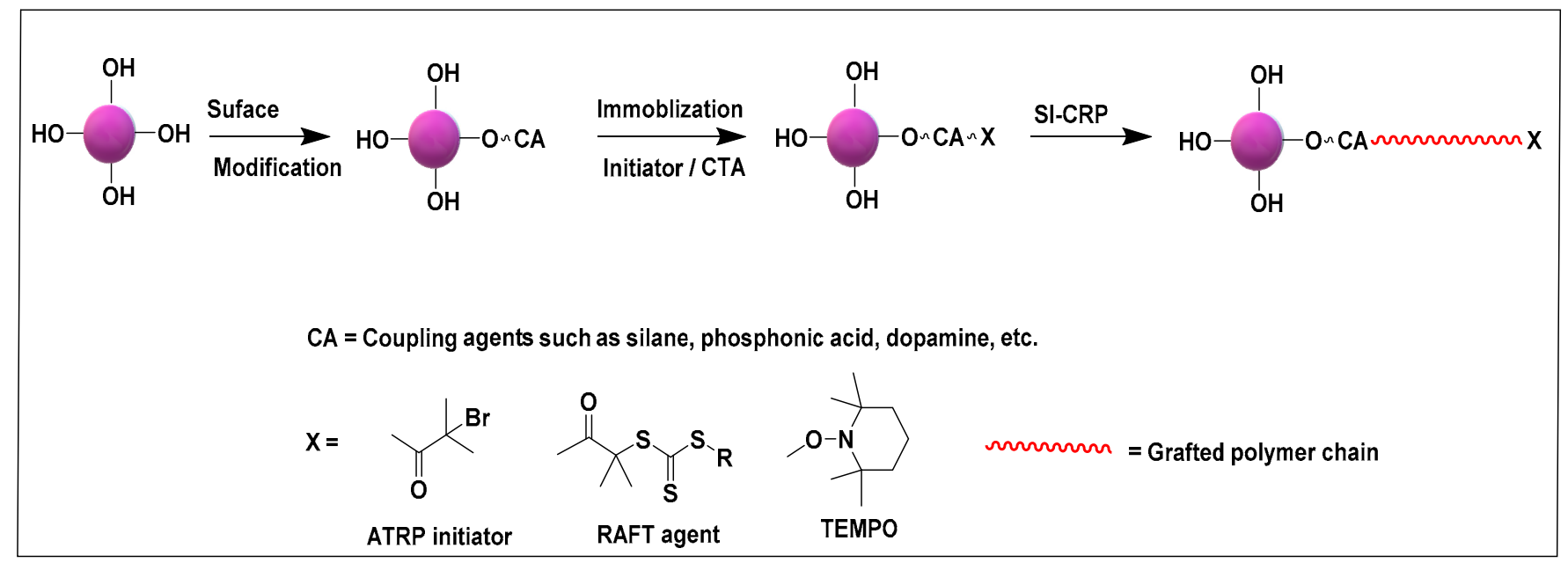

Figure 3. Scheme for surface initiated controlled radical polymerization methods. 
Table 2. Comparison of advantages and disadvantages of grafting from methods.

\begin{tabular}{|c|c|c|}
\hline Grafting from Methods & Advantages & Disadvantages \\
\hline ATRP & $\begin{array}{l}\text { Control of molecular weights and dispersity. } \\
\text { Variation to ATRP technique broaden the } \\
\text { applicability of the technique to a range of surface } \\
\text { initiated polymer grafting [ } 48]\end{array}$ & $\begin{array}{l}\text { Small amount of copper persists along } \\
\text { with polymer, its removal is difficult and } \\
\text { affects the properties of the final product. } \\
\text { Not suitable for acidic monomers } \\
\text { Difficulty in synthesizing high molecular } \\
\text { weight grafts [71] }\end{array}$ \\
\hline RAFT & $\begin{array}{c}\text { Adaptability of RAFT to a range of polymerization } \\
\text { conditions high degree of fidelity, ability to work } \\
\text { in the presence of oxygen, compatibility with a } \\
\text { broad range of functional groups [48] }\end{array}$ & $\begin{array}{l}\text { Because of the presence of sulfur } \\
\text { containing moiety RAFT polymers are } \\
\text { often colored and have foul odor and the } \\
\text { synthesis of RAFT agents involves } \\
\text { multiple steps [48] }\end{array}$ \\
\hline NMP & $\begin{array}{l}\text { NMP is one of the successfully used SI-CRP } \\
\text { techniques for polymer grafting [72] }\end{array}$ & $\begin{array}{l}\text { However, it is not applicable for most of } \\
\text { monomers and functional groups [48] } \\
\text { It requires high temperatures and longer } \\
\text { time due to slow polymerization kinetics. } \\
\text { There are difficulties associated with } \\
\text { synthesis and stability of nitroxide and } \\
\text { alkoxy amine [73] }\end{array}$ \\
\hline
\end{tabular}

\section{Atom Transfer Radical Polymerization (ATRP)}

Atom transfer radical polymerization (ATRP) is one of the most versatile polymerization techniques adopted towards the synthesis of PGNPs because the technique can be used under broad experimental conditions and can be adapted to synthesis of polymers with a wide range of functional groups $[74,75]$. The polymerization of activated vinyl monomer by ATRP process generally requires alkyl halide initiator and a transition metal complex as catalyst (e.g., $\mathrm{CuBr}$ /ligand). ATRP involves reversible activation-deactivation equilibrium between a metal-ligand complex and halide end-capped chain to form radical species which propagates the polymerization. Mechanistic details of ATRP can be found in the literature $[71,74,76-78]$.

Several modifications to ATRP have been studied such as, activator regenerated by electron transfer ATRP (ARGET ATRP), reverse ATRP, UV Light mediated ATRP, and electrochemical mediated ATRP, etc. In ARGET ATRP a reducing agent viz., 2-ethylhexanoate or ascorbic acid or glucose is employed to regenerate the active transition metal complex via reduction of the higher oxidation state transition metal complex [79]. On the other hand, "reverse" ATRP consists of the addition of transition metal complexes in the higher oxidation state and the generation of the lower oxidation state activator by reaction with a conventional free radical initiator $[76,80,81]$. Initially, alkyl halide initiators are immobilized onto the NP surface. Using $\mathrm{CuBr} /$ ligand system, the polymerization proceeds like the classical ATRP polymerization in bulk or solution and monomers are polymerized on the surface of the NPs in a controlled manner.

\subsection{SI-ATRP Polymerization to Prepare Polymer-Grafted $\mathrm{SiO}_{2}$ Nanoparticles}

ATRP reactions have been extensively used to grow polymer/block copolymer brushes from the surface of silica with controlled graft densities [82-84]. For example, polymer/copolymer brushes of PMMA [83,85], polystyrene (PS) [86,87], poly(glycidyl methacrylate) (PGMA) [88,89], poly(2-hydroxyethyl methacrylate) (PHEMA [90], poly(4-vinylpyridine) (PVP) [91], poly(N-isopropylacrylamide) (PNiPAAm) [92], poly(sodium 4-styrene sulfonate) (PSS) [93], poly((ethylene glycol)methyl ether methacrylate) (POEGMA) [94], poly(2(dimethylamino)ethyl methacrylate) (PDMAEMA) [95,96], etc. have been successfully grafted on $\mathrm{SiO}_{2}$ surface via SI-ATRP. Pinto et al. [97] employed SI-ATRP for grafting of PMMA brushes thinner than $50 \mathrm{~nm}$ on $\mathrm{SiO}_{2}$ substrate for tunnel emitter transistor application at operating voltage below $5 \mathrm{~V}$ (which is an important requirement for industrial 
adoption). Hwang et al. [98] employed SI-ATRP for grafting PS brushes on silica surface with controlled molecular weight $(24,600-135,000 \mathrm{~g} / \mathrm{mol})$ as well as grafting density (0.34-0.54 chains $\left./ \mathrm{nm}^{2}\right)$. The performance of pentacene-based thin-film transistor fabricated from PS-grafted $\mathrm{SiO}_{2}$ as a gate dielectric was evaluated as a function of polymer brush thickness viz. 12.4, 47.5 and $113.1 \mathrm{~nm}$. The device fabricated from $47 \mathrm{~nm}$ thickness of PS brush exhibited highest mobility $\left(\mu_{\mathrm{FET}}=0.099 \mathrm{~cm}^{2} / \mathrm{V} \cdot \mathrm{s}\right)$ indicating that optimum molecular weight polymer brushes need to be grown from the surface of dielectric for achieving best performance. The OTFTs with the PS-grafted $\mathrm{SiO}_{2}$ layer showed 2 times higher mobility $\left(\mu_{\mathrm{FET}}=0.099 \mathrm{~cm}^{2} / \mathrm{V} \cdot \mathrm{s}\right)$ than that of bare $\mathrm{SiO}_{2}$ layer $\left(\mu_{\mathrm{FET}}=0.05 \mathrm{~cm}^{2} / \mathrm{V} \cdot \mathrm{s}\right)$. The electrode/active layer interface showed enhanced mobility which could be attributed to grafted PS influencing the morphology of pentacene by enhancing the crystalline structure [98]. Li and coworkers synthesized PMMA- $g-\mathrm{SiO}_{2}$ NPs with $\sim 10 \mathrm{~nm}$ PMMA brush onto the $\mathrm{SiO}_{2}$ layer ( $\sim 9 \mathrm{~nm}$ ) via SI-ATRP. PMMA brush $/ \mathrm{SiO}_{2}$ bilayer dielectrics showed the lowest leakage compared to bare $\mathrm{SiO}_{2}$ and spin coated $\mathrm{PMMA} / \mathrm{SiO}_{2}$ dielectrics which could be attributed to improved interfacial morphology, a smaller number of pinholes at the interface due to the close packing of polymer brush (Figure 4). The surface-grafted PMMA brush $(10 \mathrm{~nm}) / \mathrm{SiO}_{2}(9 \mathrm{~nm})$ on silicon wafer exhibited lower leakage and higher breakdown strength than that of surface-grafted PMMA brush $(20 \mathrm{~nm})$ on silicon wafer (free of $9 \mathrm{~nm} \mathrm{SiO}_{2}$ layer) (Figure $4 \mathrm{~A}, \mathrm{~B}$ ). The authors attributed the enhancement in the breakdown strength of PMMA brush $(10 \mathrm{~nm}) / \mathrm{SiO}_{2}(9 \mathrm{~nm})$ on silicon wafer over PMMA brush $(20 \mathrm{~nm}$ ) grafted on silicon wafer (free of $9 \mathrm{~nm} \mathrm{SiO}$ layer) due to the presence of bilayer and improved interaction between polymer brush and $\mathrm{SiO}_{2}$ layer $[99,100]$. The PMMA-g-SiO ${ }_{2}$ nanodielectric exhibited good operational stability, and good compatibility with organic semiconductors, which enabled OFETs to work at high performance and low voltage [101].

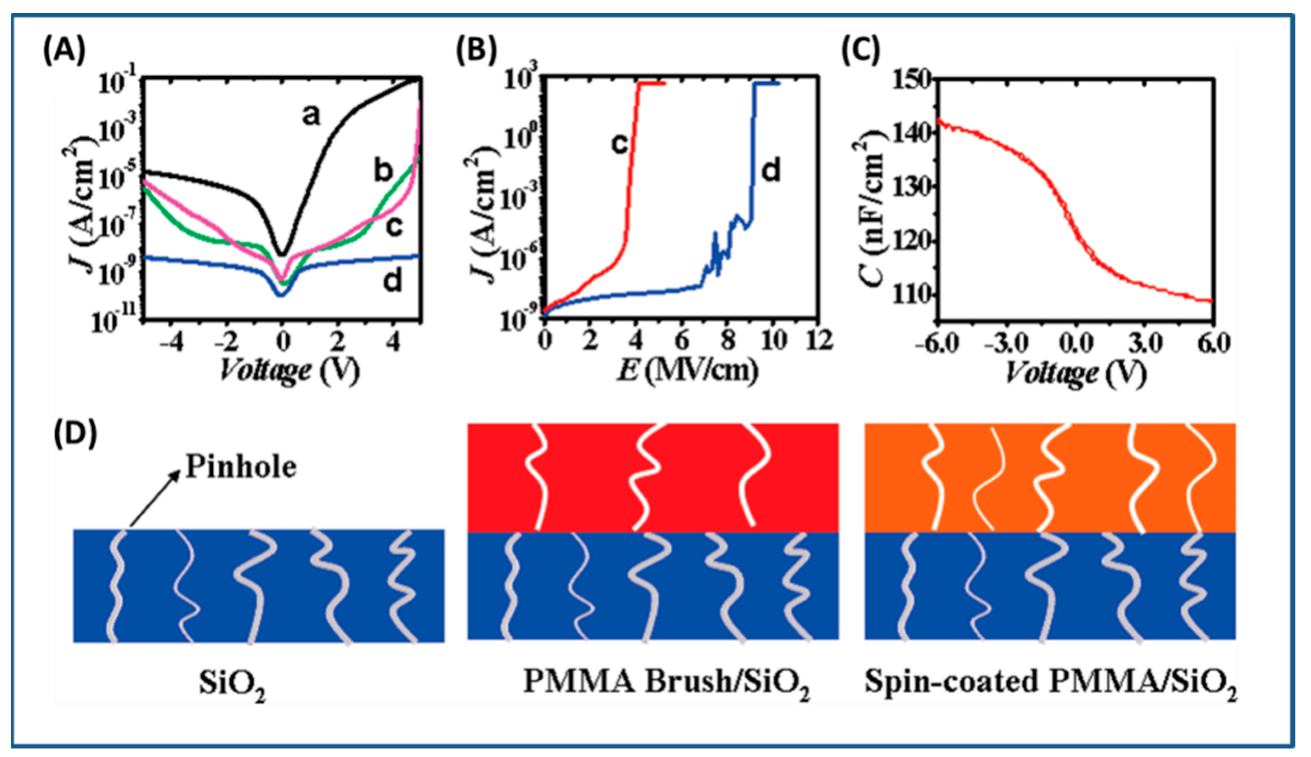

Figure 4. (A) Leakage characteristics and (B) breakdown electric field characteristics for different dielectrics measured with the structure of $\mathrm{Au}$ /dielectric/Si capacitor. Curve a, $\mathrm{SiO}_{2}(9 \mathrm{~nm})$; curve b, spin-coated PMMA (10 nm)/ $\mathrm{SiO}_{2}(9 \mathrm{~nm})$; curve c, surface-grafting PMMA (20 nm); curve d, surfacegrafting PMMA $(10 \mathrm{~nm}) / \mathrm{SiO}_{2}(9 \mathrm{~nm})$. (C) Capacitance-voltage characteristics for $\mathrm{PMMA} / \mathrm{SiO}_{2}$ dielectrics. $C-V$ curves were measured at an ac signal frequency of $1 \mathrm{MHz}$. (D) Schematic diagram of distribution of pinhole defect in the dielectrics, indicating the reason why $\mathrm{PMMA}$ brush $/ \mathrm{SiO}_{2}$ bilayer dielectrics show the lowest the leakage compared bare $\mathrm{SiO}_{2}$ and spin coated $\mathrm{PMMA} / \mathrm{SiO}_{2}$ dielectrics. Reproduced with permission from Ref. [101]. 
Similar observations were also made by $\mathrm{Li}$ and coworkers by operating copper phthalocyanine $(\mathrm{CuPc})$ transistors at an operational voltages of $2.0 \mathrm{~V}$ using surface-grafted $\sim 10 \mathrm{~nm}$ PMMA brush on silica [70]. Additionally, it was noted that the thickness of the polymer brush on silica could be modulated based on the activity of the catalyst, the reactant concentration and reaction time. The PMMA brushes on silica showed high-quality dielectric property, including excellent insulating characteristics, large capacitance, and low charge-trapping density. Field-effect transistors with PMMA brush as the dielectric layer demonstrate excellent charge transport. Table 3 summarizes dielectric and electronic properties of transistors fabricated from surface-grafted polymer brushes.

Table 3. Summary of dielectric and electronic properties of polymer brushes grafted from $\mathrm{SiO}_{2}$ using ATRP.

\begin{tabular}{|c|c|c|c|c|c|c|c|c|}
\hline $\begin{array}{c}\text { Polymer } \\
\text { Grafted Filler }\end{array}$ & $\begin{array}{c}\text { Mean } \\
\text { Diameter }\end{array}$ & $\begin{array}{c}\text { Polymer } \\
\text { Diameter/Graft } \\
\text { Density }\end{array}$ & $\begin{array}{c}\text { Active } \\
\text { Semiconductor } \\
\text { Layer }\end{array}$ & $\begin{array}{l}\text { Molecular } \\
\text { Weight }\end{array}$ & $\begin{array}{c}\text { Capacitance } \\
\left(\mathrm{nF} / \mathrm{cm}^{2}\right)\end{array}$ & $\begin{array}{c}\mathrm{Eb} \\
(\mathrm{MV} / \mathrm{cm})\end{array}$ & $V T$ & $\begin{array}{c}\mu_{\mathrm{FET}} \\
\mathrm{cm}^{2} /(\mathrm{V} \cdot \mathrm{s})\end{array}$ \\
\hline $\begin{array}{c}\mathrm{PS}-g-\mathrm{SiO}_{2}(\mathrm{WF}) \\
{[98]}\end{array}$ & $300 \mathrm{~nm}$ & $113 \mathrm{~nm}$ & Pentacene & $\begin{array}{l}135,000 \\
\mathrm{~g} / \mathrm{mol}\end{array}$ & $7.5 @ 100 \mathrm{~Hz}$ & NA & -38 & 0.094 \\
\hline $\begin{array}{c}\text { PMMA- } g-\mathrm{SiO}_{2} \\
\text { [101] }\end{array}$ & $\sim 9 \mathrm{~nm}$ & $\sim 10 \mathrm{~nm}$ & Pentacene & NA & $142 @ 1 \mathrm{MHz}$ & 7 & -1 & $\sim 0.2$ \\
\hline $\begin{array}{c}\text { PMMA-g-SiO } \\
\text { [70] }\end{array}$ & $2-3 \mathrm{~nm}$ & $10 \mathrm{~nm}$ & $\mathrm{CuPc}$ & NA & $220 @ 1 \mathrm{MHz}$ & NA & -0.75 & 0.12 \\
\hline
\end{tabular}

\subsection{SI-ATRP Polymerization to Prepare Polymer-Grafted $\mathrm{TiO}_{2}$ Nanoparticles}

ATRP has also been widely used to grow PMMA [102-106], PS [107-110], poly(styrene sulfonic acid) (PSSA) [111,112], poly (oxyethylene methacrylate) (POEM) [113,114], PNIPAAm, [115,116], PHEMA [117] on the surface of $\mathrm{TiO}_{2}$. For example, Krysiak et al.; [118] performed the SI-ATRP grafting of poly(di (ethylene glycol) methyl ether methacrylate) on the surface of $\mathrm{TiO}_{2}$ (rutile) so as to yield polymer brushes with thickness of 10-15 nm (as measured by TEM) and molecular weight, Mn of $\sim 60,000 \mathrm{~g} / \mathrm{mol}$. Similarly, Park et al. [114] utilized ATRP for the synthesis of $\mathrm{TiO}_{2}$ nanoparticles grafted with POEM and PSSA. In the first step, the -OH groups on the surface of $\mathrm{TiO}_{2}$ nanoparticles were converted to $-\mathrm{Cl}$ groups by the reaction of $\mathrm{TiO}_{2}$ with 2-chloropropionyl chloride (CPC) (ATRP initiator) which was used to initiate POEM and PSSA grafting on the surface of the $\mathrm{TiO}_{2}$ nanoparticles. The modified $\mathrm{TiO}_{2}$ nanoparticles showed better dispersion in alcohol than unmodified nanoparticles. $X$-ray diffraction $(\mathrm{XRD})$ studies of polymer-grafted- $\mathrm{TiO}_{2}$ nanoparticles revealed that there was no significant change in the crystalline structure of the $\mathrm{TiO}_{2}$ nanoparticles. There are number of reports on utilization of SI-ATRP for grafting of polymer on $\mathrm{TiO}_{2}$ nanoparticles, however no significant studies have been reported on the dielectric properties of SI-ATRP polymer grafted TIO2 nanoparticles filled polymer nanocomposites.

\subsection{SI-ATRP Polymerization to Prepare Polymer-Grafted $\mathrm{BaTiO}_{3}$ Nanoparticles}

The initial reporting about the use of SI-ATRP approach to graft polymer on $\mathrm{BaTiO}_{3}$ nanoparticles was based on performing hydroxylation, sialylation, grafting of the anchoring group, followed by chain growth polymerization [119]. Table 4 summarizes the conditions used to synthesize various polymer-grafted $\mathrm{BaTiO}_{3}$ nanoparticles. Figure 5 presents the scheme for synthesis of $\mathrm{PMMA}$-grafted $\mathrm{BaTiO}_{3}$ nanoparticles. This study showed that the thickness of the PMMA shell could be varied by changing the feed ratio of $\mathrm{BaTiO}_{3}(76 \%$ to $0 \%$ ) to MMA resulting in grafted nanoparticles with dielectric constant ranging from 14.6 to 3.49 (pure PMMA). The PMMA-grafted $\mathrm{BaTiO}_{3}$ nanoparticles showed dielectric loss below 0.04, which was slightly lower than that of PMMA. 


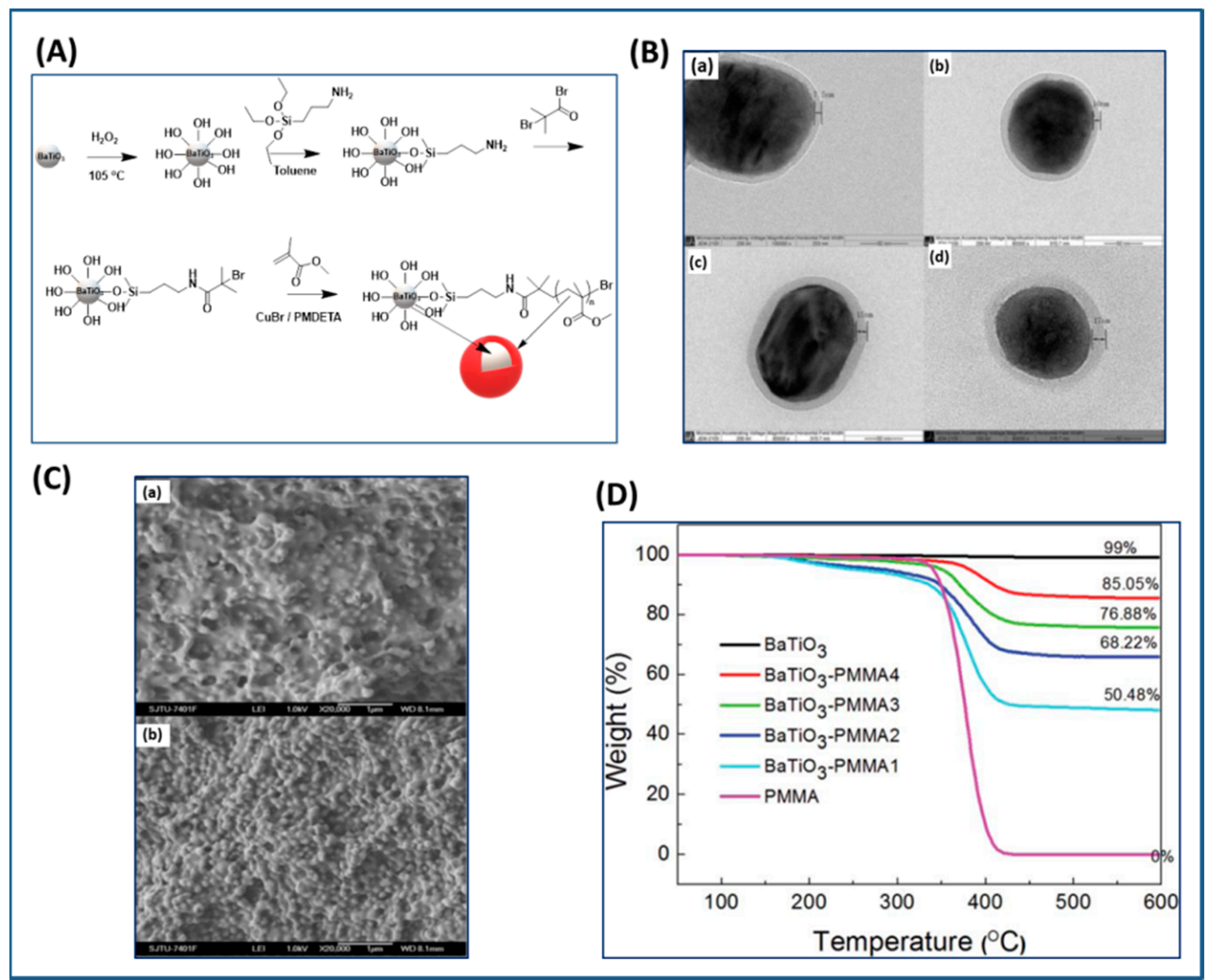

Figure 5. (A) Schematic diagram illustrating ATRP approach of growing $\mathrm{PMMA}$ from $\mathrm{BaTiO}_{3}$ (B) TEM images of $\mathrm{PMMA}_{-\mathrm{BaTiO}_{3}}$ (a), $\mathrm{PMMA}_{3}-\mathrm{BaTiO}_{3}$ (b) $\mathrm{PMMA}_{2}-\mathrm{BaTiO}_{3}$ (c), $\mathrm{PMMA}^{-}-\mathrm{BaTiO}_{3}$

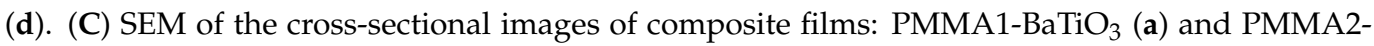
$\mathrm{BaTiO}_{3}$ (b). (D)TGA curves for the pure PMMA and $\mathrm{PMMA}-\mathrm{BaTiO}_{3}$. Reproduced with permission from Ref. [119].

Likewise, You et al. [120] demonstrated an approach to tune the dimension of $\mathrm{BaTiO}_{3}$ nanoparticles and vary the polymer shell thickness using ATRP method in the absence of metal catalyst. Initially, the $\mathrm{BaTiO}_{3}$ nanoparticles were formed by polycondensation of precursors (barium hydroxide $\left(\mathrm{Ba}(\mathrm{OH})_{2}\right)$ and titanium(IV) tetraisopropoxide $\left(\mathrm{Ti}(\mathrm{OiPr})_{4}\right)$ and HBPA) followed by calcination. (Figure 6) The NPs were then modified by bi-functional ligands (12-hydroxydodecanoic acid and 2-bromophenylacetyl bromide) followed by MMA polymerization using white light and photocatalyst. Using this approach, the authors demonstrated that the dimensions of $\mathrm{BaTiO}_{3}$ nanoparticles could be adjusted based on the molar ratio of HBPA and precursors, while the thickness of polymeric shell could be adjusted based upon the duration of white LED irradiation. The dielectric properties of core/shell $\mathrm{BaTiO}_{3} / \mathrm{PMMA}$ hybrid nanoparticles were found to depend upon the dimension of $\mathrm{BaTiO}_{3}$ core and the molecular weight of PMMA shell. For example, the dielectric constant of core/shell $\mathrm{BaTiO}_{3} / \mathrm{PMMA}$ hybrid nanoparticles with larger core size (core size: $\sim 39 \mathrm{~nm}, \varepsilon=22.23 \pm 1.09$, shell thickness: $6 \mathrm{~nm}$ ) was found to be higher than that of smaller core size sample (core: $\sim 17 \mathrm{~nm}, \varepsilon=17.06 \pm 0.58$, shell thickness: $6 \mathrm{~nm}$ ). This is due to the increased contribution of $\mathrm{BaTiO}_{3}$ to the overall dielectric constant with increase in the core size of $\mathrm{BaTiO}_{3}$ and changes in the crystallinity from cubic (paramagnetic) to tetragonal (ferromagnetic). Similarly, the dielectric constant of core/shell $\mathrm{BaTiO}_{3} / \mathrm{PMMA}$ hybrid nanoparticles with varying molecular weight of PMMA shell were studied and it showed an inverse relationship to the thickness of the PMMA shell. For example, the dielectric constant of core/shell $\mathrm{BaTiO}_{3} / \mathrm{PMMA}$ hybrid nanoparticles with smaller shell thickness (shell thickness: $6 \mathrm{~nm}$ core size $\sim 39 \mathrm{~nm}, \varepsilon=22.23 \pm 1.09$ ) was found to be higher than that of larger shell thickness (shell thickness: $8 \mathrm{~nm}$ core size $\sim 39 \mathrm{~nm}, \varepsilon \sim 13$ ). This is because larger shell thickness corresponds to the higher proportion of PMMA contribution 
to the overall dielectric constant of core-shell nanoparticles, especially given that PMMA has lower dielectric constant than that of core $\mathrm{BaTiO}_{3}$.

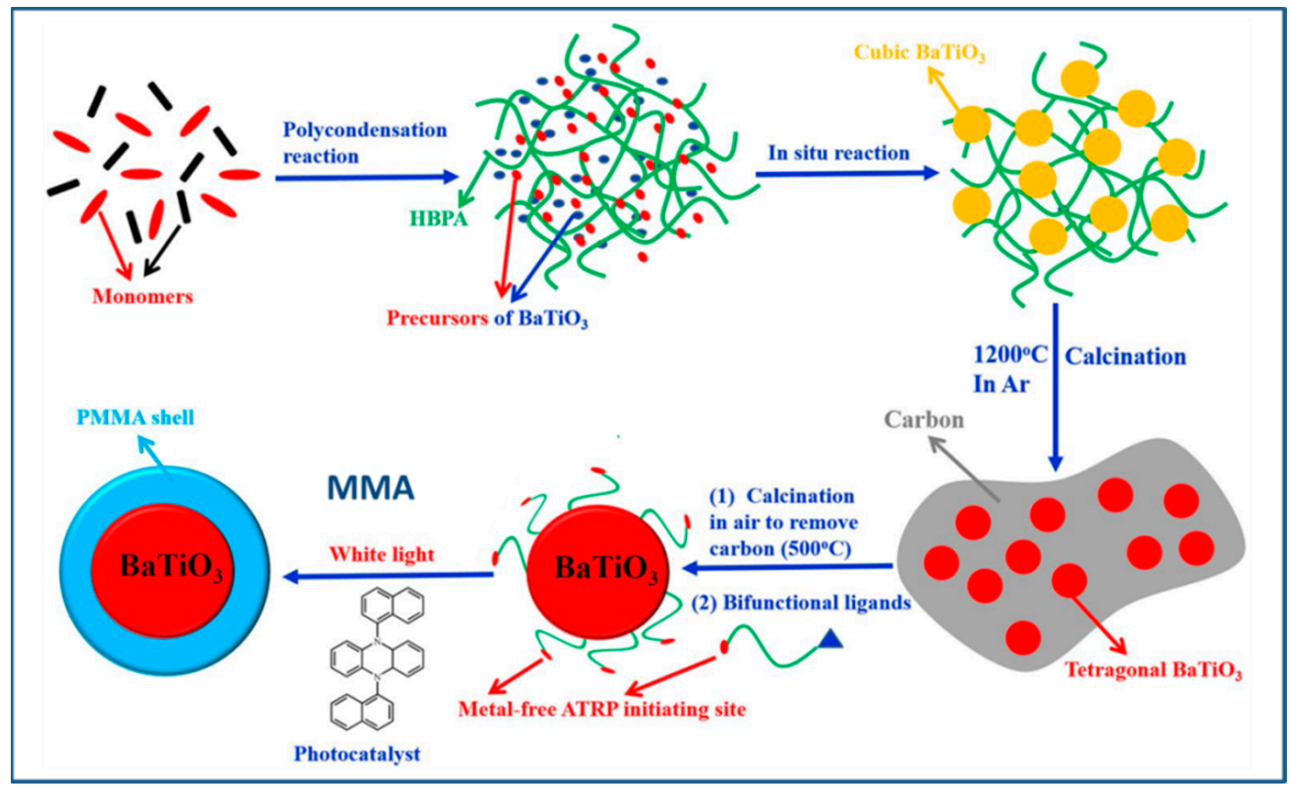

Figure 6. Scheme for the preparation of core/shell ferroelectric $\mathrm{BaTiO}_{3} / \mathrm{PMMA} \mathrm{Mybrid}$ nanoparticles by metal-free ATRP process driven by visible light based on novel hyperbranched aromatic polyamides (HBPA) as functional matrix. Reproduced with permission from Ref. [120].

Apart from $\mathrm{BaTiO}_{3}$ core size, polymer shell thickness, also the composition of polymer shell can influence the dielectric properties of nanocomposites. In this regard, Zhang et al. [121] studied core-shell structured ${\mathrm{PMMA} @ \mathrm{BaTiO}_{3} \text { (brush thickness, 7-12 nm) and PTFEMA@BaTiO }}_{3}$ (brush thickness, $\sim 5 \mathrm{~nm}$ ) nanoparticles that were synthesized by reacting (3-aminopropyl) trimethoxysilane (APTMS) and $\alpha$-bromoisobutyrylbromide (BIBB) with $\mathrm{BaTiO}_{3}$ nanoparticles followed by reaction with methyl methacrylate (MMA) or 1,1,1-trifluoroethyl methacrylate (TEFMA). At 1:1 weight feed ratio, $\left(\mathrm{BaTiO}_{3}\right.$ and $\mathrm{MMA}$ or TFEMA), the polymer brush thickness for PMMA@BaTiO 3 and PTFEMA@BaTiO 3 was found to be $7 \mathrm{~nm}$ and $4.5 \mathrm{~nm}$, respectively with grafting density of $5.5 \%$ and $1.5 \%$, respectively. MMA formed larger shell due to its enhanced reactivity than TFEMA. The study of the dielectric properties of PMMA@BaTiO 3 and PTFEMA@BaTiO 3 exhibited significant improvement in dispersity of polymer-grafted $\mathrm{BaTiO}_{3}$ nanoparticles in polyvinylidene fluoride (PVDF)

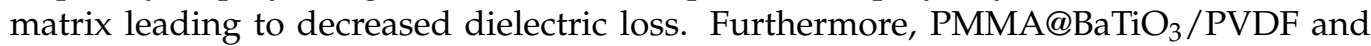
PTFEMA@BaTiO 3 /PVDF nanocomposites exhibited attenuation of dielectric constant of $16.6 \%$ and $5.5 \%$ at grafted density of $5.5 \%$ and $1.5 \%$, respectively compared to controls. A comparison of the performance of PTFEMA@BaTiO 3 nanoparticles in PVDF matrix showed

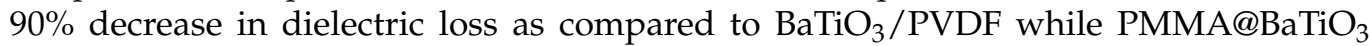
nanoparticles/PVDF nanocomposites showed $80 \%$ decrease in dielectric loss as compared to $\mathrm{BaTiO}_{3} / \mathrm{PVDF}$. This could be attributed to the stronger interaction between PFTEMA with PVDF matrix resulting in an enhancement in the interfacial polarization and stabilization of electric field (Figure 7). 


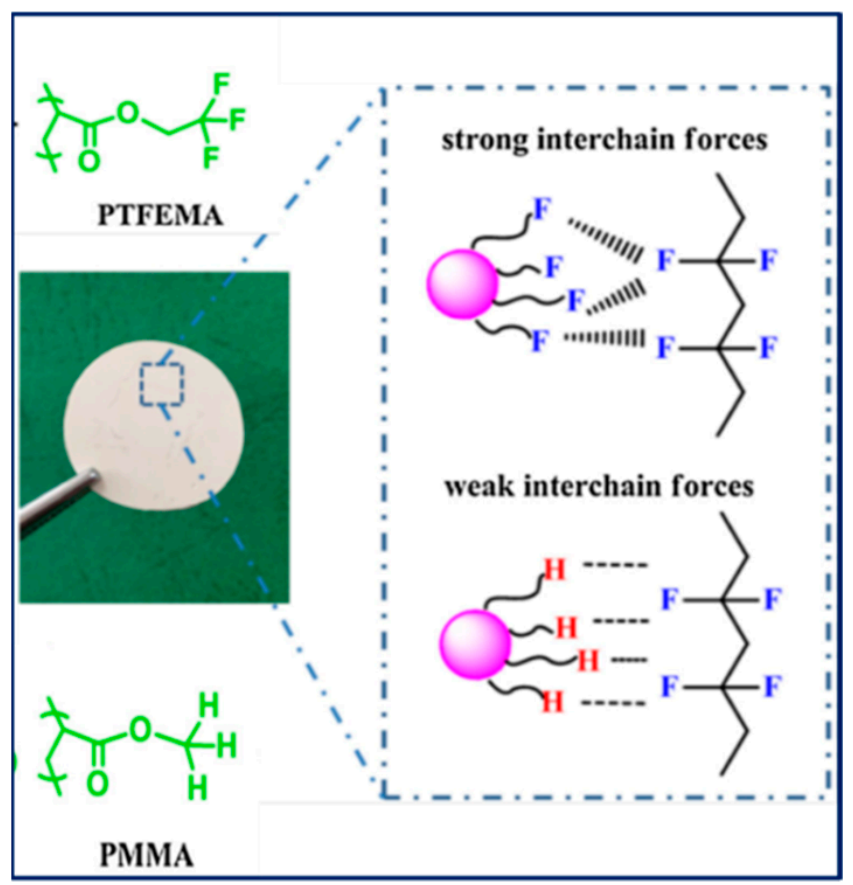

Figure 7. Fluorine-fluorine and hydrogen-fluorine interactions in the nanocomposites of PVDF and $\mathrm{BaTiO}_{3}$ grafted with PTFEMA and PMMA, respectively. Reproduced with permission from Ref. [121].

Alternatively, PMMA can be grafted on $\mathrm{BaTiO}_{3}$ nanoparticles by coating of a highly polarizable tetrameric metallophthalocyanine (TMPc) as ATRP initiator on the surface of $\mathrm{BaTiO}_{3}$ nanoparticles instead of conventional ATRP initiator followed by polymerization of MMA (Figure 8). As control, R2-PMMA@BaTiO 3 nanoparticles without TMPc interfacial layer were synthesized via phosphonate coupling of (R2-Br) followed by ATRP polymerization of MMA. Due to the high polarizability of the TMPc interfacial layer and the high dielectric constant of TMPc [122,123], poly(vinylidene fluoride-co- hexafluoropropylene) (PVDF-HFP)/PMMA-TMPc@BaTiO ${ }_{3}$ films exhibited higher dielectric constant ( $26 \%$ higher than nanocomposite without TMPc), and improved higher energy density ( $20 \%$ higher than neat (PVDF-HFP)) at nanofiller filling ratios of $4.69 \mathrm{vol} \%$ [124].

\section{(A)}

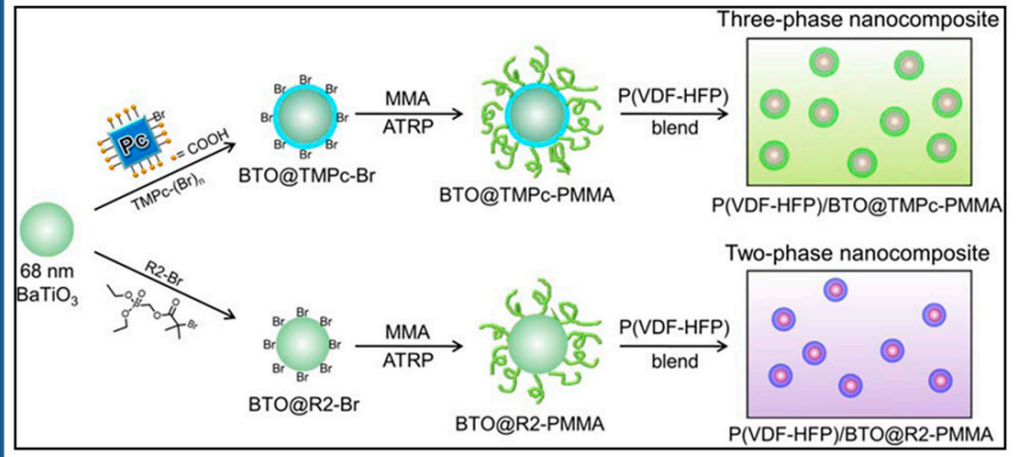

(B)

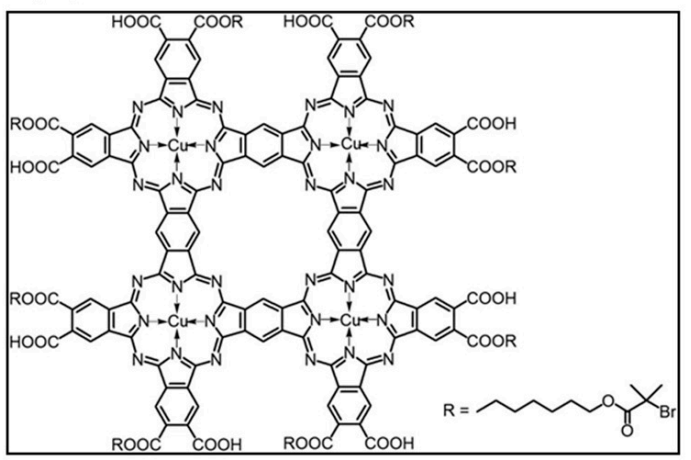

Figure 8. (A) Schematic illustration of the preparation of three- and two-phase $\mathrm{P}(\mathrm{VDF}-\mathrm{HFP}) / \mathrm{BaTiO}_{3}$ nanocomposites, respectively; (B) Chemical structure of the TMPc-Br ATRP initiator. Reproduced with permission from Ref. [124]. 
Table 4. Details about various polymer-grafted nanoparticles using ATRP.

\begin{tabular}{|c|c|c|c|c|}
\hline Polymer-Grafted & Nanomaterial & Anchoring Moiety & Polymerization Conditions & Ref. \\
\hline PPMA & $\mathrm{BaTiO}_{3}$ & & $\begin{array}{c}\text { White Light, } \\
\text { Photocatalyst5,10-di(1- } \\
\text { naphthyl)-5,10- } \\
\text { dihydrophenazine } \\
\text { DMF, RT }\end{array}$ & [120] \\
\hline $\begin{array}{c}\text { Poly(2- hydroxyl ethyl } \\
\text { methacrylate)-b-poly (methyl } \\
\text { methacrylate); } \\
\text { Sodium polyacrylate-b- } \\
\text { poly(2-hydroxyl ethyl } \\
\text { methacrylate) }\end{array}$ & $\mathrm{BaTiO}_{3}$ & & $\begin{array}{c}\mathrm{CuBr} / \mathrm{CuBr}_{2}, \text { PMDETA } \\
\mathrm{H}_{2} \mathrm{O} / \mathrm{DMF}, \\
60^{\circ} \mathrm{C}, 24 \mathrm{~h}\end{array}$ & [127] \\
\hline $\begin{array}{l}\text { Poly }(1 \mathrm{H}, 1 \mathrm{H}, 2 \mathrm{H}, 2 \mathrm{H}- \\
\text { perfluorooctyl } \\
\text { methacrylate })\end{array}$ & $\mathrm{BaTiO}_{3}$ & & $\begin{array}{c}\text { CuBr, PMDETA, DMF } \\
70^{\circ} \mathrm{C}, 24 \mathrm{~h}\end{array}$ & [126] \\
\hline PMMA & $\mathrm{BaTiO}_{3}$ & & $\begin{array}{l}\text { CuBr, PMDETA, DMF } \\
60^{\circ} \mathrm{C}, 24 \mathrm{~h}\end{array}$ & [119] \\
\hline $\begin{array}{c}\text { PMMA } \\
\text { Poly(Trifluoroethyl } \\
\text { methacrylate) PTFEMA }\end{array}$ & $\mathrm{BaTiO}_{3}$ & & $\begin{array}{c}\text { CuBr, PMDETA, DMF } \\
70^{\circ} \mathrm{C}, 12 \mathrm{~h}\end{array}$ & [121] \\
\hline PMMA & $\mathrm{BaTiO}_{3}$ & $\mathrm{BaTiO}_{3} @ \mathrm{TMPc}-\mathrm{Br}$ & $\begin{array}{c}\mathrm{CuCl} / \mathrm{CuCl}_{2}, \mathrm{Me}_{6} \mathrm{TREN}, \\
60^{\circ} \mathrm{C}, 24 \mathrm{~h}\end{array}$ & [124] \\
\hline PMMA & $\mathrm{BaTiO}_{3}$ & 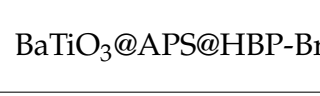 & $\begin{array}{l}\text { CuBr, PMDETA, } \\
60^{\circ} \mathrm{C}, 24 \mathrm{~h}\end{array}$ & [125] \\
\hline PS/PMMA & $\mathrm{BaTiO}_{3}$ & $-0^{-1}$ & $\begin{array}{c}\mathrm{CuCl}_{2}, \mathrm{Me}_{6} \mathrm{TREN}, \mathrm{Tin}(\mathrm{II}) \\
\text { ethylhexanoate, Anisol, } \\
110^{\circ} \mathrm{C}\end{array}$ & [27] \\
\hline Poly(lauryl methacrylate) & $\mathrm{Al}_{2} \mathrm{O}_{3}$ & & $\begin{array}{l}\mathrm{CuBr} / \mathrm{CuBr}_{2}, \mathrm{HMTETA} \\
\text { Toluene, } 100^{\circ} \mathrm{C}, 16 \mathrm{~h}\end{array}$ & [128] \\
\hline
\end{tabular}

Xie et al. [125] synthesized a core@double-shell structured PMMA@HBP@BT nanocomposite via a two-step process as depicted in Figure 9. In the first step, the hyperbranched aromatic polyamide was grafted on the surface of $\mathrm{BaTiO}_{3}$ nanoparticles, and in the second step, the hyperbranched amine was used for grafting of PMMA shell via SI-ATRP. The thickness of the second shell was controlled by adjusting the ratio of MMA and macro initiator, BT@HBP-Br. The SEM morphology of PMMA@HBP@BT revealed improved adhesion between BT nanoparticles and polymers (HPB and PMMA, covalently attached) as compared to BT@HBP/PMMA nanocomposite. The PMMA@HBP@BT/PMMA nanocomposite exhibited high dielectric constant (39.3, 10 times higher than that of PMMA) as well as low dielectric loss (0.0276). The nanocomposite of BT@HBP in PMMA matrix (56.7\% loading) resulted in high dielectric constant of 113 while loss was increased to 0.485 (16.6 times higher than that of PMMA@HBP@BT). Thus, double core-shell structured PMMA@HBP@BT provides another approach for preparing nanocomposites with higher dielectric constant and low dielectric loss. 


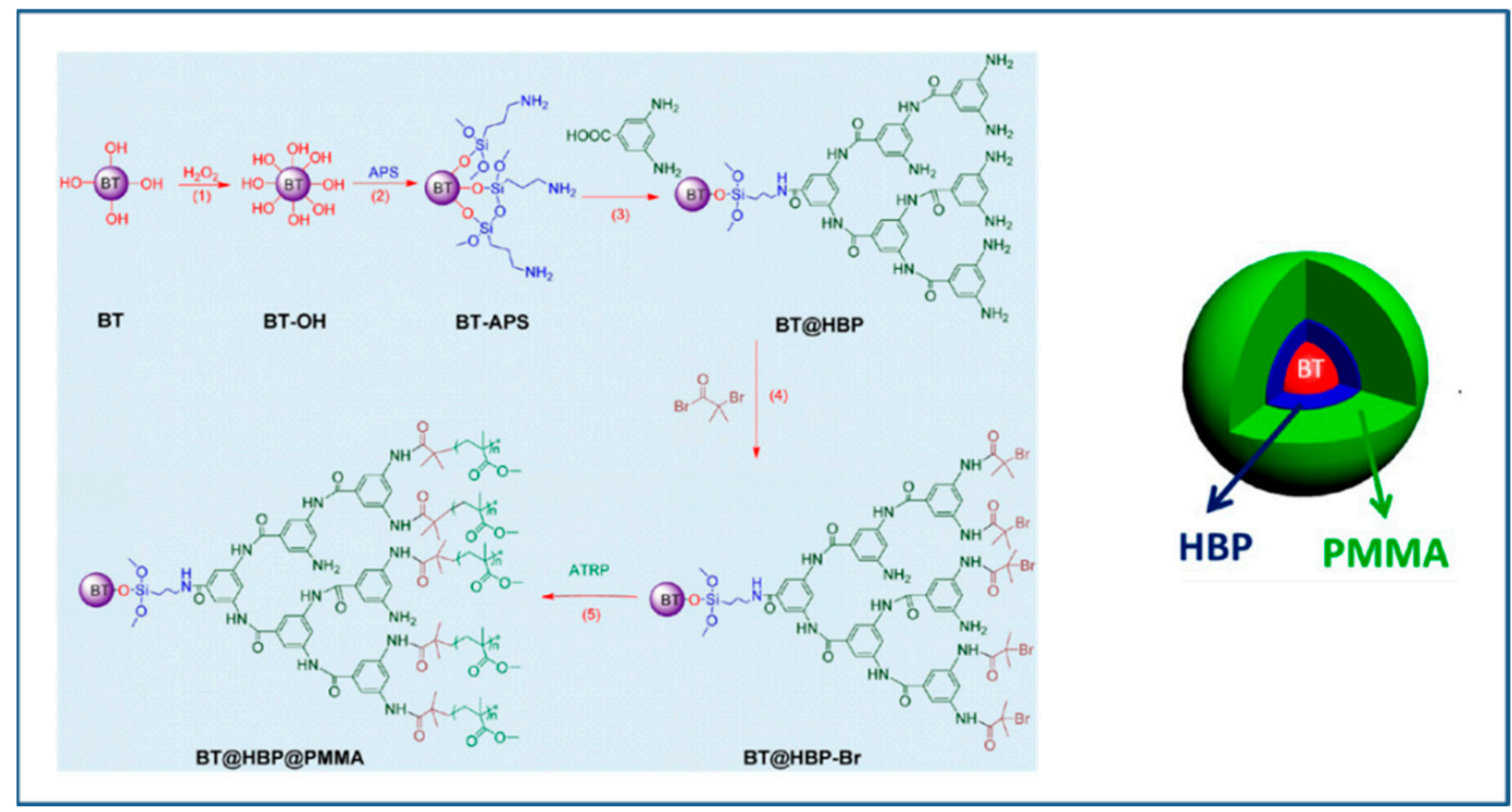

Figure 9. Schematic illustrating the preparation of PMMA@HBP@BT. Reproduced with permission from Ref. [125].

The attachment of phosphonic acid-based ATRP initiator on $\mathrm{BaTiO}_{3}$ nanoparticles followed by growth of PMMA on $\mathrm{BaTiO}_{3}$ nanoparticles via activated regenerated by electron transfer (AGRET) ATRP approach (Figure 10) was reported to compare and contrast the dielectric performance of single- and multi-component nanocomposites [27].

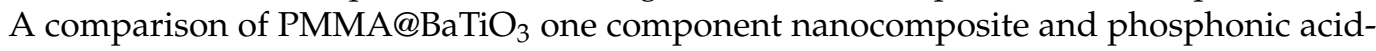
modified $\mathrm{BaTiO}_{3}$ mixed PMMA two component nanocomposite, at same loading of $16 \mathrm{vol} \%$, showed that the two-component nanocomposite has energy density of $\sim 1.9 \mathrm{~J} / \mathrm{cm}^{3}$ at $256 \mathrm{~V} / \mu \mathrm{m}$ while one component nanocomposite has energy density of $\sim 2 \mathrm{~J} / \mathrm{cm}^{3}$ at a $25 \%$ lower field strength $(220 \mathrm{~V} / \mu \mathrm{m})$ which implies a 2-fold enhancement in energy density due to the covalent attachment of $\mathrm{PMMA}$ to $\mathrm{BaTiO}_{3}$ nanoparticles.

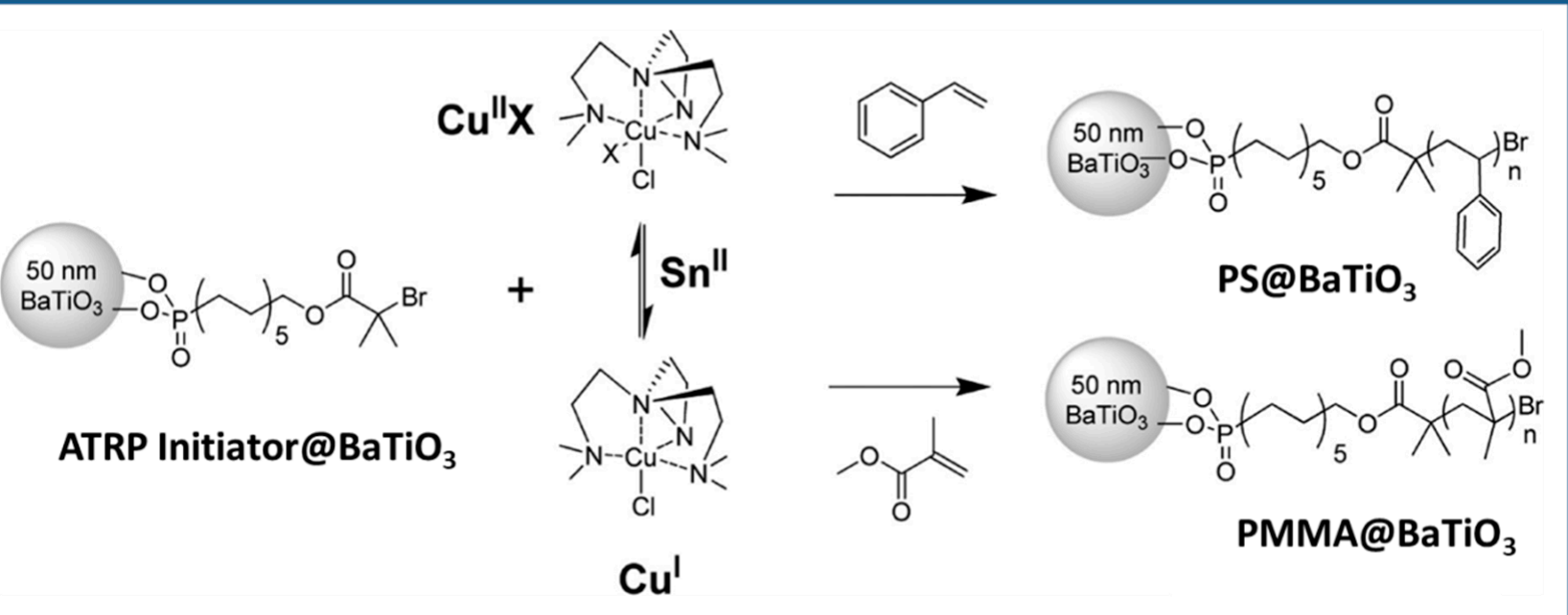

Figure 10. Surface-initiated polymerization of styrene or methyl methacrylate via ARGET ATRP. Reproduced with permission from Ref. [27]. 
Zhang et al. [126] synthesized core-shell structured poly $(1 \mathrm{H}, 1 \mathrm{H}, 2 \mathrm{H}, 2 \mathrm{H}-$ perfluorooctyl methacrylate) (PPFOMA )@BaTiO ${ }_{3}$ nanoparticles via SI-ATRP and was used for the formulation of single component nanocomposite. One of the distinct advantages of single component nanocomposite is the ability to load high \% of ceramic nanofiller with minimal effect on dispersibility. The dielectric properties of single component nanocomposites (various core-shell nanoparticles were formed by changing the feed ratio of PFOMA and $\mathrm{BaTiO}_{3}$ ) were evaluated over a broad frequency from $40 \mathrm{~Hz}$ to $30 \mathrm{MHz}$ at room temperature. The results revealed that the dielectric constant $(\mathrm{k})$ increased and dielectric loss reduced significantly with the addition of $\mathrm{BaTiO}_{3}$. The $\mathrm{k}$ of the composite was up to 7.4 at $100 \mathrm{kHz}$ at room temperature when the $\mathrm{BaTiO}_{3}$ loading was up to $70 \mathrm{wt} \%$ which is almost three times greater that of pure PPFOMA $(\mathrm{k}=2.6)$. However, the dielectric loss $(0.01)$ of PPFOMA@BaTiO ${ }_{3}$ composite of one component polymer nanocomposite for $70 \mathrm{wt} \%$ loading was much lower than that of the pure PPFOMA (0.04). It is interesting to highlight that the nanocomposite despite high loading of nanofiller exhibited low loss even less than that of pure polymer at $70 \%$ nanoparticle loading.

The structure-property relationship study of polymer-grafted $\mathrm{BaTiO}_{3}$ nanoparticles (synthesized by ATRP technique) filled polymer nanocomposites [27,119-121,124-126] clearly indicates that several factors influence the dielectric performance of the nanocomposite including the thickness of the core and the shell of the core-shell nanoparticles and the type of polymer-grafted on the nanoparticles, interfacial separation between core NPs and polymer shell, the composition of nanocomposite (single or multicomponent type of nanocomposite), the type of interfacial layer and double shell coverage of nanoparticles.

\subsection{SI-ATRP Polymerization to Prepare Polymer-Grafted $\mathrm{Al}_{2} \mathrm{O}_{3}$ Nanoparticles}

Sanchez et al., [128] reported the modification of aluminum oxide nanoparticles by poly(lauryl methacrylate) (PLMA) using surface-initiated ATRP (SI-ATRP) technique. The molecular weight of grafted polymer ranged between 23,000 and $83,000 \mathrm{~g} / \mathrm{mol}$. PLMAgrafted nanoparticles filled LDPE matrix resulted in lower dielectric loss-tangent $(\sim 0.0008$ to $\sim 0.0003$ with $1 \mathrm{wt} \%$ at $100 \mathrm{~Hz}$ ) compared to LDPE filled with bare $\mathrm{Al}_{2} \mathrm{O}_{3}$. This may be a result of the enhanced adhesion between LDPE and the lauryl chains of the grafted polymer on the nanoparticles. Table 5 summarizes of dielectric properties of polymer nanocomposites fabricated from polymer brushes-grafted ceramic nanoparticles obtained using different grafting techniques. 
Table 5. Summary of dielectric properties of polymer nanocomposites fabricated from polymer brushes-grafted ceramic nanoparticles.

\begin{tabular}{|c|c|c|c|c|c|c|c|c|c|}
\hline Polymer@filler & Mean Diameter & $\begin{array}{l}\text { Shell Thickness } \\
\text { (nm) }\end{array}$ & $\%$ Loading & Matrix & $\begin{array}{l}\text { Grafting } \\
\text { Approach }\end{array}$ & $\varepsilon \mathbf{r}$ & $\tan \delta$ & $E_{b}(k V / m m)$ & $\begin{array}{c}\text { Energy Density U } \\
\left(\mathrm{J} / \mathrm{cm}^{3}\right)\end{array}$ \\
\hline 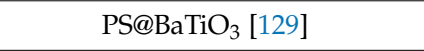 & $\sim 7 \mathrm{~nm}$ & NA & $22 \% v / v$ & PS & Grafting to & 5.8 & NA & 143 & NA \\
\hline $\mathrm{PTFMPCS@BaTiO}_{3}$ [130] & $100 \mathrm{~nm}$ & $11 \mathrm{~nm}$ & $5 \mathrm{vol} \%$ & PVDF-TrFE-CTFE & SI-RAFT & $\sim 58$ & NA & 459 & $36.6 @ 514 \mathrm{kV} / \mathrm{mm}$ \\
\hline 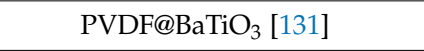 & $\sim 100 \mathrm{~nm}$ & NA & $30 \mathrm{vol} \%$ & PVDF & Grafting to & 27.9 & 0.08872 & 117.3 & NA \\
\hline $\mathrm{PS} @ \mathrm{Al}_{2} \mathrm{O}_{3}$ [132] & $50 \mathrm{~nm}$ & 0.13 & $25 \mathrm{wt} \%$ & PS & Grafting to & 2.63 & NA & NA & NA \\
\hline $\mathrm{PS} @ \mathrm{Al}_{2} \mathrm{O}_{3}[132]$ & $50 \mathrm{~nm}$ & 0.13 & $25 \mathrm{wt} \%$ & PMMA & Grafting to & 3.19 & NA & NA & NA \\
\hline 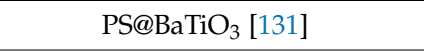 & $\sim 100 \mathrm{~nm}$ & NA & $30 \mathrm{vol} \%$ & PVDF & Grafting to & 23.6 & 0.0866 & 107 & NA \\
\hline $\mathrm{P}(\mathrm{VDF}-\mathrm{HFP}) @ \mathrm{BaTiO}_{3}[133]$ & $100 \mathrm{~nm}$ & NA & $50 \mathrm{vol} \%$ & NA & Grafting to & 34.8 & 0.128 & $20 \mathrm{MV} / \mathrm{m}$ & $0.3 @ 20 \mathrm{MV} / \mathrm{m}$ \\
\hline $\mathrm{PGMA@BaTiO}_{3}$ [134] & $<100 \mathrm{~nm}$ & $\sim 20 \mathrm{~nm}$ & NA & PGMA & SI-ATRP & 54 & 0.039 & $\sim 3 \mathrm{MV} / \mathrm{m}$ & $\sim 21.51 @ 3 \mathrm{MV} / \mathrm{m}$ \\
\hline PHEMA@PMMA @ $\mathrm{BaTiO}_{3}$ [127] & $100 \mathrm{~nm}$ & $10 \mathrm{~nm}$ & $38 \mathrm{vol} \%$ & NA & SI-ATRP & NA & $\sim 0.025$ & NA & $\sim 0.061 @ 70 \mathrm{kV} / \mathrm{cm}$ \\
\hline PANa@PHEMA@BaTiO 3 [127] & $100 \mathrm{~nm}$ & $10 \mathrm{~nm}$ & $21 \mathrm{vol} \%$ & NA & SI-ATRP & NA & $\sim 0.022$ & NA & $\sim 0.09 @ 70 \mathrm{kV} / \mathrm{cm}$ \\
\hline 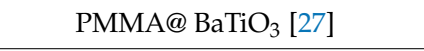 & $50 \mathrm{~nm}$ & NA & $22 \mathrm{vol} \%$ & NA & SI-ATRP & 11.4 & NA & 218 & $3 @ \sim 220 \mathrm{~V} / \mu \mathrm{m}$ \\
\hline PTTEMA@BaTiO $_{3}$ [135] & $\sim 50 \mathrm{~nm}$ & $14-15 \mathrm{~nm}$ & $20 \mathrm{vol} \%$ & PTTEMA & SI-RAFT & $\sim 20$ & $<0.02$ & $\sim 220$ & $\sim 3.4 @ 210 \mathrm{~V} / \mu \mathrm{m}$ \\
\hline $\mathrm{PMMA@BaTiO}_{3}$ [119] & $100 \mathrm{~nm}$ & $10 \mathrm{~nm}$ & $76 \mathrm{wt} \%$ & NA & SI-ATRP & 14.6 & 0.0372 & NA & NA \\
\hline $\mathrm{PTFEMA@BaTiO}_{3}$ [121] & $\sim 200 \mathrm{~nm}$ & $4.5 \mathrm{~nm}$ & $80 \mathrm{wt} \%$ & PVDF & SI-ATRP & $\sim 35$ & 0.022 & NA & NA \\
\hline PPFOMA@BaTiO 3 [126] & $30-50 \mathrm{~nm}$ & $5 \mathrm{~nm}$ & $70.70 w \mathrm{wt} \%$ & NA & SI-ATRP & 7.4 & 0.01 & NA & NA \\
\hline PMMA@TiO 2 [136] & 50 to $100 \mathrm{~nm}$ & $5 \mathrm{~nm}$ & $1 \mathrm{vol} \%$ & PVDF-HFP & In situ & 10.5 & $<0.04$ & 560 & $14.2 @ 500 \mathrm{~V} / \mu \mathrm{m}$ \\
\hline 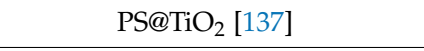 & $40-50 \mathrm{~nm}$ & NA & $27 \mathrm{wt} \%$ & NA & Grafting to & 6.4 & 0.04 & NA & NA \\
\hline 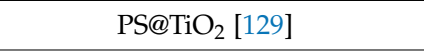 & $18 \mathrm{~nm}$ & NA & $39 \% v / v$ & NA & Grafting to & 12.8 & 0.1 & 114 & NA \\
\hline 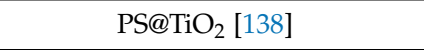 & $25-30 \mathrm{~nm}$ & NA & $36.9 \mathrm{vol} \%$ & PS & SI-RAFT & $\sim 65$ & $\sim 0.03$ & NA & NA \\
\hline $\mathrm{PS} @ \mathrm{Al}_{2} \mathrm{O}_{3}[139]$ & $50-200 \mathrm{~nm}$ & 0.12 & $30 \mathrm{wt} \%$ & iso-Al NPs@PS & Grafting to & 9.50 & 0.01 & 175 & 1.70 \\
\hline $\mathrm{PEB@Al} 2 \mathrm{O}_{3}[140]$ & $100 \mathrm{~nm}$ & $2-5 \mathrm{~nm}$ & $25.0 \mathrm{vol} \%$ & $\mathrm{PP}$ & Grafting to & 5.7 & NA & 37.5 & NA \\
\hline 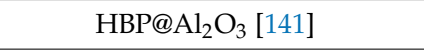 & $30 \mathrm{~nm}$ & NA & $20 \mathrm{wt} \%$ & Epoxy & In situ & 5.0 & $<0.025$ & 32.83 & NA \\
\hline $\mathrm{PP} @ \mathrm{Al}_{2} \mathrm{O}_{3}[142]$ & $140 \mathrm{~nm}$ & NA & $10.4 \mathrm{vol} \%$ & NA & In situ & 10.5 & 0.24 & 120 & $14.4 @ 120$ V/ $\mu \mathrm{m}$ \\
\hline
\end{tabular}




\section{Reversible Addition-Fragmentation Chain-Transfer Polymerization (RAFT)}

Living free-radical polymerization by reversible addition-fragmentation chain transfer (RAFT), is one of the most versatile and powerful technique for controlled radical polymerization which was invented in 1998 by Moad and co-workers [143] RAFT polymerization involves a degenerative chain transfer method to control polymerization [144] unlike ATRP and NMP which has a persistent radical in the system [76,145-147]. The control in RAFT polymerization is derived from the chain transfer agent (CTA) and the details about RAFT mechanism can be found in the following references [144,148-150]. In comparison to other CRPs, RAFT polymerization has number of advantages such as being adaptable to almost all free radical polymerizable monomers, the ability to synthesize multi-block copolymers with a high degree of fidelity, the ability to work in the presence of oxygen, no need of inorganic catalysts and mild polymerization conditions, similar to that of conventional free radical polymerization [151-156]. SI-RAFT has been widely used for the preparation of polymer-grafted nanoparticles by attaching CTA functionality to the surface of nanoparticles. In SI-RAFT polymerization, the attachment of the CTA moiety to the NP surface could be done via " $Z$ " group or " $\mathrm{R}$ " group. If the NP is attached to the " $Z$ " group of the CTA then growing polymer chains will detach propagate, and then reattach to the NP surface, just like a "graft to" approach $[157,158]$. Thus, "Z" group attachment of CTA lead to decreased graft density because of the bulky nature of the polymer chains being grafted to nanoparticles using graft to approach. However, if the NP is attached to the " $R$ " group of the CTA then the monomer gets sequentially added to the propagating polymer radicals present on the NP surface. This approach is the preferred pathway to synthesize core-shell NPs using SI-RAFT. Table 6 summarizes some examples of the anchored CTA structures and polymerization conditions used to synthesize various polymer grafted nanoparticles via SI-RAFT.

\subsection{SI-RAFT Polymerization to Prepare Polymer-Grafted $\mathrm{SiO}_{2}$ Nanoparticles}

A variety of polymers such as PMMA, PS, PNiPAAm, PAA, PHEMA, P4VP, polyisoprene have been grown from the surface of silica nanoparticles through "grafting from" approach via SI-RAFT polymerization [48,159-165]. For example, the amino-functionalized $\mathrm{SiO}_{2}\left(\mathrm{SiO}_{2}-\mathrm{NH}_{2}\right)$ nanoparticles served as the precursor for RAFT polymerization and were synthesized by reacting amino propyl triethoxysilane (APTES) with the bare $\mathrm{SiO}_{2}$ nanoparticles. Subsequently, the RAFT-CTA viz, 4-cyano-4-(dodecylsulfanylthiocarbonyl) sulfanyl pentanoic acid (CDP) agent was immobilized on the surface of $\mathrm{SiO}_{2}-\mathrm{NH}_{2}$ nanoparticles by amide forming reaction. The $\mathrm{CDP}$ immobilized $\mathrm{SiO}_{2}$ nanoparticles were then used in the surface-initiated RAFT polymerization of HEMA with AIBN as the free radical initiator, to form PHEMA-g-SiO 2 nanoparticles [164].

There are several other examples of immobilization of RAFT-CTA on the surface of $\mathrm{SiO}_{2}$ nanoparticles. For example, dopamine is reacted with silanized nanoparticles followed by dicyclohexyl carbodiimide (DCC) coupling, [160] or silanization of nanoparticles with modified RAFT-CTA agent where the RAFT-CTA agent was precoupled with silane agent [166-168], or silanization of nanoparticles with chloro functionality so as to eventually react with sodium/potassium ethyl xanthate to form xanthate $[162,163]$. 
Table 6. Details about various polymer grafted nanoparticles using SI-RAFT.

\begin{tabular}{|c|c|c|c|c|}
\hline Grafted Polymer & Nanoparticle & Anchoring CTA & $\begin{array}{l}\text { Polymerization } \\
\text { Conditions }\end{array}$ & Ref. \\
\hline Poly(vinylidene fluoride) & $\mathrm{BaTiO}_{3}$ & $\dot{\mathbf{s}}$ & $\begin{array}{l}\text { TBPPi, DMC } \\
65^{\circ} \mathrm{C}, 15 \mathrm{~h}\end{array}$ & [169] \\
\hline $\mathrm{F}_{\mathrm{F}} \quad \mathrm{C}_{\mathrm{P}-5 \mathrm{~F}} \mathrm{o} \mathrm{F}_{\mathrm{F}}$ & $\mathrm{BaTiO}_{3}$ & & $\begin{array}{l}\text { AIBN, THF } \\
80^{\circ} \mathrm{C}, 15 \mathrm{~h}\end{array}$ & [170] \\
\hline $\begin{array}{l}\text { Poly }\{2,5 \text {-bis }[(4- \\
\text { methoxyphenyl)oxycarbonyl]styrenes }\} \\
\text { (PMPCS) }\end{array}$ & $\mathrm{BaTiO}_{3}$ & & $\begin{array}{l}\text { AIBN, THF } \\
80^{\circ} \mathrm{C}, 6 \mathrm{~h}\end{array}$ & [171] \\
\hline Polystyrene & $\mathrm{BaTiO}_{3}$ & & $\begin{array}{l}\text { AIBN, DMF } \\
80^{\circ} \mathrm{C}, 12 \mathrm{~h}\end{array}$ & [172] \\
\hline $\begin{array}{c}\text { Poly }\left(2-\left(2,2^{\prime}: 5^{\prime}, 2^{\prime \prime} \text {-terthien-5- }\right.\right. \\
\text { yl)ethyl methacrylate) } \\
\text { (PTTEMA) }\end{array}$ & $\mathrm{BaTiO}_{3}$ & & $\begin{array}{c}\text { AIBN, Dioxane } \\
90^{\circ} \mathrm{C}, 3 \mathrm{~h}\end{array}$ & {$[173,174]$} \\
\hline $\begin{array}{c}\operatorname{Poly}(1 \mathrm{H}, 1 \mathrm{H}, 2 \mathrm{H}, 2 \mathrm{H}- \\
\text { heptadecafluorodecyl acrylate) } \\
\text { (PHFDA) }\end{array}$ & $\mathrm{BaTiO}_{3}$ & & $\begin{array}{l}\text { AIBN, DMF } \\
60^{\circ} \mathrm{C}, 6 \mathrm{~h}\end{array}$ & [175] \\
\hline Polystyrene & $\mathrm{BaTiO}_{3}$ & & $\begin{array}{l}\text { AIBN, DMF, } \\
\quad 80^{\circ} \mathrm{C}\end{array}$ & [176] \\
\hline $\begin{array}{l}\text { Poly(stearyl } \\
\text { methacrylate) }\end{array}$ & $\mathrm{SiO}_{2}$ & & $\begin{array}{l}\text { AIBN, THF, } \\
\quad 60^{\circ} \mathrm{C}\end{array}$ & {$[177,178]$} \\
\hline $\begin{array}{l}\text { Poly(2-hydroxyethyl } \\
\text { methacrylate) }\end{array}$ & $\mathrm{SiO}_{2}$ & & $\begin{array}{l}\text { AIBN, } \mathrm{THF}, \\
70{ }^{\circ} \mathrm{C}\end{array}$ & [164] \\
\hline Poly(acrylic acid) & $\mathrm{SiO}_{2}$ & & $\begin{array}{l}\text { AIBN, DMF } \\
70^{\circ} \mathrm{C}, 3 \mathrm{~h}\end{array}$ & [162] \\
\hline $\begin{array}{l}\text { Poly(stearyl } \\
\text { methacrylate) }\end{array}$ & $\mathrm{SiO}_{2}$ & & $\begin{array}{l}\text { AIBN, THF, } \\
60{ }^{\circ} \mathrm{C}\end{array}$ & {$[177,178]$} \\
\hline Polystyrene & $\mathrm{TiO}_{2}$ & & $110{ }^{\circ} \mathrm{C}, 96 \mathrm{~h}$ & [138] \\
\hline $\begin{array}{l}\text { Poly(methyl } \\
\text { methacrylate)-b-polystyrene }\end{array}$ & $\mathrm{TiO}_{2}$ & & $\begin{array}{l}\text { AIBN, DMF, } \\
90^{\circ} \mathrm{C}, 6 \mathrm{~h}\end{array}$ & [179] \\
\hline
\end{tabular}

Literature presents several examples of the use of unimodal polymer grafted $\mathrm{SiO}_{2}$ nanoparticles to enhance the breakdown strength of polymer grafted $\mathrm{SiO}_{2}$ filled nanocomposites $[177,178,180]$. For example, SI-RAFT technique has been used in the synthesis of poly(stearyl methacrylate) (PSMA) $\left(\mathrm{Mn}=45 \mathrm{~kg} / \mathrm{mol}\right.$ and the graft density $=0.04$ chain $/ \mathrm{nm}^{2}$ ) grafted $\mathrm{SiO}_{2}$ (10-15 nm diameter) nanoparticles [177]. The dielectric performance of PSMA-grafted $\mathrm{SiO}_{2}$ nanoparticles/XLPE was compared with XLPE, pure PSMA/XLPE and unmodified $\mathrm{SiO}_{2} /$ XLPE. Among the systems evaluated, the unmodified $\mathrm{SiO}_{2}$ nanoparticles filled/XLPE exhibited lowest dielectric breakdown strength while PSMA grafted 
$\mathrm{SiO}_{2}$ nanoparticles dispersed in XLPE showed the highest dielectric breakdown strength. (Figure 11A) The internal field distortion of PSMA grafted $\mathrm{SiO}_{2}$ nanoparticles in XLPE was found to be the least (less than 10.6\%) among the nanocomposites (Figure 11B) studied over a wide range of DC fields from $-30 \mathrm{kV} / \mathrm{mm}$ to $-100 \mathrm{kV} / \mathrm{mm}$ indicating tremendous potential for improving HVDC power cable insulation. The long alkyl chain of PSMA present on nanoparticles appears to have enhanced the interaction of nanoparticles with XLPE matrix hence the improved breakdown strength of nanocomposite [177].

A)

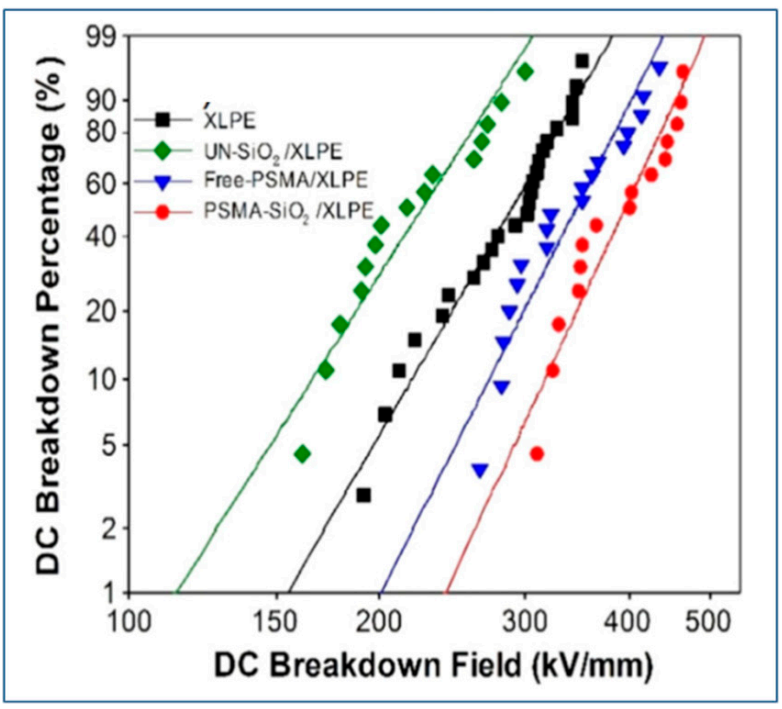

B)

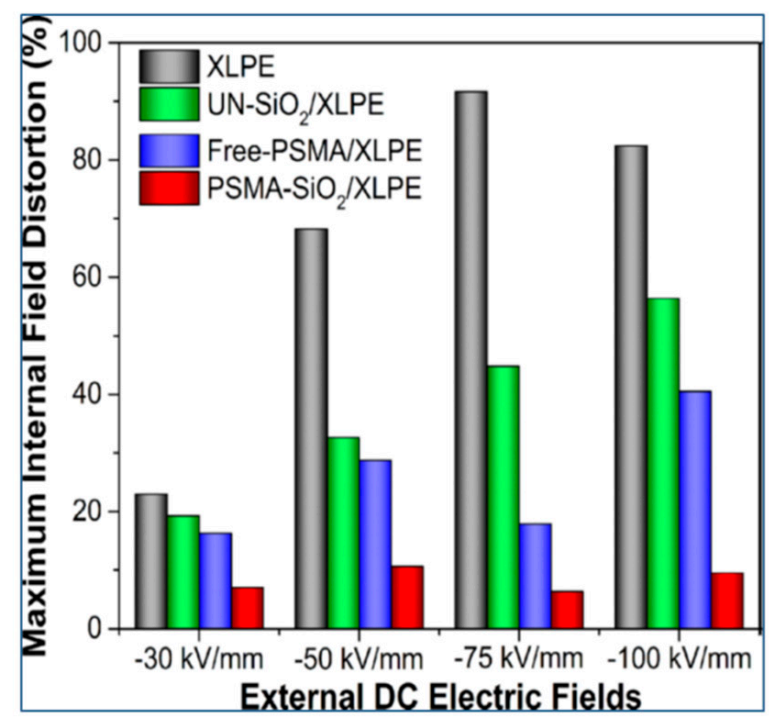

Figure 11. (A) Weibull distribution of DC breakdown strength, (B) Maximum internal field distortion under external DC electric fields. Reproduced with permission from Ref. [177].

The use of bimodal polymer grafted nanoparticles in polymer nanocomposite offers an attractive alternative approach for achieving improved breakdown strength and better nanoparticle dispersion in polymer nanocomposites. The synthesis of bimodal polymer grafted nanoparticles was explored by Benicewicz, Schadler and coworkers [181-184]. Bimodal polymer grafted $\mathrm{SiO}_{2}$ nanoparticles were synthesized by sequential attachment of electroactive conjugated surface ligands followed by surface-initiated RAFT polymerization of GMA (Figure 12) to form PGMA. The electroactive functionality (anthracene, thiophene, and terthiophene) was also grafted on the nanoparticles. Grafting of conjugated molecules (anthracene, thiophene and terthiophene) to the nanoparticle surface offers an approach to promote electron trapping at isolated regions of the composite while restricting the formation of conductive pathway [185], while the grafted PGMA chains promoted improved dispersion of the multifunctional $\mathrm{SiO}_{2}$ nanoparticles in epoxy resin. Bimodal terthiophene-PGMA functionalized $\mathrm{SiO}_{2}$ nanoparticles filled composites showed the highest enhancement in dielectric breakdown strength followed by bimodal anthracene-PGMA functionalized nanoparticles filled epoxy sample and the least was for thiophene-PGMA functionalized nanoparticles filled epoxy sample. The role of substituted aromatics grafted on nanoparticles in improving the dielectric breakdown strength of nanocomposite was explained on the basis of the Hammett relationship [186]. 


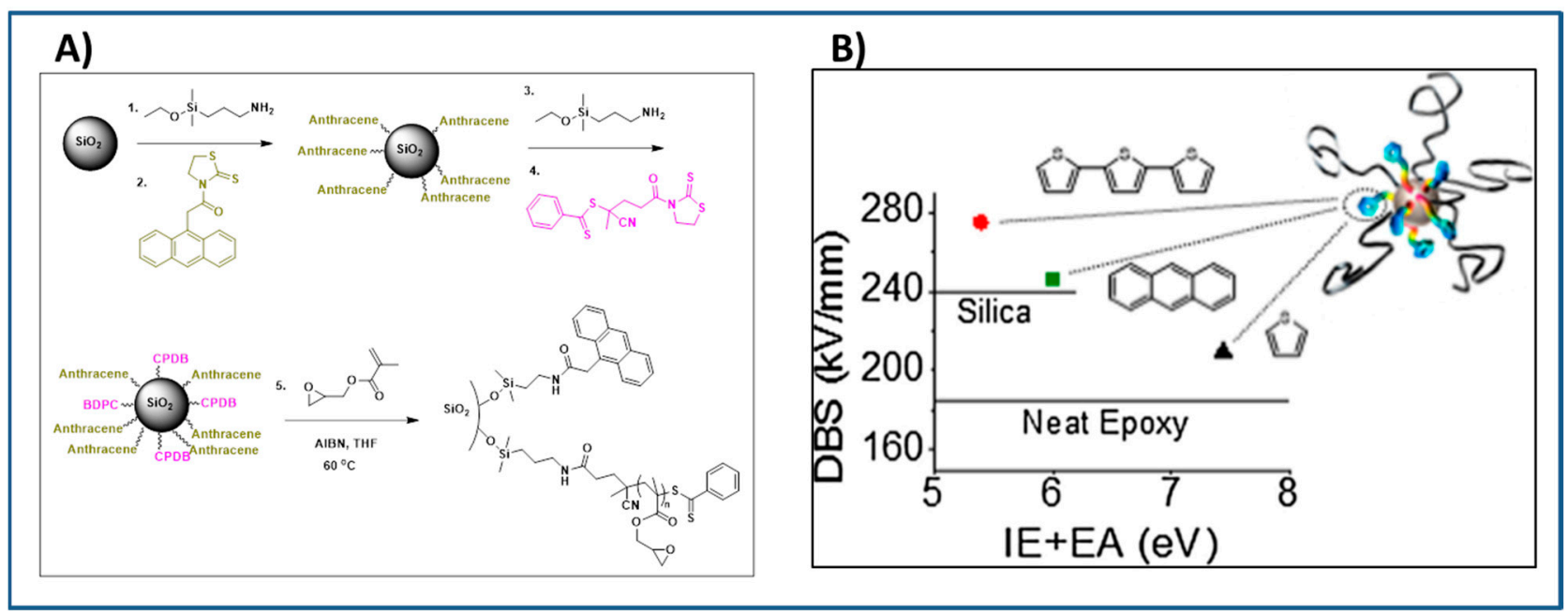

Figure 12. (A) Synthesis of bimodal anthracene-PGMA silica nanoparticles (B) calculated summation of ionization energy and electron affinity for electroactive ligands V.s. experimentally determined dielectric breakdown strength of several bimodal composites. Reproduced with permission from Ref. [187].

Similarly, bimodal anthracene-PSMA grafted $\mathrm{SiO}_{2}$ nanoparticles were dispersed in polypropylene. The dispersion of bimodal modified $\mathrm{SiO}_{2}$ nanoparticles in polypropylene resulted in the enhancement of dielectric permittivity by $20 \%$ and an improvement in the dielectric breakdown strength under both AC and DC test conditions by about $15 \%$ compared to neat polypropylene [178]. As noted earlier, the long alkyl chain of PSMA on grafted nanoparticles appears to have improved the compatibility of nanoparticles with XLPE matrix hence the improved dielectric properties of nanocomposites.

Alternatively, the bimodal functionalized nanoparticles can be synthesized with long brushes of PS chains and short P2VP chains using SI-RAFT technique. The combined effect of interaction of PS brushes of the grafted nanoparticles with the matrix and the reduction in silica core-core NPs interaction because of the dense short grafts of P2VP present in the grafted nanoparticles, contributed to the improved dispersion of nanoparticles in PS matrix. Unlike the earlier papers on bimodal grafted nanoparticles which dealt with dielectric properties of nanocomposites, the emphasis of Kumar et al. publication [188] was on the dispersion of nanoparticles in polymer matrix and the impact of microstructure on the mechanical properties of nanocomposites.

\subsection{SI-RAFT Polymerization to Prepare Polymer Grafted $\mathrm{TiO}_{2}$ Nanoparticles}

SI-RAFT has been employed for growing polymers such as PMMA [189,190], PS [138], polyacrylic acid (PAA) [191,192], poly(n-vinylpyrrolidone) [193], poly(chloromethyl styrene) [194], poly(2-hydroxyethyl acrylate) [195], PMMA-b-PS, [179,196], etc. on the surface $\mathrm{TiO}_{2}$. PS $(\mathrm{Mn}=4800 \mathrm{~g} / \mathrm{mol})$ was grown from rutile $\mathrm{TiO}_{2}$ nanoparticles via SI-RAFT polymerization and dispersed in PS matrix at various concentrations to investigate the dielectric properties of nanocomposites. The PS chains attached to the surfaces of $\mathrm{TiO}_{2}\left(\mathrm{PS}_{\mathrm{TiO}}\right)$ nanoparticles maintained a "brush-like" structure and resulted in chestnut-burr (Figure 13C) self-

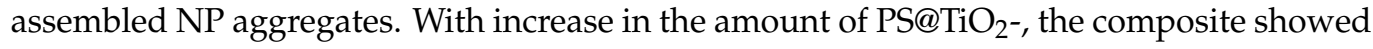
a higher dielectric constant $(\sim 65)$ which could be attributed to the self-assembled chestnutburr aggregates of the nanoparticles where a number of rutile crystals shared lateral faces and formed capacitive microstructures. The crystals in these aggregates are separated by a polymer thin layer and allow a high percolation threshold, $41 \% v / v$ of filler amount, before the formation of a continuous network responsible for the sudden change of the dielectric characteristics, (from random orientation to conductive pathways to conductive network) as depicted in Figure 13. Despite the high content of inorganic filler, the dissipation factor remained low, even approaching the lower frequencies. 


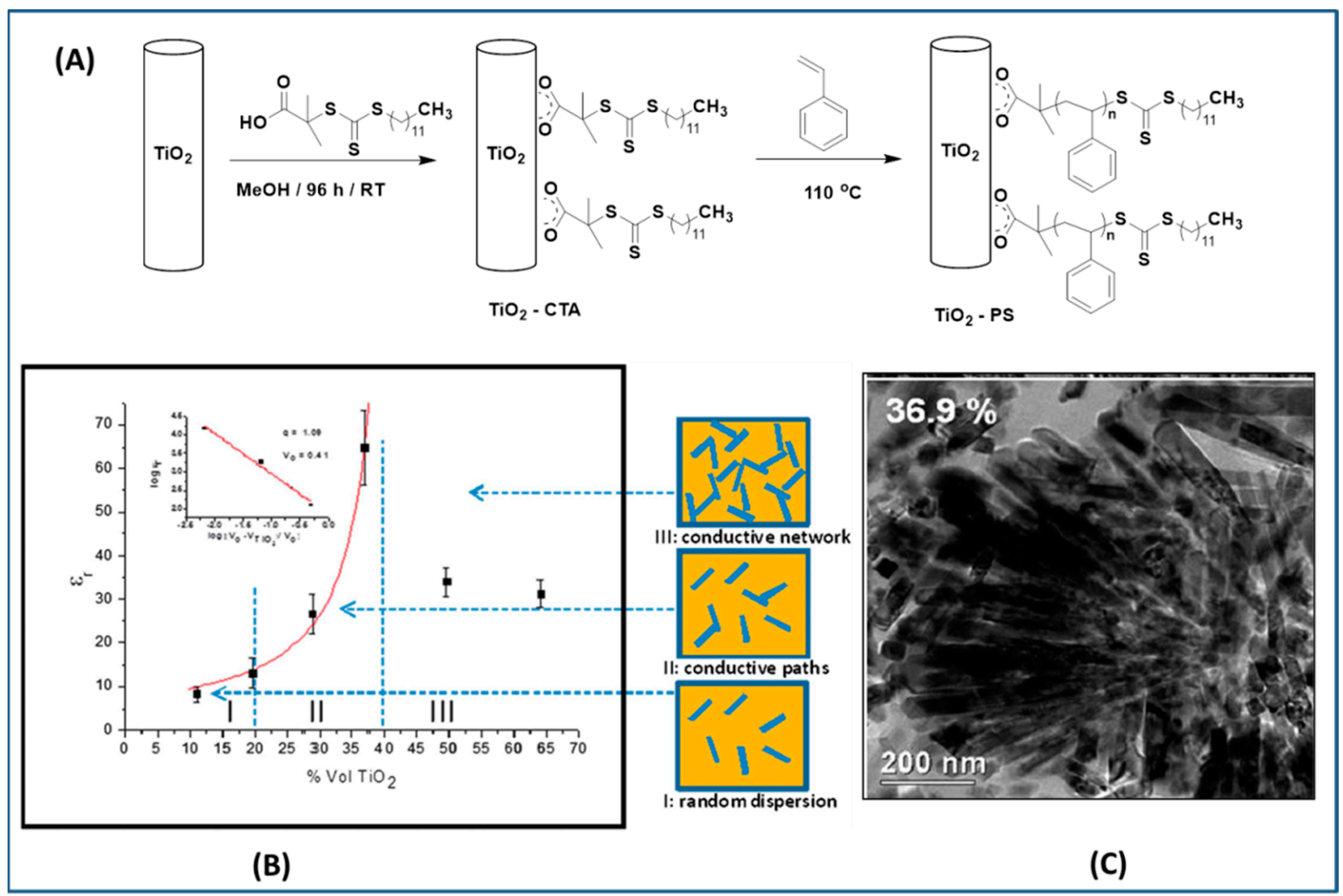

Figure 13. (A) Schematic diagram illustrating the process of RAFT polymerization on the surface of rutile nanoparticles;

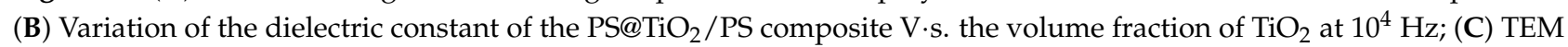
micrograph of the $\mathrm{TiO}_{2}-\mathrm{PS}$ composites (at $36.9 \% \mathrm{TiO}_{2}$ content). Reproduced with permission from Ref. [138].

\subsection{SI-RAFT Polymerization to Prepare Polymer Grafted $\mathrm{BaTiO}_{3}$ Nanoparticles}

Ming Zhu et al. [197] synthesized core-shell structured polymer@BaTiO ${ }_{3}$ nanoparticles of varying polymer composition (PMMA@BT, PGMA@BT, and PHEMA@BT) and constant shell thickness (Figure 14) using SI-RAFT technique. The synthesized nanoparticles were used to study the compositional effect of the polymeric shells of PGNPs on the dielectric properties of the nanocomposites i.e., breakdown strength, leakage currents, energy storage capability, and energy storage efficiency of the nanocomposites. The differences in the dielectric properties of the various core-shell NPs (with PHEMA, PGMA and PMMA shell) were attributed to the differences in the dipole moment of pendant groups in the shell. The hydroxyethyl pendant group in PHEMA was responsible for the larger dipole moment and higher moisture absorption, resulting in the higher dielectric constant and higher loss as compared to PGMA and PMMA. Among the systems studied, PHEMA@BT/PVDF nanocomposite exhibited highest storage energy density due to the high dielectric constant of PHEMA@BT while the PGMA@BT/PVDF nanocomposite exhibited highest discharge density due to the high breakdown strength and low dielectric loss of PGMA@BT (20\% loading), while PMMA@BT/PVDF (20\% loading) nanocomposite exhibited highest energy storage efficiency with moderate dielectric constant and moderate breakdown strength.

Some studies have systematically studied the role of pendant groups in the polymeric shell of encapsulated nanoparticles on the dielectric properties of nanocomposite. For example, Zhang and workers [170] varied the number of fluorine substituents present on the molecular structure of polymer shell of core shell structured rigid-fluoro-polymer@ $\mathrm{BaTiO}_{3}$ nanoparticles by performing RAFT polymerization with styrenic monomers containing different number of fluorine (M-3F, M-5F and M-7F) (Figure 15A), Evaluation of dielectric performance of the nanocomposites of rigid-fluoro-polymer nanoparticles@ $\mathrm{BaTiO}_{3}(\mathrm{P}-3 \mathrm{~F}$, P-5F and P-7F) and poly (Vinylidene fluoride-trifluororethylene-chlorotrifluoroethylene 
(PVDF-TrFE-CTFE) indicated a strong dependance of permittivity and energy densities on the molecular structure of fluorinated styrenic monomer. For $5 \%$ loading, the nanocomposite formulated with fluorinated styrenic monomer containing $3 \mathrm{~F}$ exhibited the highest breakdown strength $\left(542 \mathrm{kV} \mathrm{mm}{ }^{-1}\right)$ and highest energy density $\left(14.5 \mathrm{~J} \mathrm{~cm}^{-3}\right)$ which could be attributed to compact interfacial interactions of P-3F with PVDF-TrFE-CTFE matrix.

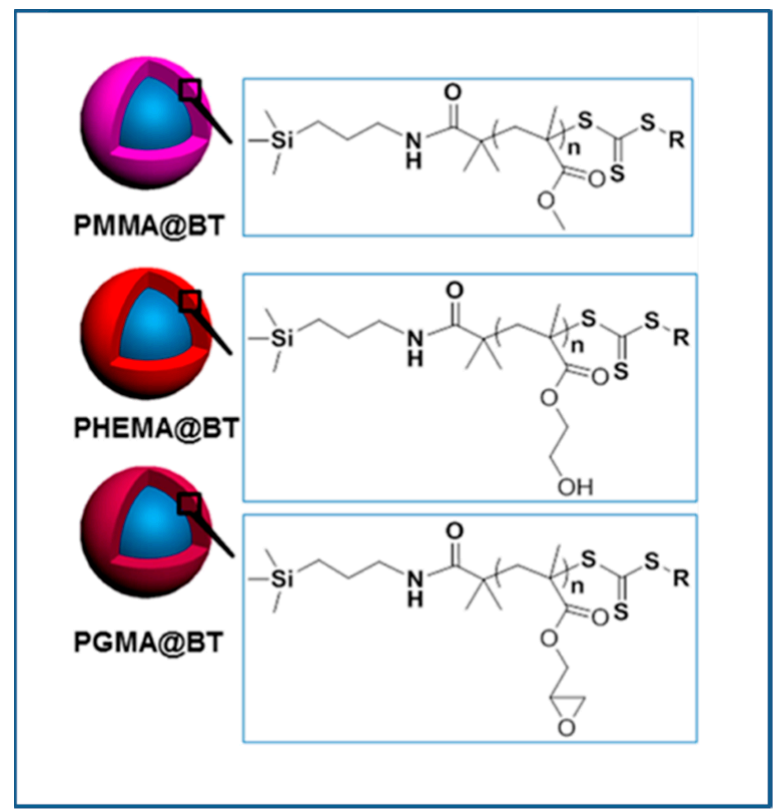

Figure 14. $\mathrm{BaTiO}_{3}$ core-shell nanoparticles by surface-initiated RAFT polymerization. Reproduced with permission from Ref. [197].

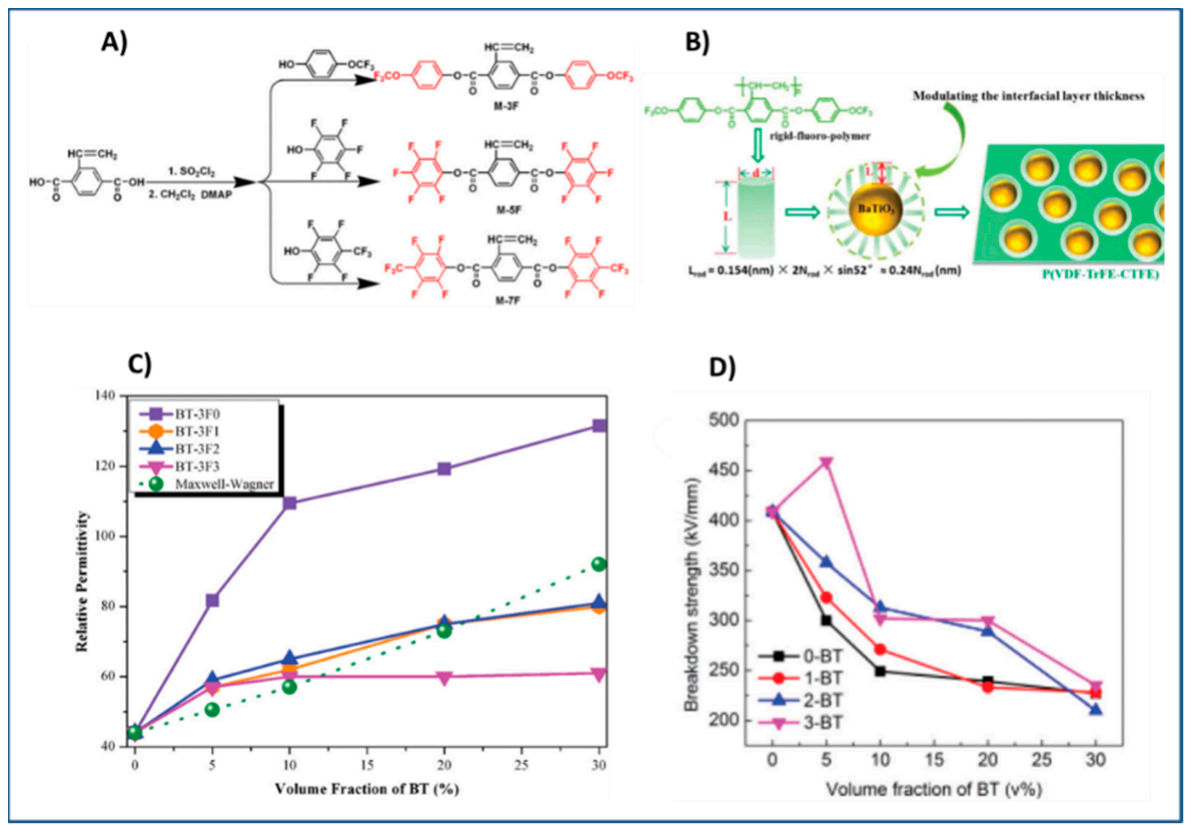

Figure 15. (A) Synthetic route for formation of TFMPCS monomer (B) schematic illustration of rigid-fluoropolymer@ $\mathrm{BaTiO}_{3} / \mathrm{PVDF}-\mathrm{TrFE}-\mathrm{CTFE}$ dielectric nanocomposite films (C) The permittivity of PVDF-TrFE-CTFE nanocomposites films with BT-3F0, BT-3F1, BT-3F2, and BT-3F3 at $1 \mathrm{kHz}$. (D) Variation of characteristic breakdown strength from Weibull distribution for samples with various volume fractions of fillers. Reproduced with permission from Ref. [130]. 
Other studies have explored the effect of shell thickness on the dielectric properties of nanocomposite while maintaining similar composition of the polymer shell of core-shell nanoparticles. Zhang et al. [130] synthesized core shell structured rigid-fluoro-polymer@BaTiO nanoparticles via SI-RAFT polymerization of 2,5-bis[(4-trifluoromethoxyphenyl)oxycarbonyl] styrene (TFMPCS) with RAFT agent anchored to $\mathrm{BaTiO}_{3}$ nanoparticles. TFMPCS was synthesized starting from 2-vinylterephthalic acid as depicted in Figure 15A. The PGNPs were incorporated in PVDF-TrFE-CTFE matrix to study the dielectric properties of the nanocomposite. A careful analysis of the results revealed that the dielectric constant, breakdown strength and energy density of the polymer nanocomposites were significantly affected by the thickness of rigid-fluoro-polymer shell around the $\mathrm{BaTiO}_{3}$ nanoparticles. For instance, nanocomposite with higher shell thickness (i.e., obtained from BT-3F3) exhibited higher breakdown strength while dielectric permittivity showed an inverse relationship with shell thickness (Figure 15). This is expected because polymers in general have higher breakdown strength while bare nanoparticles have higher permittivity. The energy density for $5 \mathrm{vol} \%$ BT-3F3/PVDF-TrFE-CTFE nanocomposite (36.6 $\mathrm{J} \mathrm{cm}^{-3}$ at the electric field of $514 \mathrm{kV} \mathrm{mm}^{-1}$ ) was significantly higher compared to pure PVDF-TrFE-CTFE $\left(15.4 \mathrm{~J} \mathrm{~cm}^{-3}\right.$ at the electric field of $457 \mathrm{kV} \mathrm{mm}^{-1}$ ).

Similarly, Yang et al. [176] studied the effect of shell thickness of PGNPs on the dielectric properties of nanocomposite while keeping the polymer composition of core-shell NPs constant. The RAFT agent (EDMAT) was initially immobilized on the surface of silanized $\mathrm{BaTiO}_{3}$ nanoparticles by conducting reaction with n-hydroxysuccinimide activated ester of EDMAT (NHS-EDMAT). A series of PS @ $\mathrm{BaTiO}_{3}$ nanoparticles were prepared by RAFT polymerization where, the shell thickness was tuned by changing the feed ratios of styrene and $\mathrm{BaTiO}_{3}-\mathrm{EDMAT}$. The dielectric constant of single component core-shell (shell thickness varying from 7 to $12 \mathrm{~nm}$ ) nanocomposite ranged from 14-24 depending upon the shell thickness (7 to $12 \mathrm{~nm}$ ) and the dielectric loss ranged from 0.009-0.13. Additionally, the dielectric constant as well as the dielectric loss of all the nanocomposites showed a weak frequency dependence over a wider range of frequencies $(1 \mathrm{~Hz}$ to $1 \mathrm{MHz}$ ).

$\mathrm{BaTiO}_{3}$-EDMAT nanoparticles have not only been utilized for surface-initiated RAFT polymerization of styrene but also for the polymerization of fluoroalkyl acrylates viz., 1H,1H,2H,2H-heptadecafluorodecyl acrylate (HFDA) and trifluoroethyl acrylate (TFEA) [175]. The surface energies of poly(fluoroalkyl acrylate)are generally lower than those of hydrogenated polymers e.g., PS. Several fluoroalkyl acrylate monomers with different structures were grafted on $\mathrm{BaTiO}_{3}$ nanoparticles and surface-initiated RAFT polymerization was conducted so as to synthesize polymer grafted $\mathrm{BaTiO}_{3}$ nanoparticles with the least surface energy. Dielectric evaluation of fluoro-polymer@ $\mathrm{BaTiO}_{3}, \mathrm{PVDF}-\mathrm{HFP}$ nanocomposites revealed that the energy density of 50\% PTFEA@ $\mathrm{BaTiO}_{3} / \mathrm{PVDF}-\mathrm{HFP} /$ nanocomposites $\left(6.23 \mathrm{~J} . \mathrm{cm}^{-3}\right)$ was $150 \%$ greater than that of the pure PVDF-HFP $\left(\sim 4.10 \mathrm{~J} . \mathrm{cm}^{-3}\right)$. Further, nanocomposite derived from PTFEA@BaTiO $\mathrm{P}_{3}$ exhibited slightly better dielectric performance over that derived from poly $(1 \mathrm{H}, 1 \mathrm{H}, 2 \mathrm{H}, 2 \mathrm{H}$-heptadecafluorodecyl acrylate) PHFDA@BaTiO 3 because PTFEA has pendent trifluoroethyl group which promotes a more compact interface compared to PHFDA which has long perfluoroalkyl pendant group.

The structure-property relationship study of polymer-grafted $\mathrm{BaTiO}_{3}$ nanoparticles (synthesized by RAFT technique) filled polymer nanocomposites clearly indicates that several factors influence the dielectric performance of the nanocomposite including the polymer composition of the shell, the pendant groups of the polymer shell, and the shell thickness of the core-shell nanoparticles.

\section{SI-Nitroxide-Mediated Polymerization (SI-NMP) to Prepare Polymer Grafted Nanoparticles}

Nitroxide-mediated polymerization (NMP) involves reversible activation-deactivation of propagating polymer chains by a nitroxide radical [198]. NMP polymerization has been widely used for grafting styrenic monomers however, other monomers methyl methacrylate, n-butyl acrylate, $\mathrm{N}$-isopropylacrylamide, acrylic acid, etc. have also been grafted on the surface of NPs [32,199-205]. The initiators used for NMP polymerization include 
2,2,6,6-tetramethylpiperidinyloxy (TEMPO) [57], N-tert-butyl-N-[1-diethylphosphono-(2,2dimethylpropyl)] nitroxide (DEPN) [206] and TIPNO [207]. The, SI-NMP of grafting polymer chains on NPs involves initially immobilizing TEMPO or DEPN or TIPNO initiator functionalities on the NP surface [48]. The beauty of NMP polymerization is in that the nitroxide radical endcaps the polymer chain to form a persistent radical effect without the need for a separate initiator or catalyst (The propagating species are formed via dissociation of a nitroxide radical). During polymerization, the equilibrium between dormant and active species shifts towards the dormant species and limits the number of active radical species present and also restrict possible termination reactions.

\subsection{SI-NMP Polymerization to Prepare Polymer Grafted $\mathrm{SiO}_{2}$ Nanoparticles}

Yang et al. [208] utilized SI-NMP polymerization for the preparation of polystyrene grafted $\mathrm{SiO}_{2}$ nanoparticles. The $\mathrm{SiO}_{2}$ nanoparticles were initially treated with thionyl chloride, and the modified nanoparticles were then reacted with tertiary butyl hydroperoxide (TBHP) to introduce peroxide groups on the surfaces of nanoparticles. Then NMP polymerization was initiated in the presence of TEMPO agent to graft polystyrene on the surface of $\mathrm{SiO}_{2}$ particles [208]. Alternatively, Chevigny and coworkers employed APTMS modified $\mathrm{SiO}_{2}$ nanoparticles and grafted MAMA-SG1 (BlocBuilder), (NMP initiator) for subsequent SI-NMP grafting of PS to $\mathrm{SiO}_{2}$ nanoparticles. The SI-NMP polymerization of styrene was carried out in the presence of free MAMA-SG1 as a sacrificial initiator to ensure a better control of the polymerization (Figure 16).

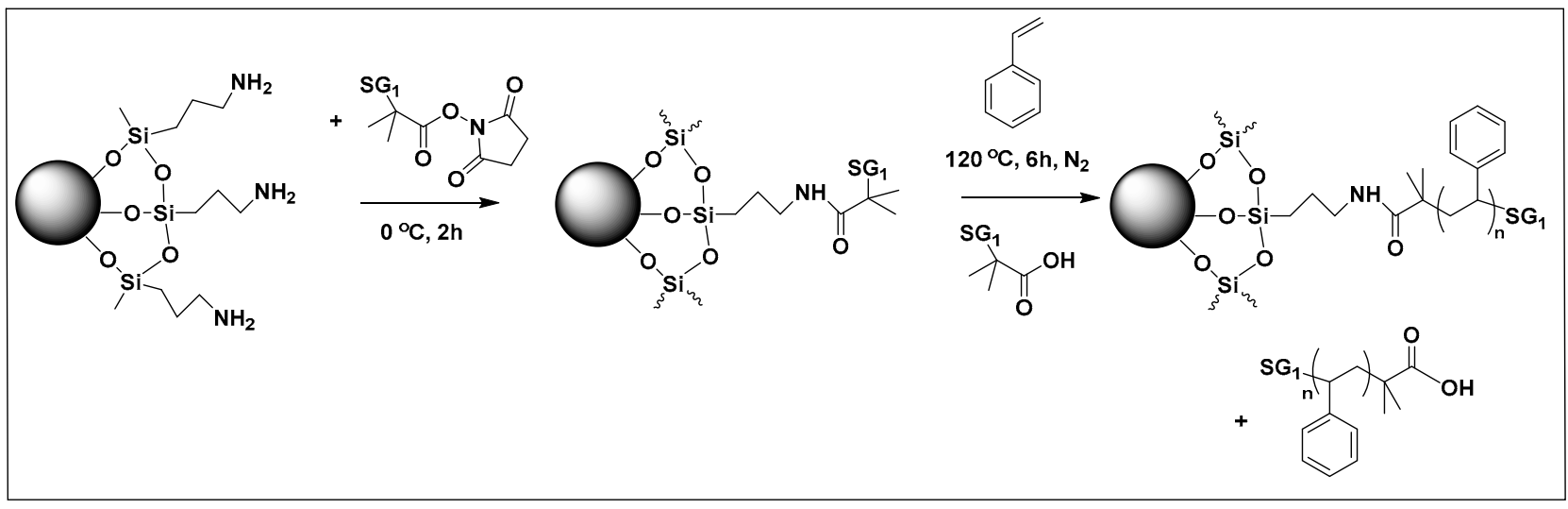

Figure 16. Scheme for anchoring of the MAMA-SG1 initiator and SI-NMP polymerization of styrene on the $\mathrm{SiO}_{2} \mathrm{NP}$ surface. Reproduced with permission from Ref. [32].

\subsection{SI-NMP Polymerization to Prepare Polymer Grafted $\mathrm{TiO}_{2}$ and $\mathrm{BaTiO}_{3}$ Nanoparticles}

SI-NMP has also been employed for grafting of PS $[209,210]$ and poly(4-chloromethyl styrene-g-4-vinylpyridine) (PCMSt-g-P4VP) [211] on $\mathrm{TiO}_{2}$ as well as poly(4-hydroxystyrene) (PVP) [212] and poly(styrene-co-maleic anhydride) (PSMA) copolymers [213] on $\mathrm{BaTiO}_{3}$ nanoparticles to obtain surface modified NPs. However, there has been no dielectric data reported of polymer grafted nanoparticles synthesized using SI-NMP technique.

\section{Grafting to Method to Prepare Polymer Grafted Nanoparticles}

The grafting to method is based on the use of polymer chain with functional groups that is randomly distributed along the chain or attached at the end of the polymer chain. The attachment of the graft polymer on nanoparticle surface requires coupling reaction of the functionalized backbone or the end-group functionalized polymer chain with the surface functionalized nanoparticles. Common reaction techniques used to synthesize functional polymers for grafting to method include free-radical polymerization, anionic polymerization, ATRP, and RAFT. The coupling reactions generally used in grafting to 
methods are click reactions, silanization, phophonate coupling, esterification, etherfication, etc.

\subsection{Grafting to Method to Prepare Polymer-Grafted $\mathrm{SiO}_{2}$ Nanoparticles}

The combination of CRP techniques (ATRP, [214] RAFT, [215] etc.) and coupling reactions has been useful in grafting PMMA, PS, PNiPAAm, poly(N-vinylcarbazole), poly(7-(6-(acryloyloxy) hexyloxy) coumarin), etc. on $\mathrm{SiO}_{2}$ nanoparticles. Initially, silaneterminated polymer or phosphonate-terminated polymer is synthesized so as to graft polymer on nanoparticles [216-218]. For example, PS samples with end-functionalized dimethylchlorosilane of different molecular weights (8 kDa, $26 \mathrm{kDa}, 108 \mathrm{kDa}$, and $126 \mathrm{kDa})$ were grafted on $\mathrm{SiO}_{2}$ bilayer. The bilayer was then used as organic-oxide hybrid gate dielectrics to fabricate solution-processed triethylsilylethynyl anthradithiophene (TES-ADT) organic field-effect transistors (OFETs). The molecular weights of PS chains significantly altered the areal grafting densities (due to steric hindrance), the interfacial structure and the dielectric properties as well as the performance of the OFETs. The lower molecular weight PS- $g-\mathrm{SiO}_{2}$ surface exhibited smoother brush like structure while higher molecular weight $\mathrm{PS}-g-\mathrm{SiO}_{2}$ surface exhibited pancake like structure. The smoother surface of $8 \mathrm{kDa}$ PS- $g-\mathrm{SiO}_{2}$ surface showed the highest mobility $\left(2.12 \mathrm{~cm}^{2} \cdot \mathrm{V}^{-1} \cdot \mathrm{s}^{-1}\right)$ whereas the pancake surface of $135 \mathrm{kDa} P S-g-\mathrm{SiO}_{2}$ showed the lowest mobility $\left(0.85 \mathrm{~cm}^{2} \cdot \mathrm{V}^{-1} \cdot \mathrm{s}^{-1}\right)$ [219].

\subsection{Grafting to Method to Prepare Polymer Grafted $\mathrm{TiO}_{2}$ Nanoparticles}

Phosphonic ester end capped PS has been synthesized using ATRP technique (Figure 17). The phosphonic acid end-functionalized PS was then coupled with oleic acid stabilized

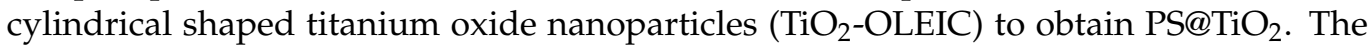
PS@ $\mathrm{TiO}_{2}$ nanoparticles thus prepared were used for the fabrication of capacitors as well

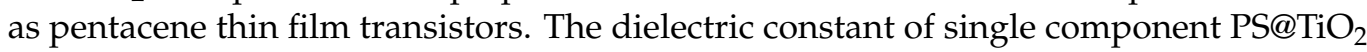
nanocomposite was $\sim 9$ (which is nearly 3.6 times higher than that of polystyrene) at 18.2 volume \% loading of PS @ $\mathrm{TiO}_{2}$, while the mobilities of PS@ $\mathrm{TiO}_{2} / \mathrm{ITO}$ (bilayer) approached $0.2 \mathrm{~cm}^{2} / \mathrm{V} \cdot \mathrm{s}$. [220] showing the importance of synthesized PS grafted $\mathrm{TiO}_{2}$ nanoparticles via grafting to approach in electronics and dielectric applications.

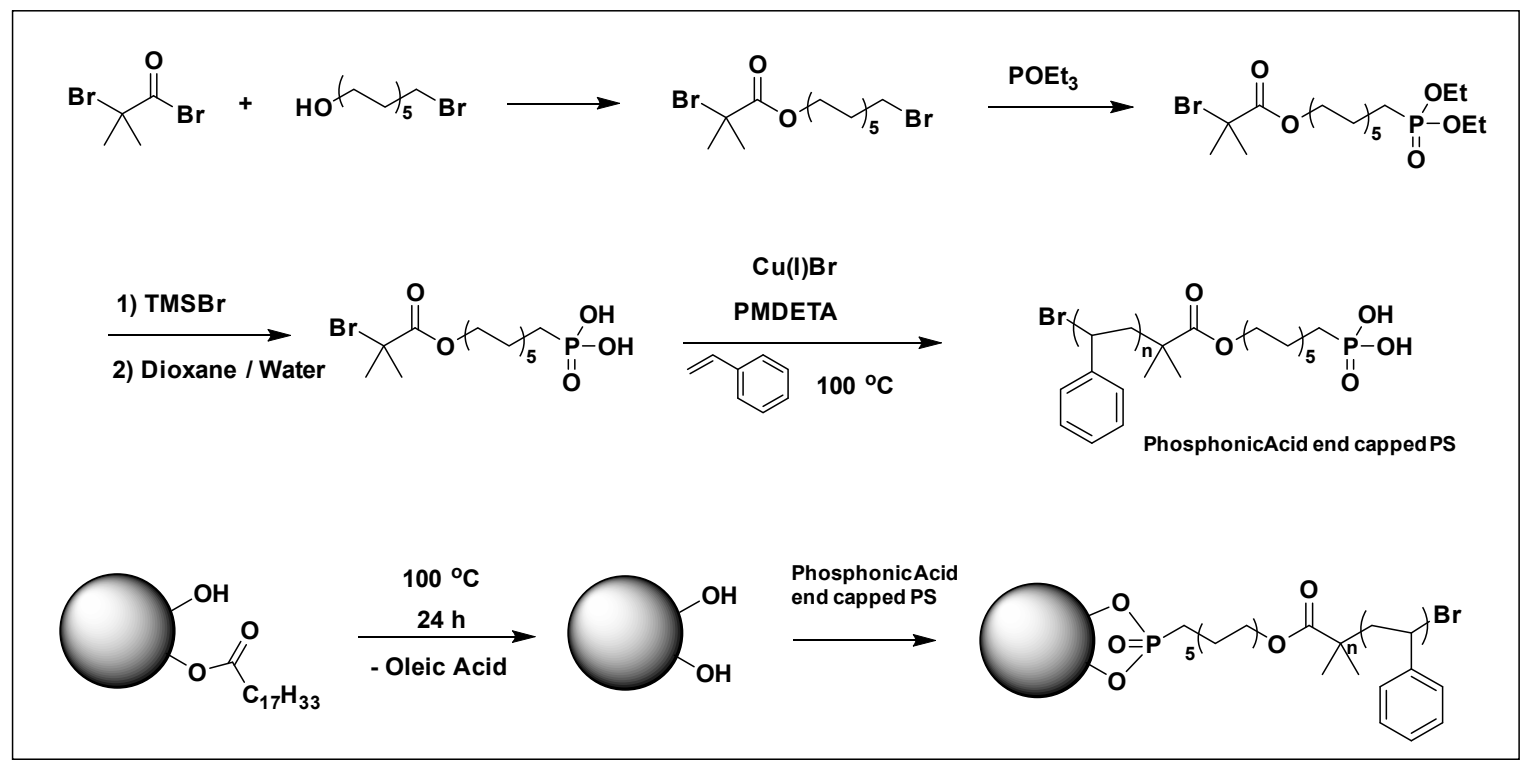

Figure 17. Synthesis of phosphonate end capped polystyrene and ligand exchange reaction of diethyl phosphonate end capped polystyrene with oleic acid terminated $\mathrm{TiO}_{2}$ nanoparticles to generate polystyrene coated $\mathrm{TiO}_{2}\left(\mathrm{PS} @ \mathrm{TiO}_{2}\right)$ Reproduced with permission from Ref. [220]. 
Using "grafting to" approach, block copolymer has been grafted to $\mathrm{TiO}_{2}$ nanoparticles with hydroxyl group as the end functionality of the anchoring block copolymer. Hailu and coworkers [221] demonstrated using "grafting-to" approach the ability to graft PMMAb-PS-OH to silylated $\mathrm{TiO}_{2}$ nanoparticles to form block copolymer grafted nanoparticle (Figure 18). It was observed that the dispersion of PMMA-b-PS-g- $-\mathrm{TiO}_{2}$ nanoparticles in PMMA and PS-PMMA BCP films was far better compared to that in PS films which could be attributed to the improved interactions of the outer corona of the PMMA-b-PS- $g-\mathrm{TiO}_{2}$ NPs with the PMMA component of BCP. The addition of $2.6 \mathrm{vol} \%$ of $\mathrm{BCP}-g-\mathrm{TiO}_{2} \mathrm{NPs}$ resulted in $18 \%$ enhancement in the permittivity and lower dielectric loss compared to the bare $\mathrm{TiO}_{2}$ nanoparticles filled $\mathrm{BCP}$ nanocomposite [222].

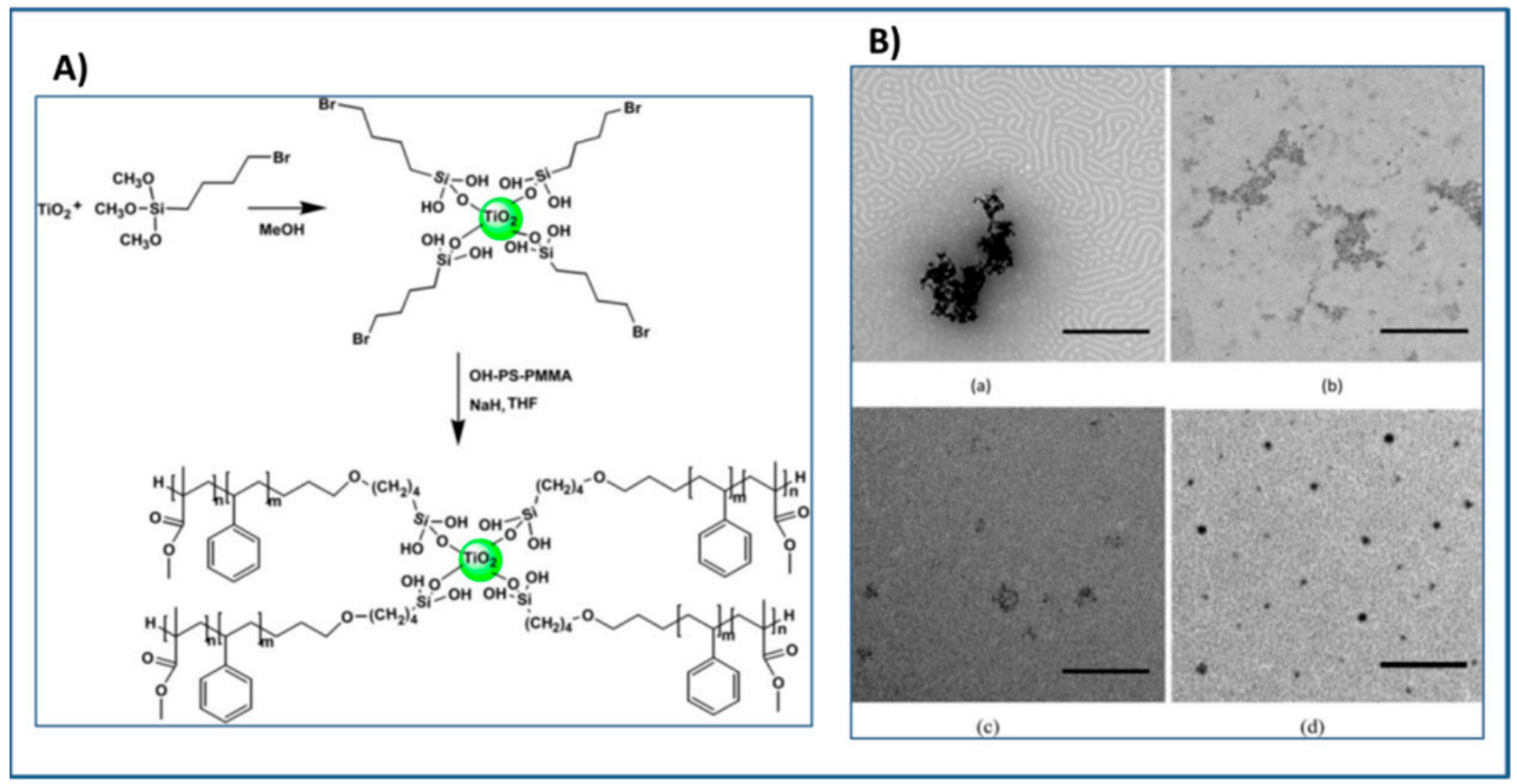

Figure 18. (A) Scheme for synthesis of PMMA-b-PS - $g-\mathrm{TiO}_{2}$ nanoparticles; (B) TEM (no stain) images of (a) oven annealed pristine $\mathrm{TiO}_{2}(10 \mathrm{wt} \%$ )-BCP (57 k-b-25 k) composite (b) As-cast PS (60 k) with $10 \mathrm{wt} \%$ BCP-g-TiO 2 (c) As-cast PMMA (33 k) with $10 \mathrm{wt} \% \mathrm{BCP}-\mathrm{g}-\mathrm{TiO}_{2}$, and (d) Oven annealed PMMA (33 k) with $10 \mathrm{wt} \% \mathrm{BCP}-\mathrm{g}-\mathrm{TiO}_{2}$. (scale bar: $0.5 \mu \mathrm{m}$ ). Reproduced with permission from Ref. [221].

Similarly, using "grafting to" approach, block copolymer was grafted onto $\mathrm{TiO}_{2}$ nanoparticles with dopamine as the anchoring group. Obata et al. synthesized copolymer containing dopamine as pedant groups via RAFT technique and subsequently coupled it with $\mathrm{TiO}_{2}$ nanoparticles to yield block copolymer grafted $\mathrm{TiO}_{2}$ nanoparticles [223]. Alternatively, silylation approach can also be used to graft $\mathrm{PMMA}$ on $\mathrm{TiO}_{2}$ nanoparticles by coupling of $\mathrm{TiO}_{2}$ with preformed trimethoxysilyl functionalized PMMA that was synthesized via ATRP technique [224].

\subsection{Grafting to Method to Prepare Polymer Grafted $\mathrm{BaTiO}_{3}$ Nanoparticles}

The silylation route has also been used in the grafting to approach of polymer grafted $\mathrm{BaTiO}_{3}$ nanoparticles. Xie et al. [133] formed PVDF-HFP@BaTiO ${ }_{3}$ nanocomposites by initially synthesizing) $\mathrm{P}(\mathrm{VDF}-\mathrm{HFP})$ with glycidyl methacrylate (GMA) functionality via ATRP (Fluorine atom of the PVDF-HFP was utilized to initiate the ATRP of the GMA) technique. The functionalized polymer was then reacted with the APTMS-functionalized $\mathrm{BaTiO}_{3}$ nanoparticles. The coupling reaction between PVDF-HFP-GMA (epoxy functionality) and amino-functionalized $\mathrm{BaTiO}_{3}$ yielded PVDF-HFP@BaTiO $\mathrm{B}_{3}$ nanocomposite with superior dielectric properties. For example, the nanocomposite with $50 \%$ nanoparticle 
loading exhibited dielectric constant of 34.8 at $1 \mathrm{MHz}$, about 3.9 times greater than that of pristine PVDF-HFP while dielectric loss observed was 0.128 at $1 \mathrm{MHz}$.

Alternatively Yang and coworkers [225] synthesized core-shell structured polymer@Ba $\mathrm{TiO}_{3}$ nanoparticles for dielectric applications via "grafting to" route using a combination of "thiol-

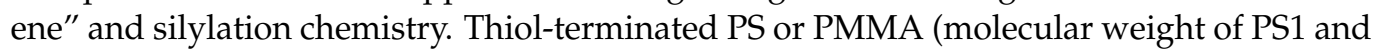
PMMA1 10K, PS2 and PMMA2 40K and PS3 and PMMA3 80K) were prepared by RAFT polymerization and was allowed to react with vinyl-functionalized (methacryloxypropyltrimethoxy) silanized $\mathrm{BaTiO}_{3}$ nanoparticles to form a series of polymer grafted nanoparti-

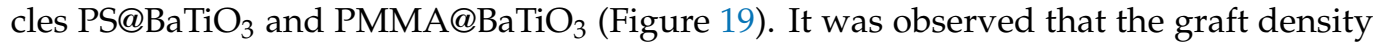
decreased with increase in the molecular weight of the grafted polymer. The dielectric constant of PS@BT ( $\mathrm{k}=30-33)$ and PMMA@BT $(\mathrm{k}=34-38)$ single component nanocomposites was greater than that of pure polymers $(\mathrm{k}$ for $\mathrm{PS}=2.74$ and $\mathrm{k}$ for PMMA $=3.69$ ) while the low dielectric loss (for PS@ BT=0.013 and for PMMA@ BT=0.032) was maintained over a wider range of frequency. Compared to PMMA@BT nanocomposites, PS@BT nanocomposites exhibited higher energy efficiency due to lower remnant polarization. Furthermore, the energy efficiency of both PS@BT and PMMA@BT nanocomposites exhibited a strong dependence on the molecular weight of the grafted polymer chains and the grafting density indicating that the design of core-shell nanoparticle filled polymer nanocomposites with high energy density and high energy efficiency is intricately related to the shell structure.

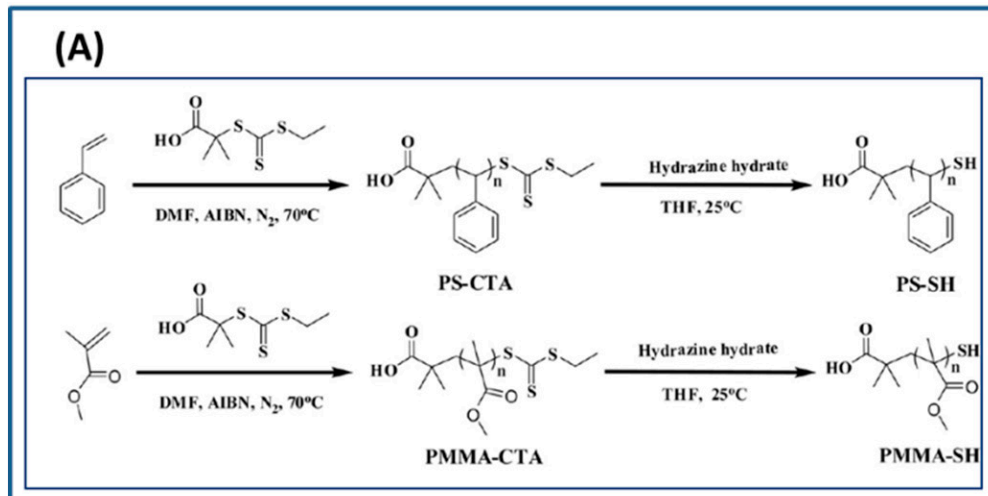

(B)

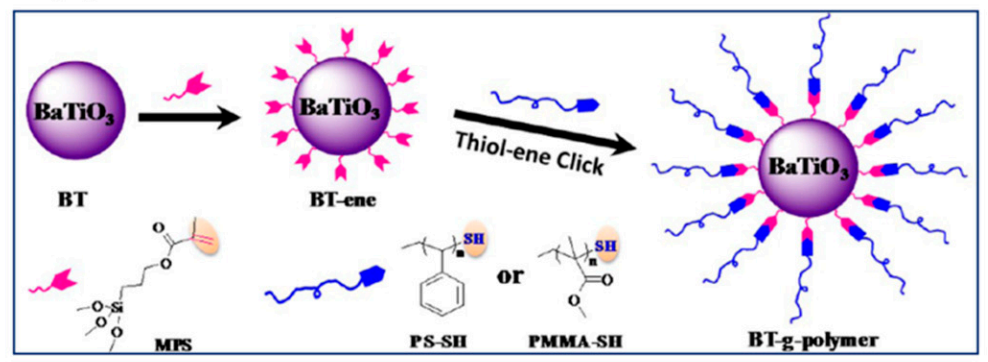

(C)

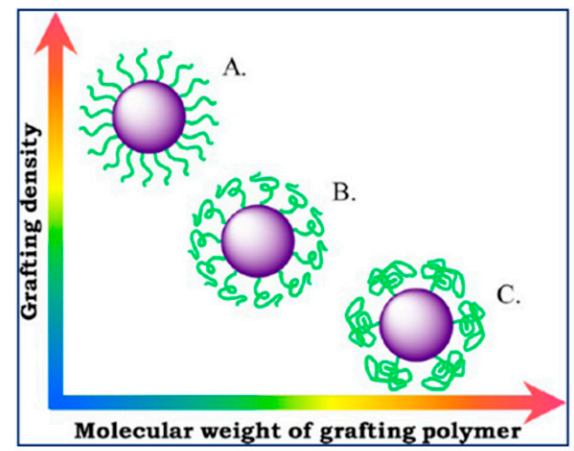

(D)

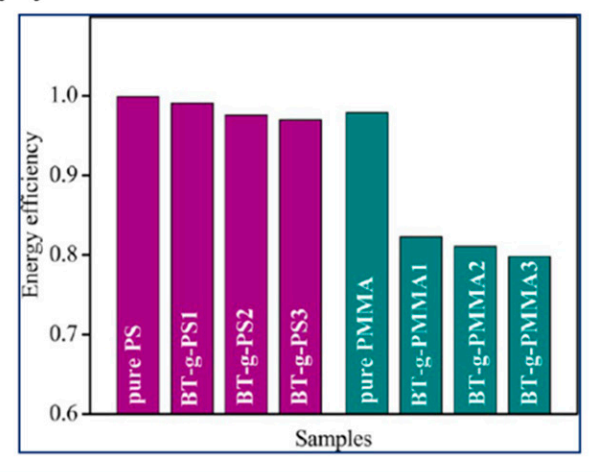

Figure 19. Schematic illustration for (A) synthesis of thiol-terminated PS and thiol-terminated PMMA via RAFT polymerization and (B) preparation of core-shell structured polymer@BaTiO 3 nanocomposites by thiol-ene click reaction. (C) The relationship between the molecular weight of grafting polymer and grafting density of the core-shell structured nanoparticles (D) Energy efficiency of the core-shell structured polymer@BT nanocomposites under the electric field of $10 \mathrm{kV} / \mathrm{mm}$. Reproduced with permission from Ref. [225]. 
Similarly, Ma et al. [131] synthesized core-shell structured PVDF@BT and PS@BT nanoparticles via thiol-ene coupling. Where thiol-terminated poly(vinylidene fluoride) (PVDF-SH) and thiol-terminated polystyrene (PS-SH), was reacted with $\gamma$-methacryloxypropyltrimethoxysilane (MPS) functionalized $\mathrm{BaTiO}_{3}$ nanoparticles (as depicted in Figure 20). It was observed that the dielectric permittivity and Eb of PVDF@BT/PVDF $(117 \mathrm{kV} / \mathrm{mm})$ and PS@BT/PVDF composites $(107 \mathrm{kV} / \mathrm{mm})$ was better than that of unmodified-BT/PVDF composites $(58.5 \mathrm{kV} / \mathrm{mm})$. The superior $\varepsilon r$ of PVDF compared to PS resulted in higher dielectric constant of PVDF@BT/PVDF ( $\varepsilon r=33$ at $30 \%$ loading) over PS@BT /PVDF composites ( $\varepsilon r=25$ at $30 \%$ loading). Furthermore, PVDF@BT NPs exhibited better compatibility with PVDF matrix compared to PS@BT resulting in improved breakdown strength of nanocomposite. In other words, PVDF shell act as a buffer layer and reduced the electrical mismatch between the matrix and core nanofillers compared to the PS hell.

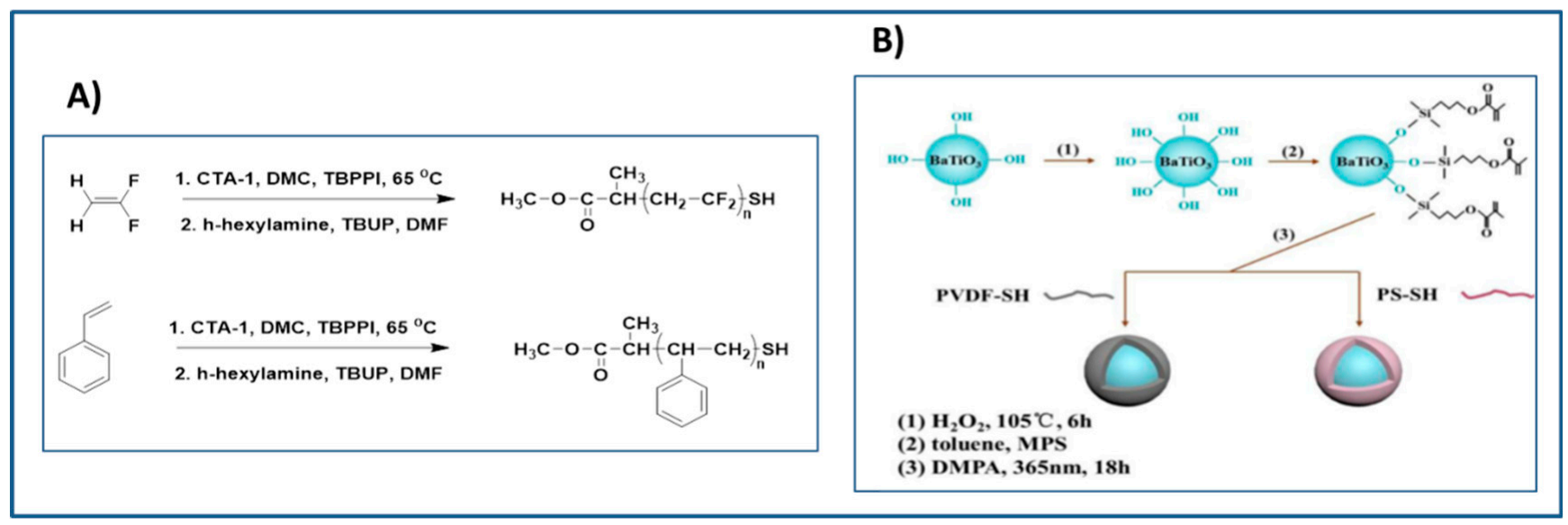

Figure 20. (A) Synthesis of SH-terminated PS and SH-terminated PVDF. (B) Grafting to approach for synthesis of hybrid nanoparticles. Reproduced with permission from Ref. [131].

\subsection{Grafting to Method to Prepare Polymer Grafted $\mathrm{Al}_{2} \mathrm{O}_{3}$ Nanoparticles}

The "grafting to" techniques has also been used to graft PS with -COOH end groups by reacting with $-\mathrm{OH}$ groups on the surface of $\mathrm{Al}_{2} \mathrm{O}_{3}$ nanoparticles (Al NPs) [139]. The PS with - $\mathrm{COOH}$ end group was initially synthesized by free radical polymerization initiated by $4,4^{\prime}$-azobis (4-cyanovaleric acid) (ACVA) in toluene. The grafting of high surface energy Al NPs with PS having - $\mathrm{COOH}$ end group greatly reduced the aggregation of Al NPs in comparison to the bare Al NPs in PS matrix. When the Al NPs and PS grafted Al NPs were mixed with PS to form PS nanocomposite films, the results showed larger voids for agg-Al NPs filled PS composite film but a more homogeneous composite film for PS grafted Al NPs. The dielectric constant of the pristine PS film, the PS films doped with $30 \mathrm{wt} \%$ agg-Al NPs and PS grafted Al NPs at $10^{5} \mathrm{~Hz}$ were found to be 2.80, 4.75 and 9.50, respectively. The breakdown strength and energy density of the PS film doped with PS grafted Al NPs (211-175 $\mathrm{kVmm}^{-1}$ and $1.70 \mathrm{~J} / \mathrm{cm}^{3}$ at $1000 \mathrm{~Hz}$ ) was greater than PS film doped with agg-Al NPs (183.77 to $30 \mathrm{kVmm}^{-1}$ and $0.26 \mathrm{~J} / \mathrm{cm}^{3}$ at $1000 \mathrm{~Hz}$ ) and this was ascribed to the good compatibility and good dispersion of the PS grafted Al NPs in the PS film.

PS- $g-\mathrm{Al}_{2} \mathrm{O}_{3}$ nanoparticles were also synthesized by silanization of $\mathrm{Al}_{2} \mathrm{O}_{3} \mathrm{NPs}$ with dimethylchlorosilane-end-capped polystyrene (PS) to obtain grafted nanoparticles with graft density of 0.13 chains $/ \mathrm{nm}^{2}$. The different $\mathrm{wt} \%$ of $\mathrm{PS}-\mathrm{Al}_{2} \mathrm{O}_{3}$ nanoparticles were blended with PS to fabricate nanocomposites with dielectric constant in the range 2.59 to 7.79. The nanocomposite film was found to be an efficient surface passivator for the oxide dielectric layer in organic field-effect transistors (OFETs). The field-effect mobility $\left(1.4 \times 10^{-3} \mathrm{~cm}^{2} / \mathrm{V} \cdot \mathrm{s}\right)$ and threshold voltage $(4.4 \mathrm{~V})$ of OFETs with $\mathrm{PS}-\mathrm{Al}_{2} \mathrm{O}_{3}$ nanoparticles were found to be significantly better than that of nanocomposite with bare $\mathrm{Al}_{2} \mathrm{O}_{3}$ nanoparticles (field-effect mobility $=1.7 \times 10^{-4} \mathrm{~cm}^{2} / \mathrm{V} \cdot \mathrm{s}$ threshold voltage $=6.7 \mathrm{~V}$ ) [132] 


\section{In Situ Polymerization to Prepare Polymer Grafted Nanoparticles}

In situ polymerization has been widely used for producing well-dispersed metal oxide nanoparticle/polymer composite. In this technique, nano-sized metal oxide particles are mixed with organic monomers either in the presence or absence of a solvent followed by polymerization of the respective monomers. The nanoparticles are encapsulated in polymer shell via physical or chemical adsorption by taking advantage of the reactive functionality (e.g., acrylate functionality, it can be termed as "grafting through" or "grafting onto") on NP surface. Both emulsion and suspension polymerization methods or in situ synthesis of both NPs (sol-gel synthesis) and polymers (free radical polymerization) have been employed $[45,59,226-230]$.

Morales-Acosta and coworkers performed sol-gel and in situ polymerization using tetraethyl orthosilicate (TEOS) as $\mathrm{SiO}_{2}$ precursor, methyl methacrylate (MMA) as monomer, and 3-(trimethoxysilyl)propyl methacrylate (TMSPM) as coupling agent to improve the compatibility between PMMA and $\mathrm{SiO}_{2}$. Various core-shell nanoparticles with equimolar proportion of TEOS and MMA and varying concentrations of coupling agent, TMSPMA were prepared so as to study the effect of coupling agent concentration on the properties of fabricated nanocomposite films. All of the $\mathrm{PMMA}_{-} \mathrm{SiO}_{2}$ hybrid films exhibited higher dielectric constant (5.7 to 14) than that of PMMA ( $\kappa=3.2$ at $1 \mathrm{MHz})$ and bare $\mathrm{SiO}_{2}(\kappa=3.9$ at $1 \mathrm{MHz})$. The enhancement in the permittivity was attributed to residual solvents (-OH groups) and MMA (-C=C-groups, due to incomplete conversion into PMMA) present in the nanocomposite films [230].

Morales-Acosta and coworkers utilized low-temperature sol-gel and in situ polymerization to obtain PS- or PMMA-grafted-metal oxide $\left(\mathrm{SiO}_{2}, \mathrm{TiO}_{2}, \mathrm{ZrO}_{2}\right)$ hybrid films for gate dielectric applications in the thin film transistors [231-234]. Similarly, Sánchez-Ahumada et al. synthesized $\mathrm{PS}-\mathrm{TiO}_{2}$ hybrid dielectric films by performing sol-gel process with titanium butoxide (TB) as precursor and in situ polymerization of styrene in presence of the coupling agent, 3-trimetoxy-silyl-propyl-methacrylate (TMSPM) simultaneously. The dielectric constant of the hybrid film was 5.2 at $1 \mathrm{MHz}$, which is higher than that of pristine PS (2.74). PS- $\mathrm{TiO}_{2}$ hybrid dielectric films exhibited leakage current of $1 \times 10^{-6} \mathrm{~A} / \mathrm{cm}^{2}$ which is low enough to qualify the hybrid material as a dielectric gate in electronic devices [235].

PMMA embedded $\mathrm{TiO}_{2}$ nanoparticles were also synthesized via in situ free radical polymerization of methyl methacrylate using benzyl peroxide as an initiator in aqueous solution of polyvinyl alcohol (PVA) and sodium phosphate along with preformed $\mathrm{TiO}_{2}$ nanoparticles. The dielectric properties of PMMA embedded $\mathrm{TiO}_{2}$ nanoparticle filled PMMA nanocomposite showed high dielectric constant with low dielectric loss, [236].

Wang and coworkers reported the synthesis of $\mathrm{PMMA}-\mathrm{g}-\mathrm{TiO}_{2}$ via in situ emulsion polymerization technique. The dielectric study of PMMA- $g-\mathrm{TiO}_{2} / \mathrm{PVDF}-\mathrm{HFP}$ nanocomposite film showed that the permittivity of the nanocomposite was enhanced by $13.9 \%$ compared to the pristine PVDF-HFP film whereas the breakdown field strength of the nanocomposite was nearly doubled compared to bare $\mathrm{TiO}_{2}$ PVDF-HFP nanocomposite. The enhanced dielectric performance of the nanocomposite resulted the improvement in the energy density of the PMMA- $g-\mathrm{TiO}_{2} / \mathrm{PVDF}-\mathrm{HFP}$ nanocomposite (at $1 \mathrm{vol} . \%$ nanoparticle loading) by $14.4 \%$ w.r.t pristine PVDF-HFP (from 12.4 to $14.2 \mathrm{~J} / \mathrm{cm}^{3}$ ) and an improvement in charge-discharge energy efficiency of $47 \%$ below $500 \mathrm{MV} / \mathrm{m}$ electric field [136].

Recently, Zhou et al. synthesized polyurea-grafted core-shell nanoparticles $\left(\mathrm{PUA} @ \mathrm{BaTiO}_{3}\right)$ via in situ polymerization using 4,4'-methylene diphenyl diisocyanate and 4,4'-oxydianiline as monomers. The PUA@BaTiO 3 nanoparticles were subsequently blended with PVDFCTFE to fabricate nanocomposite films for evaluation of dielectric properties. The incorporation of $\mathrm{PUA} @ \mathrm{BaTiO}_{3}$ in PVDF-CTFE matrix resulted in 1.65 times higher energy density $\left(8.94 \mathrm{~J} / \mathrm{cm}^{3}\right)$ than that of pristine PVDF-CTFE $\left(5.41 \mathrm{~J} / \mathrm{cm}^{3}\right)$. Further, the energy density of PUA@ $\mathrm{BaTiO}_{3} / \mathrm{PVDF}-\mathrm{CTFE}$ nanocomposite was also 1.45 times higher than that of pristine $\mathrm{BaTiO}_{3} /$ PVDF-CTFE nanocomposite [237].

Similarly, Jinhong et al., [141] reported the grafting of hyperbranched aromatic polyamide on $\mathrm{Al}_{2} \mathrm{O}_{3}$ nanoparticles (HBP@ $\mathrm{Al}_{2} \mathrm{O}_{3}$ ) and the use of functionalized nanoparticles to en- 
hance the dielectric properties of epoxy nanocomposite. The incorporation of $\mathrm{HBP}_{\mathrm{A}} \mathrm{Al}_{2} \mathrm{O}_{3}$ nanoparticles to epoxy matrix resulted in an enhancement in the glass transition temperatures (176.3 to $208.1{ }^{\circ} \mathrm{C}$ with $20 \mathrm{wt} \%$ of the filler). Furthermore, the dielectric constant of the HBP@ $\mathrm{Al}_{2} \mathrm{O}_{3}$ / epoxy nanocomposite was reported to be 5.0, compared to neat epoxy (3.5) and that of composite formed with $20 \mathrm{wt} \%$ bare $\mathrm{Al}_{2} \mathrm{O}_{3}$ nanoparticles (4.75). It was concluded that the improvement of Tgs (176.3 to $208.1{ }^{\circ} \mathrm{C}$ ), dielectric strength (29.40 to $32.83 \mathrm{KV} / \mathrm{mm}$ ) and the reduction of dielectric loss $(0.024$ to 0.020$)$ were due to the good dispersion of the grafted NPs in the polymer matrix and also because of good interfacial adhesion of the grafted hyperbranched aromatic polyamide $\mathrm{Al}_{2} \mathrm{O}_{3}$ nanoparticles with the epoxy matrix.

\section{Templated Approach to Prepare Polymer Grafted Nanoparticles}

Template-assisted method involves the formation of nanoparticles within the specific area of the template and the method can be efficiently used for fabrication of well-defined core-shell nanomaterials. Especially, template-assisted polymer grafting approach has been employed to control the size and shape (spherical, cylindrical, nanotubes, etc.) of core nanostructure as well as the structure of graft present on the surface of the nanoparticles [58,238-250].

Template-assisted polymer grafting which offers an easier way to synthesize nanoparticles (in situ) through micelle formation is a relatively straightforward technique. However, Gou et al. noticed bimodal distribution of PS/PMMA-g-CdS quantum dots on the core of the self-assembly of PS- $b$-PAA-b-PMMA triblock copolymer micelles [46]. This aspect was addressed by the selection of unimolecular star block copolymer micelles which often yields hairy nanoparticles with uniform sizes, various shapes, and sometimes unusual morphologies [47].

Matyjaszewski and coworkers demonstrated the utilization of poly(styrene-co-acrylonitrile)b-poly (acrylic acid)-poly(divinylbenzene) (PSAN-b-PAA-PDVB) star-shaped copolymers obtained via activator regenerated by electron transfer atom transfer radical polymerization (ARGET ATRP) (as depicted in Figure 21) as template for the synthesis of $\mathrm{TiO}_{2}$ nanoparticles. PMMA gate dielectrics layers fabricated with $0.4 \%$ wt. of the hybrid $\mathrm{TiO}_{2}$ nanoparticles was used in the measurement of organic field effect transistors (OFETs). The efficiency of OFETs was significantly better than OFETs based of pure PMMA as gate dielectric (charge carrier mobility has increased nearly 10-fold from $\sim 0.06$ to $\sim 0.5 \mathrm{~cm}^{2} / \mathrm{V} \cdot \mathrm{s}$ ). The improved performance of OFET could be ascribed to a significant decrease of roughness of dielectric layer (root mean square roughness was reduced from $15.3 \mathrm{~nm}$ to $0.43 \mathrm{~nm}$ ) and changes to the surface energy (from 32.4 to $45.5 \mathrm{mN} / \mathrm{m}$ ) of the gate dielectric layer after incorporation of hybrid nanoparticles [251].

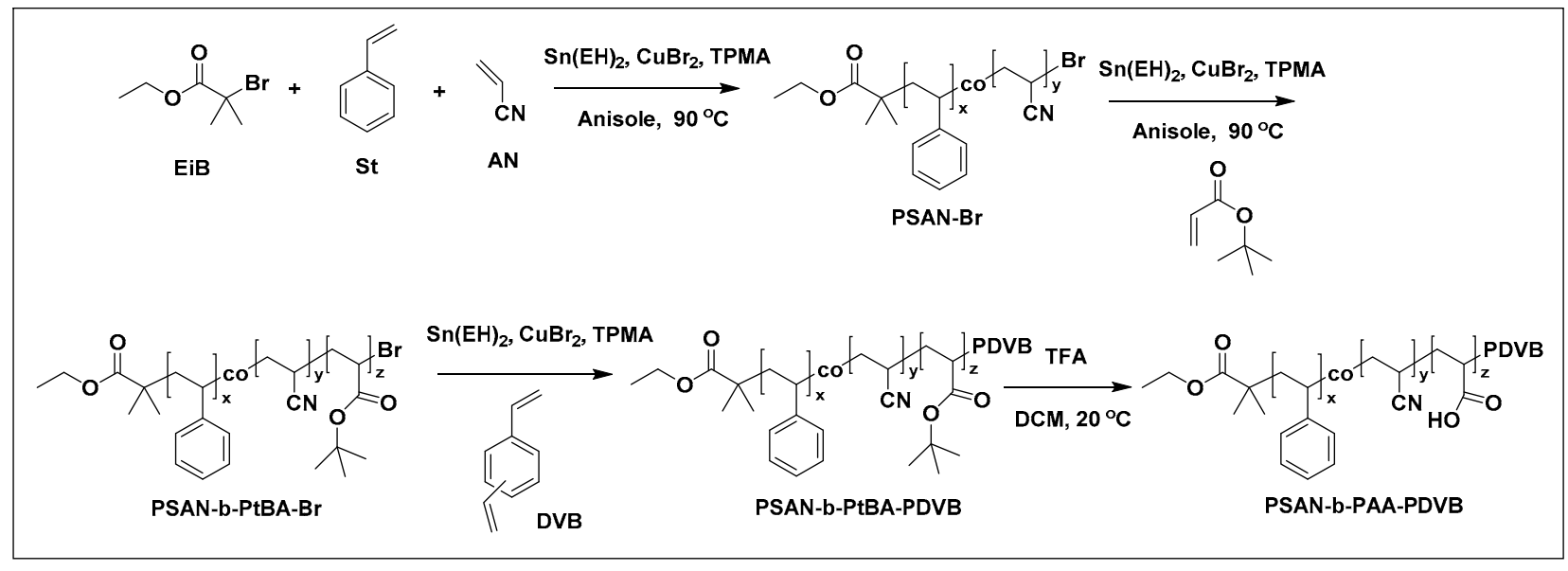

Figure 21. Synthesis of PSAN-b-PAA-PDVB star-shaped polymer templates. Reproduced with permission from Ref. [252]. 
Guo et al. synthesized PS-grafted $\mathrm{BaTiO}_{3}$ nanoparticles with sizes of $11 \mathrm{~nm}$ and $27 \mathrm{~nm}$ using amphiphilic star-like poly(acrylic acid)-b-polystyrene (PAA-b-PS) diblock copolymer templates. PAA- $b$-PS was obtained by sequential atom transfer radical polymerization $[252,253]$. The dielectric performance with respect to temperature was studied for $\mathrm{PS}_{-} \mathrm{BaTiO}_{3}$ nanoparticles of $11 \mathrm{~nm}$ and $27 \mathrm{~nm}$.

Lin and coworkers also prepared PS-functionalized $\mathrm{BaTiO}_{3}$ NPs with different sizes $(\sim 27 \mathrm{~nm}$ and $\sim 11 \mathrm{~nm})$ by exploiting amphiphilic unimolecular star-like PAA-b-PS diblock copolymer as template. The synthesized nanoparticles were dispersed in low molecular weight PS-b-PMMA $\left(\mathrm{M}_{\mathrm{PS}}=45,900\right.$ and $\left.\mathrm{M}_{\mathrm{PMMA}}=138,000\right)$ and high molecular weight

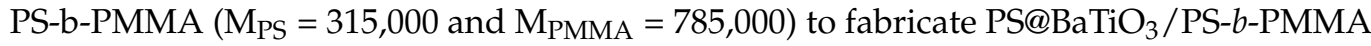
nanocomposite thin film. The incorporation of $\mathrm{PS}_{\mathrm{BaTiO}}$ NPs into PS- $b$-PMMA, resulted in the preferential location of the $\mathrm{BaTiO}_{3}$ NPs in the PS nanocylinders. PS grafting to $\mathrm{BaTiO}_{3} \mathrm{NPs}$ not only prevented aggregation by van der Waals forces, but also offered selective chemical affinity to the PS block of BCP. The measurements of dielectric properties of nanocomposite thin film revealed that the dielectric performance of the film was dependent upon the molecular weight of PS- $b$-PMMA and the size of $\mathrm{PS} @ B a T i O_{3} \mathrm{NPs}$. BCP nanocomposite of $27 \mathrm{~nm} \mathrm{PS@BaTiO} \mathrm{NP}_{3}$ exhibited higher permittivity than that of $11 \mathrm{~nm}$ $\mathrm{PS}_{\mathrm{BaTiO}}$ NP due to higher dielectric constant of large sized $27 \mathrm{~nm}$ NPs. Moreover, it was noticed that the nanocomposites of low molecular weight $\mathrm{BCP}$ exhibit higher dielectric constant than that of nanocomposite of high molecular weight due to lower permittivity of high molecular weight BCP. The low permittivity of higher molecular weight polymers could be attributed to the higher degree of chain coiling of longer polymer grafts than the low molecular weight polymer grafts [254].

Jiang and coworkers [58] synthesized PVDF-functionalized $\mathrm{BaTiO}_{3}$ nanoparticles by template-assisted approach. Firstly, they synthesized amphiphilic star diblock copolymer, by ATRP technique (Figure 22). PAA-b-PVDF (PAA as inner hydrophilic block while PVDF as outer hydrophobic block with well-controlled molecular weight of narrow dispersity) was dissolved in a mixture of DMF and benzyl alcohol followed by the addition of $\mathrm{BaCl}_{2} \cdot 2 \mathrm{H}_{2} \mathrm{O}$ and $\mathrm{TiCl}_{4}$ as precursor and $\mathrm{NaOH}$. Precursors assemble in the space of PAA blocks and PVDF chains serve as the arm of the self-assembled structure. The size of the nanoparticles was tuned based on the molecular weight of the PAA and PVDF blocks of the star copolymer. Notably, $\mathrm{PVDF} \mathrm{BaTiO}_{3}$ nanocomposites (single component) displayed not only high dielectric constant $(\sim 80$ at $100 \mathrm{~Hz})$ but also low dielectric loss $(<0.2)$ over broad frequency range as compared to PVDF.

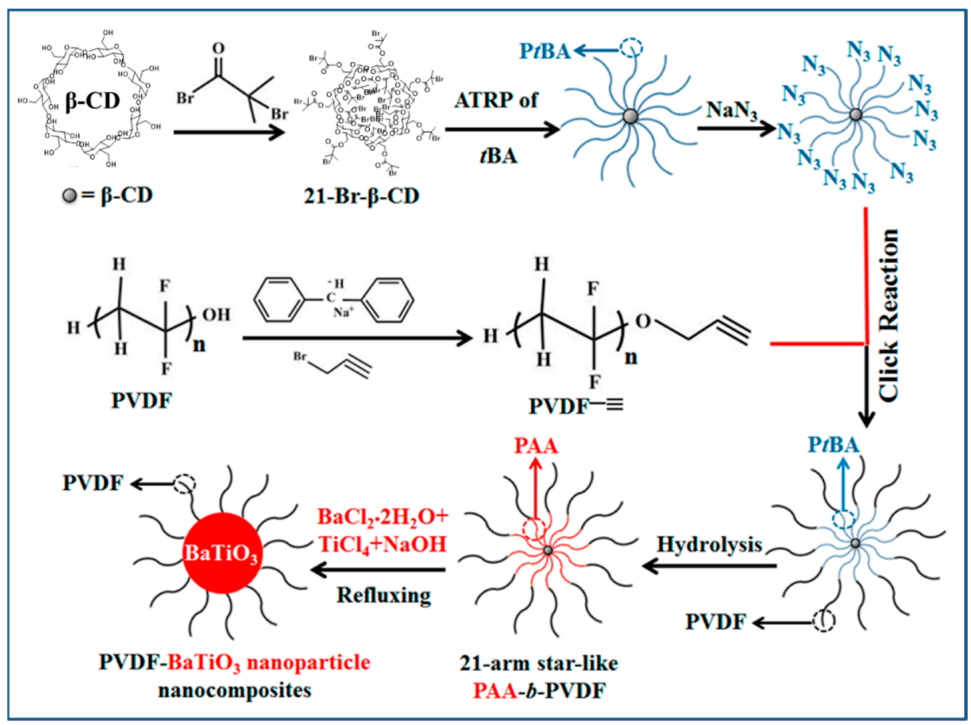

Figure 22. Synthesis of amphiphilic 21-arm, star-like PAA-b-PVDF diblock copolymer and PVDF@BaTiO 3 nanoparticles. Reproduced with permission from Ref. [58]. 
However, one of the challenges of unimolecular star block copolymer micelles using template approach in formulating core shell nanoparticles is the low graft density of the polymer grafted nanoparticles. Like the grafting to method, template assisted polymer grafting is not as widely sought-after technique for the synthesis of core-shell nanoparticles.

\section{Discussion}

Current technologies for pulsed power applications utilize polymers as the dielectric material of choice due to their high electrical resistance, low dielectric loss, self-healing capability, formability and flexibility. However, the most widely used polymeric system namely metallized biaxially oriented polypropylene (BOPP) and its variants do not meet the demands of next generation film dielectrics. Composite dielectrics offer an unique opportunity to combine the high $\varepsilon_{\mathrm{r}}$ of inorganic fillers with the high $\mathrm{E}_{\mathrm{bd}}$ of a polymer matrix to achieve high energy density capacitors. For significant gains in permittivity in polymer composites so as to achieve higher energy density, loadings of dispersed fillers in the composite need to be above $20 \% v / v$. At these loading levels, achieving good NP dispersion-especially in non-polar polymer matrices-is challenging due to particle agglomeration during film preparation. Aggregated nanoparticles of high permittivity act as electrical field expulsion defect centers in filled polymers. Such defect centers effectively distort the distribution of electric field, making the local electrical field in the matrix much higher than the average electric field and also lower the overall energy storage of the nanocomposite. The extent of the field distortion is adversely influenced by the discontinuous (sharp and large) permittivity contrast between the NPs and the polymer matrix. An approach to address the field distortion is to consider high permittivity nanoparticles with core-shell architectures so that the nanoparticles permittivity gradually approaches that of the polymer matrix.

We discuss various approaches to synthesize polymer grafted nanoparticles. Among the three commonly used SI-CRPs, SI-ATRP has been shown to be one of the most versatile polymerization techniques because it can be used under broad experimental conditions and can be adapted to synthesize nanoparticles with polymer grafts having a wide range of functional groups. Additionally, ATRP can be used to synthesize core@ double-shell structured nanoparticle via a two-step process. It was noted that the thickness of the second shell can be controlled by adjusting the ratio of monomer and macro initiator. The polymerization of activating monomer by ATRP process requires the use of alkyl halide initiator and a transition metal complex as catalyst (e.g., $\mathrm{CuBr}$ /ligand). However, the persistence of small amount of copper catalyst in the grafted nanoparticle can pose challenges because of the potential adverse effect the copper ions could have on the dielectric properties of the nanocomposite. In this regard, ATRP techniques with extremely low amounts of copper have been investigated for the synthesis of polymer grafted nanoparticles. For example, PS and PMMA were grafted from phosphonic acid functionalized $\mathrm{BaTiO}_{3} \mathrm{NPs}$ via activated regenerated by electron transfer (AGRET) ATRP approach using only ppm amount of the copper catalyst [27]. Alternatively, efforts have focused on conducting ATRP using light without the addition of any metal catalyst and the thickness of polymeric shell was tunable based on the duration of white LED irradiation. These approaches to conduct ARGET ATRP with limited $\mathrm{Cu}$ species or light mediated ATRP offer novel opportunities and new routes for engineering surfaces and interfaces of nanoparticles with polymer grafts without significant copper residues.

In contrast to ATRP, RAFT can be considered as a conventional radical polymerization with the addition of a chain transfer agent (CTA), which mediates the polymerization. The RAFT CTAs can be bound on nanoparticle surfaces via two main approaches. In the first approach, the CTA is synthesized with a reactive anchoring group (chlorosilyl group, phosphonic acid group) and then covalently bound to an unmodified NP. The second approach relies on grafting a functional RAFT agent to pre-modified nanoparticles. There are several examples in the literature where RAFT polymerization has been successfully used to synthesize unimodal or bimodal brush modified nanoparticles so as to 
achieve optimum dielectric performance of nanocomposite $[177,178,186,187]$. Using RAFT technique, the shell thickness, polymer composition and the aerial density of polymer brush in the core-shell nanoparticles have been successfully tuned and used for energy storage applications.

Despite SI-ATRP being the most predominant and sought after technique for polymer grafting on nanoparticle surface, RAFT technique too has steadily gained popularity over the years. This is because of the adaptability of RAFT to a range of polymerization conditions. Further advances in RAFT polymerization include the ability to synthesize multi-block copolymers with a high degree of fidelity, conducting reactions in the presence of oxygen and its compatibility with a broad range of functional groups and the absence of copper residues after polymer grafting have clearly contributed to the recent drive for use of RAFT technique in the synthesis of core-shell nanoparticles.

The "grafting to" approach, on the other hand, involves surface modification of nanomaterials with functionality which is complimentary to the end-group functionality of polymer followed by coupling via suitable conjugation or click chemistry. In particular, chloro silyl-terminated polymer or phosphonate-terminated polymer or click chemistry has been used to graft polymer on nanoparticles. Because of the ability to precisely control the molecular weight of grafts in the grafting to technique, a study of low molecular weight grafts on NP revealed a relatively smooth surface while high molecular weight grafts on $\mathrm{NP}$ revealed a pancake like structure suggesting the ability of grafting to technique to control microstructure of the polymer shell at the expense of polymer graft molecular weight. Although "grafting-to" approach is easy and efficient, it presents challenges such as decreased graft density with increase in the molecular weight of the grafted polymer. Therefore, grafting to technique is not as widely sought after method for the synthesis of core-shell nanoparticles.

Template-assisted polymer grafting which offers an easier way to synthesize nanoparticles (in situ) through micelle formation is a relatively straightforward technique. An issue that has been observed is the formation of multiple NPs in the core of multi-molecular micelles [46]. To overcome this challenge, the use of unimolecular star block copolymer micelles has been tried out with a greater success in the synthesis of hairy nanoparticles with uniform sizes, various shapes, and sometimes unusual morphologies [47]. However, one of the challenges of unimolecular star block copolymer micelles using template approach is the low graft density of the polymer grafted nanoparticles. Like the grafting to method, template assisted polymer grafting is not as widely sought after graft technique for the synthesis of core-shell nanoparticles.

In in situ polymerization method, metal oxide nanoparticles are usually mixed with organic monomers, either in the presence or absence of a solvent, and then the monomers are polymerized. There is a thermodynamic compatibility at the polymer matrix-nanoparticle reinforcement interface and thus provide stronger matrix dispersion bond with very good miscibility of the nanocomposite.

Several structure-property relationship studies of polymer grafted nanoparticles filled polymer nanocomposites [27,119-121,124-126] using SI-CRP technique have been conducted and they clearly indicate that a number of factors influence the dielectric performance of the nanocomposite including the thickness of the core and the shell of the core-shell nanoparticles and the type of polymer grafted on the nanoparticles, interfacial separation between core NPs and polymer shell, the composition of nanocomposite (single or multicomponent type of nanocomposite), the presence of polarizable interfacial layer and double shell coverage of nanoparticles. For establishing clear structure-property relationships, an efficient initiator and control of polymer brush graft density is important. At present, the techniques for facile determination of polymer brush grafting density and the initiator efficiency are scarce. More importantly, a simple, versatile and accurate technique for determining the number of initiator units per square nanometer present on the nanoparticle surface is not available. This information would be highly relevant for the 
development of composition-structure-property relationship paradigm of single or multi component nanocomposite.

Another interesting application of core-shell structure is in the pursuit of all-polymer field-effect transistors in the generation of polymer brush-based gate dielectrics. Especially SI-CRP technique has drawn significant attention for design of polymer field effect transistors. The attractiveness in the use of SI-CRP technique is in the ease of device preparation and the avoidance of expensive fabrication facilities. The performance of pentacene-based thin-film transistor fabricated from PS-grafted $\mathrm{SiO}_{2}$ and PMMA-grafted $\mathrm{SiO}_{2}$ using ATRP technique as a gate dielectric showed the importance of interfacial material and its structure in the design of OFET $[97,98]$. The device fabricated from $47 \mathrm{~nm}$ thickness of PS brush exhibited highest mobility $\left(\mu_{\mathrm{FET}}=0.099 \mathrm{~cm}^{2} / \mathrm{V} \cdot \mathrm{s}\right)$ indicating that optimum molecular weight polymer brushes need to be grown from surface of dielectric for achieving desirable performance. On the other hand, the surface-grafted PMMA brush $(10 \mathrm{~nm}) / \mathrm{SiO}_{2}(9 \mathrm{~nm})$ on silicon wafer exhibited lower leakage than that of surface-grafted PMMA brush $(20 \mathrm{~nm})$ on silicon wafer (free of $9 \mathrm{~nm} \mathrm{SiO} 2$ layer). Additionally, it was noted that the thickness of the polymer brush on silica could be modulated based on the activity of the catalyst, the reactant concentration and reaction time. The PMMA brushes on silica showed excellent insulating characteristics, large capacitance, and low charge-trapping density. Field-effect transistors with PMMA brush as the dielectric layer demonstrate excellent charge transport. However, the field of polymer brush-based hybrid materials in OFET is still in its infancy stage [43] and it needs further exploration.

\section{Summary and Future Outlook}

In this review article, we described various synthetic approaches for preparation of core-shell structures of polymer grafted nanoparticles. The grafting of polymeric chains to nanoparticles can generally be accomplished by four approaches namely (i) 'grafting to'; (ii) 'grafting from'; (iii) templated and (iv) in situ polymerization or encapsulation. All the four approaches yield polymer grafted nanoparticles of varying shell architectures. Unlike grafting to method, grafting from method allows to synthesize nanoparticles with high grafting density and polymer shells of varied composition. The "grafting from" method is also termed the surface-initiated controlled radical polymerization where the initiator functionality (SI-ATRP) or CTA functionality (SI-RAFT) or alkoxy amine functionality (NMP) is anchored to the surface of nanomaterials followed by growth of polymer chains.

Recent progress in the various synthetic strategies for formulation of core-shell nanoparticles has created a myriad of architectures of core-shell nanoparticles. Interesting polymer architectures with unique features such as polymer loops, bottlebrushes have made the polymers synthesized by SI-CRP technique a valuable toolkit that can be used for a broad range of applications. Notably, the opportunity to synthesize BCP-g-NPs in formulating single-component hybrid materials has largely been unexplored and needs to be tapped for the design of nano-dielectrics. A high-performance core-shell hybrid material in which the polymer is directly grown from the nanoparticles provides an opportunity to synthesize single component nano-dielectrics. This subject need further exploration because it is possible to have high ceramic loading in the one component polymer-ceramic system with minimal negative effect of ceramics towards electrical discharge due to controlled minimal aggregation, i.e., high degree of dispersion. From an academic perspective, little is known about the structure and dynamics of self-assembling of single component BCP-g-NP system, i.e., whether a block copolymer tagged to nanoparticle can microphaseseparate and self-assemble. There is also significant interest for developing molecular level understanding of non-centrosymmetric materials from fundamental perspective, and the parameter space it presents in terms of grafting density, and copolymer length and composition is wide open. Under the appropriate processing conditions, symmetric BCPs can microphase separate to form parallel lamellae [255-257]. This arrangement presents a unique opportunity to advance the field of core-shell nanoparticles in the formulating next generation nano-dielectrics of unprecedented performance. 
Author Contributions: Conceptualization, B.V.T. and D.R.; writing-original draft preparation, B.V.T. and I.E.A.; writing-review and editing, B.V.T., I.E.A. and D.R.; supervision, D.R.; project administration, D.R. N.P. and A.K.; funding acquisition, D.R. N.P. and A.K. All authors have read and agreed to the published version of the manuscript.

Funding: This research was funded by the National Science Foundation (NSF), grant number DMR1901127.

Data Availability Statement: No new data were created or analyzed in this study. Data sharing is not applicable to this article.

Conflicts of Interest: The authors declare no conflict of interest.

Sample Availability: Samples of the compounds are not available from the authors.

\section{References}

1. Zhang, Q.M.; Li, H.; Poh, M.; Xia, F.; Cheng, Z.Y.; Xu, H.; Huang, C. An all-organic composite actuator material with a high dielectric constant. Nature 2002, 419, 284-287. [CrossRef] [PubMed]

2. Ortiz, R.P.; Facchetti, A.; Marks, T.J. High-k organic, inorganic, and hybrid dielectrics for low-voltage organic field-effect transistors. Chem. Rev. 2010, 110, 205-239. [CrossRef]

3. Chauhan, A.; Patel, S.; Vaish, R.; Bowen, C. Anti-Ferroelectric Ceramics for High Energy Density Capacitors. Materials 2015, 8, 8009-8031. [CrossRef]

4. Dang, Z.-M.; Yuan, J.-K.; Yao, S.-H.; Liao, R.-J. Flexible Nanodielectric Materials with High Permittivity for Power Energy Storage. Adv. Mater. 2013, 25, 6334-6365. [CrossRef] [PubMed]

5. Hao, X. A review on the dielectric materials for high energy-storage application. J. Adv. Dielectr. 2013, 03, 1330001. [CrossRef]

6. Palneedi, H.; Peddigari, M.; Hwang, G.-T.; Jeong, D.-Y.; Ryu, J. High-Performance Dielectric Ceramic Films for Energy Storage Capacitors: Progress and Outlook. Adv. Funct. Mater. 2018, 28, 1803665. [CrossRef]

7. Ho, J.; Jow, T.R.; Boggs, S. Historical introduction to capacitor technology. IEEE Electr. Insul. Mag. 2010, 26, 20-25. [CrossRef]

8. Kishi, H.; Mizuno, Y.; Chazono, H. Base-Metal Electrode-Multilayer Ceramic Capacitors: Past, Present and Future Perspectives. Jpn. J. Appl. Phys. 2003, 42,1-15. [CrossRef]

9. Du, H.; Lin, X.; Zheng, H.; Qu, B.; Huang, Y.; Chu, D. Colossal permittivity in percolative ceramic/metal dielectric composites. J. Alloys Compd. 2016, 663, 848-861. [CrossRef]

10. Hong, K.; Lee, T.H.; Suh, J.M.; Yoon, S.-H.; Jang, H.W. Perspectives and challenges in multilayer ceramic capacitors for next generation electronics. J. Mater. Chem. C 2019, 7, 9782-9802. [CrossRef]

11. Tan, D.Q. Review of Polymer-Based Nanodielectric Exploration and Film Scale-Up for Advanced Capacitors. Adv. Funct. Mater. 2019, 1808567. [CrossRef]

12. Dang, Z.M.; Yuan, J.K.; Zha, J.W.; Zhou, T.; Li, S.T.; Hu, G.H. Fundamentals, processes and applications of high-permittivity polymer-matrix composites. Prog. Mater. Sci. 2012, 57, 660-723. [CrossRef]

13. Singh, M.; Apata, I.E.; Samant, S.; Wu, W.; Tawade, B.V.; Pradhan, N.; Raghavan, D.; Karim, A. Nanoscale Strategies to Enhance the Energy Storage Capacity of Polymeric Dielectric Capacitors: Review of Recent Advances. Polym. Rev. 2021, 1-50. [CrossRef]

14. Tawade, B.V.; Apata, I.E.; Singh, M.; Das, P.; Pradhan, N.; Al-Enizi, A.M.; Karim, A.; Raghavan, D. Recent developments in the synthesis of chemically modified nanomaterials for use in dielectric and electronics applications. Nanotechnology 2021, $32,142004$. [CrossRef] [PubMed]

15. Luo, H.; Zhou, X.; Ellingford, C.; Zhang, Y.; Chen, S.; Zhou, K.; Zhang, D.; Bowen, C.R.; Wan, C. Interface design for high energy density polymer nanocomposites. Chem. Soc. Rev. 2019, 48, 4424-4465. [CrossRef]

16. Baer, E.; Zhu, L. 50th Anniversary Perspective: Dielectric Phenomena in Polymers and Multilayered Dielectric Films. Macromolecules 2017, 50, 2239-2256. [CrossRef]

17. Maier, G. Low dielectric constant polymers for microelectronics. Prog. Polym. Sci. 2001, 26, 3-65. [CrossRef]

18. Wang, Q.; Zhu, L. Polymer nanocomposites for electrical energy storage. J. Polym. Sci. Part B Polym. Phys. 2011, 49, 1421-1429. [CrossRef]

19. Burda, C.; Chen, X.; Narayanan, R.; El-Sayed, M.A. Chemistry and Properties of Nanocrystals of Different Shapes. Chem. Rev. 2005, 105, 1025-1102. [CrossRef] [PubMed]

20. Nikam, A.V.; Prasad, B.L.V.; Kulkarni, A.A. Wet chemical synthesis of metal oxide nanoparticles: A review. CrystEngComm 2018, 20, 5091-5107. [CrossRef]

21. Walton, R.I. Subcritical solvothermal synthesis of condensed inorganic materials. Chem. Soc. Rev. 2002, 31, 230-238. [CrossRef]

22. Park, J.; Joo, J.; Kwon, S.G.; Jang, Y.; Hyeon, T. Synthesis of Monodisperse Spherical Nanocrystals. Angew. Chemie Int. Ed. 2007, 46, 4630-4660. [CrossRef] [PubMed]

23. Hyeon, T. Chemical synthesis of magnetic nanoparticles. Chem. Commun. 2003, 927-934. [CrossRef] [PubMed] 
24. Hulkoti, N.I.; Taranath, T.C. Biosynthesis of nanoparticles using microbes-A review. Colloids Surfaces B Biointerfaces 2014, 121, 474-483. [CrossRef]

25. Wei, J.; Zhu, L. Intrinsic polymer dielectrics for high energy density and low loss electric energy storage. Prog. Polym. Sci. 2020, 106, 101254. [CrossRef]

26. Huan, T.D.; Boggs, S.; Teyssedre, G.; Laurent, C.; Cakmak, M.; Kumar, S.; Ramprasad, R. Advanced polymeric dielectrics for high energy density applications. Prog. Mater. Sci. 2016, 83, 236-269. [CrossRef]

27. Paniagua, S.A.; Kim, Y.; Henry, K.; Kumar, R.; Perry, J.W.; Marder, S.R. Surface-Initiated Polymerization from Barium Titanate Nanoparticles for Hybrid Dielectric Capacitors. ACS Appl. Mater. Interfaces 2014, 6, 3477-3482. [CrossRef]

28. Jouault, N.; Vallat, P.; Dalmas, F.; Said, S.; Jestin, J.; Boué, F. Well-Dispersed Fractal Aggregates as Filler in Polymer-Silica Nanocomposites: Long-Range Effects in Rheology. Macromolecules 2009, 42, 2031-2040. [CrossRef]

29. Oberdisse, J.; El Harrak, A.; Carrot, G.; Jestin, J.; Boué, F. Structure and rheological properties of soft-hard nanocomposites: Influence of aggregation and interfacial modification. Polymer 2005, 46, 6695-6705. [CrossRef]

30. Jestin, J.; Cousin, F.; Dubois, I.; Ménager, C.; Schweins, R.; Oberdisse, J.; Boué, F. Anisotropic Reinforcement of Nanocomposites Tuned by Magnetic Orientation of the Filler Network. Adv. Mater. 2008, 20, 2533-2540. [CrossRef]

31. Radhakrishnan, B.; Ranjan, R.; Brittain, W.J. Surface initiated polymerizations from silica nanoparticles. Soft Matter 2006, 2, 386-396. [CrossRef]

32. Chevigny, C.; Gigmes, D.; Bertin, D.; Jestin, J.; Boué, F. Polystyrene grafting from silica nanoparticles via nitroxide-mediated polymerization (NMP): Synthesis and SANS analysis with the contrast variation method. Soft Matter 2009, 5, 3741-3753. [CrossRef]

33. Yan, J.; Bockstaller, M.R.; Matyjaszewski, K. Brush-modified materials: Control of molecular architecture, assembly behavior, properties and applications. Prog. Polym. Sci. 2020, 100, 101180. [CrossRef]

34. Ma, S.; Zhang, X.; Yu, B.; Zhou, F. Brushing up functional materials. NPG Asia Mater. 2019, 11, 24. [CrossRef]

35. Bouharras, F.E.; Raihane, M.; Ameduri, B. Recent progress on core-shell structured BaTiO3@polymer/fluorinated polymers nanocomposites for high energy storage: Synthesis, dielectric properties and applications. Prog. Mater. Sci. 2020, 113, 100670. [CrossRef]

36. Chancellor, A.J.; Seymour, B.T.; Zhao, B. Characterizing Polymer-Grafted Nanoparticles: From Basic Defining Parameters to Behavior in Solvents and Self-Assembled Structures. Anal. Chem. 2019. [CrossRef] [PubMed]

37. Lenart, W.R.; Hore, M.J.A. Structure-property relationships of polymer-grafted nanospheres for designing advanced nanocomposites. Nano-Struct. Nano-Objects 2018, 16, 428-440. [CrossRef]

38. Yan, J.; Pietrasik, J.; Wypych-Puszkarz, A.; Ciekanska, M.; Matyjaszewski, K. Synthesis of High k Nanoparticles by Controlled Radical Polymerization. In Solution-Processable Components for Organic Electronic Devices; Wiley-VCH Verlag GmbH \& Co. KGaA: Weinheim, Germany, 2019; pp. 181-226.

39. Francis, R.; Joy, N.; Aparna, E.P.; Vijayan, R. Polymer Grafted Inorganic Nanoparticles, Preparation, Properties, and Applications: A Review. Polym. Rev. 2014, 54, 268-347. [CrossRef]

40. Wang, Z.; Bockstaller, M.R.; Matyjaszewski, K. Synthesis and Applications of ZnO/Polymer Nanohybrids. ACS Mater. Lett. 2021, 599-621. [CrossRef]

41. Fernandes, N.J.; Koerner, H.; Giannelis, E.P.; Vaia, R.A. Hairy nanoparticle assemblies as one-component functional polymer nanocomposites: Opportunities and challenges. MRS Commun. 2013, 3, 13-29. [CrossRef]

42. Williams, G.A.; Ishige, R.; Cromwell, O.R.; Chung, J.; Takahara, A.; Guan, Z. Mechanically Robust and Self-Healable Superlattice Nanocomposites by Self-Assembly of Single-Component "Sticky" Polymer-Grafted Nanoparticles. Adv. Mater. 2015, 27, 39343941. [CrossRef] [PubMed]

43. Sato, T.; Morinaga, T.; Marukane, S.; Narutomi, T.; Igarashi, T.; Kawano, Y.; Ohno, K.; Fukuda, T.; Tsujii, Y. Novel Solid-State Polymer Electrolyte of Colloidal Crystal Decorated with Ionic-Liquid Polymer Brush. Adv. Mater. 2011, 23, 4868-4872. [CrossRef] [PubMed]

44. Zhang, M.; Gao, G.; Li, C.-Q.; Liu, F.-Q. Titania-Coated Polystyrene Hybrid Microballs Prepared with Miniemulsion Polymerization. Langmuir 2004, 20, 1420-1424. [CrossRef] [PubMed]

45. Sondi, I.; Fedynyshyn, T.H.; Sinta, R.; Matijević, E. Encapsulation of Nanosized Silica by in Situ Polymerization of tert -Butyl Acrylate Monomer. Langmuir 2000, 16, 9031-9034. [CrossRef]

46. Guo, Y.; Moffitt, M.G. Semiconductor quantum dots with environmentally responsive mixed polystyrene/poly(methyl methacrylate) brush layers. Macromolecules 2007, 40, 5868-5878. [CrossRef]

47. Chen, Y.; Yoon, Y.J.; Pang, X.; He, Y.; Jung, J.; Feng, C.; Zhang, G.; Lin, Z. Precisely Size-Tunable Monodisperse Hairy Plasmonic Nanoparticles via Amphiphilic Star-Like Block Copolymers. Small 2016, 12, 6714-6723. [CrossRef] [PubMed]

48. Zoppe, J.O.; Ataman, N.C.; Mocny, P.; Wang, J.; Moraes, J.; Klok, H.-A. Surface-Initiated Controlled Radical Polymerization: State-of-the-Art, Opportunities, and Challenges in Surface and Interface Engineering with Polymer Brushes. Chem. Rev. 2017, 117, 1105-1318. [CrossRef]

49. Hui, C.M.; Pietrasik, J.; Schmitt, M.; Mahoney, C.; Choi, J.; Bockstaller, M.R.; Matyjaszewski, K. Surface-initiated polymerization as an enabling tool for multifunctional (Nano-)engineered hybrid materials. Chem. Mater. 2014, 26, 745-762. [CrossRef]

50. Sakellariou, G.; Priftis, D.; Baskaran, D. Surface-initiated polymerization from carbon nanotubes: Strategies and perspectives. Chem. Soc. Rev. 2013, 42, 677-704. [CrossRef] 
51. Advincula, R.C. Surface Initiated Polymerization from Nanoparticle Surfaces. J. Dispers. Sci. Technol. 2003, 24, 343-361. [CrossRef]

52. Edmondson, S.; Osborne, V.L.; Huck, W.T.S. Polymer brushes via surface-initiated polymerizations. Chem. Soc. Rev. 2004, 33, 14-22. [CrossRef] [PubMed]

53. Matyjaszewski, K.; Miller, P.J.; Shukla, N.; Immaraporn, B.; Gelman, A.; Luokala, B.B.; Siclovan, T.M.; Kickelbick, G.; Vallant, T.; Hoffmann, H.; et al. Polymers at Interfaces: Using Atom Transfer Radical Polymerization in the Controlled Growth of Homopolymers and Block Copolymers from Silicon Surfaces in the Absence of Untethered Sacrificial Initiator. Macromolecules 1999, 32, 8716-8724. [CrossRef]

54. Cheng, G.; Böker, A.; Zhang, M.; Krausch, G.; Müller, A.H.E. Amphiphilic Cylindrical Core-Shell Brushes via a “Grafting From” Process Using ATRP. Macromolecules 2001, 34, 6883-6888. [CrossRef]

55. Li, C.; Benicewicz, B.C. Synthesis of Well-Defined Polymer Brushes Grafted onto Silica Nanoparticles via Surface Reversible Addition-Fragmentation Chain Transfer Polymerization. Macromolecules 2005, 38, 5929-5936. [CrossRef]

56. Matsuno, R.; Yamamoto, K.; Otsuka, H.; Takahara, A. Polystyrene-Grafted Magnetite Nanoparticles Prepared through SurfaceInitiated Nitroxyl-Mediated Radical Polymerization. Chem. Mater. 2003, 15, 3-5. [CrossRef]

57. Husseman, M.; Malmström, E.E.; McNamara, M.; Mate, M.; Mecerreyes, D.; Benoit, D.G.; Hedrick, J.L.; Mansky, P.; Huang, E.; Russell, T.P.; et al. Controlled Synthesis of Polymer Brushes by "Living" Free Radical Polymerization Techniques. Macromolecules 1999, 32, 1424-1431. [CrossRef]

58. Jiang, B.; Pang, X.; Li, B.; Lin, Z. Organic-Inorganic Nanocomposites via Placing Monodisperse Ferroelectric Nanocrystals in Direct and Permanent Contact with Ferroelectric Polymers. J. Am. Chem. Soc. 2015, 137, 11760-11767. [CrossRef]

59. Bhanvase, B.A.; Sonawane, S.H. Ultrasound assited In-situ Emulsion polymerization for polymer nanocomposite: A review. Chem. Eng. Process. Process Intensif. 2014. [CrossRef]

60. Sato, M.; Kato, T.; Ohishi, T.; Ishige, R.; Ohta, N.; White, K.L.; Hirai, T.; Takahara, A. Precise Synthesis of Poly(methyl methacrylate) Brush with Well-Controlled Stereoregularity Using a Surface-Initiated Living Anionic Polymerization Method. Macromolecules 2016, 49, 2071-2076. [CrossRef]

61. Advincula, R.; Zhou, Q.; Park, M.; Wang, S.; Mays, J.; Sakellariou, G.; Pispas, S.; Hadjichristidis, N. Polymer Brushes by Living Anionic Surface Initiated Polymerization on Flat Silicon (SiOx) and Gold Surfaces: Homopolymers and Block Copolymers. Langmuir 2002, 18, 8672-8684. [CrossRef]

62. Zhao, B.; Brittain, W.J. Synthesis of Polystyrene Brushes on Silicate Substrates via Carbocationic Polymerization from SelfAssembled Monolayers. Macromolecules 2000, 33, 342-348. [CrossRef]

63. Zhao, B.; Brittain, W.J. Synthesis, Characterization, and Properties of Tethered Polystyrene- b -polyacrylate Brushes on Flat Silicate Substrates. Macromolecules 2000, 33, 8813-8820. [CrossRef]

64. Hadjichristidis, N.; Iatrou, H.; Pispas, S.; Pitsikalis, M. Anionic polymerization: High vacuum techniques. J. Polym. Sci. Part A Polym. Chem. 2000, 38, 3211-3234. [CrossRef]

65. Jordan, R.; Ulman, A.; Kang, J.F.; Rafailovich, M.H.; Sokolov, J. Surface-Initiated Anionic Polymerization of Styrene by Means of Self-Assembled Monolayers. J. Am. Chem. Soc. 1999, 121, 1016-1022. [CrossRef]

66. Li, Z.; Baskaran, D. Surface-Initiated Anionic Polymerization from Nanomaterials. In Anionic Polymerization; Springer: Tokyo, Japan, 2015; pp. 495-537.

67. Advincula, R. Polymer Brushes by Anionic and Cationic Surface-Initiated Polymerization (SIP). In Surface-Initiated Polymerization I; Jordan, R., Ed.; Springer: Berlin/Heidelberg, Germany, 2006; pp. 107-136. ISBN 978-3-540-30247-6.

68. Prucker, O.; Rühe, J. Synthesis of poly(styrene) monolayers attached to high surface area silica gels through self-assembled monolayers of azo initiators. Macromolecules 1998, 31, 592-601. [CrossRef]

69. Prucker, O.; Rühe, J. Mechanism of Radical Chain Polymerizations Initiated by Azo Compounds Covalently Bound to the Surface of Spherical Particles. Macromolecules 1998, 31, 602-613. [CrossRef]

70. Li, Q.; Zhang, Y.; Li, H.; Tang, Q.; Jiang, L.; Chi, L.; Fuchs, H.; Hu, W. Battery drivable organic single-crystalline transistors based on surface grafting ultrathin polymer dielectric. Adv. Funct. Mater. 2009, 19, 2987-2991. [CrossRef]

71. Patten, T.E.; Matyjaszewski, K. Atom Transfer Radical Polymerization and the Synthesis of Polymeric Materials. Adv. Mater. 1998, 10, 901-915. [CrossRef]

72. Bartholome, C.; Beyou, E.; Bourgeat-Lami, E.; Chaumont, P.; Lefebvre, F.; Zydowicz, N. Nitroxide-Mediated Polymerization of Styrene Initiated from the Surface of Silica Nanoparticles. In Situ Generation and Grafting of Alkoxyamine Initiators. Macromolecules 2005, 38, 1099-1106. [CrossRef]

73. Grubbs, R.B. Nitroxide-Mediated Radical Polymerization: Limitations and Versatility. Polym. Rev. 2011, 51, 104-137. [CrossRef]

74. Matyjaszewski, K.; Xia, J. Atom transfer radical polymerization. Chem. Rev. 2001, 101, 2921-2990. [CrossRef]

75. Kamigaito, M.; Ando, T.; Sawamoto, M. Metal-Catalyzed Living Radical Polymerization. Chem. Rev. 2001, 101, 3689-3746. [CrossRef] [PubMed]

76. Matyjaszewski, K. Atom Transfer Radical Polymerization (ATRP): Current Status and Future Perspectives. Macromolecules 2012, 45, 4015-4039. [CrossRef]

77. Konkolewicz, D.; Wang, Y.; Zhong, M.; Krys, P.; Isse, A.A.; Gennaro, A.; Matyjaszewski, K. Reversible-Deactivation Radical Polymerization in the Presence of Metallic Copper. A Critical Assessment of the SARA ATRP and SET-LRP Mechanisms. Macromolecules 2013, 46, 8749-8772. [CrossRef] 
78. Konkolewicz, D.; Wang, Y.; Krys, P.; Zhong, M.; Isse, A.A.; Gennaro, A.; Matyjaszewski, K. SARA ATRP or SET-LRP. End of controversy? Polym. Chem. 2014, 5, 4396-4417. [CrossRef]

79. Jakubowski, W.; Min, K.; Matyjaszewski, K. Activators Regenerated by Electron Transfer for Atom Transfer Radical Polymerization of Styrene. Macromolecules 2006, 39, 39-45. [CrossRef]

80. Wang, J.-S.; Matyjaszewski, K. “Living”/Controlled Radical Polymerization. Transition-Metal-Catalyzed Atom Transfer Radical Polymerization in the Presence of a Conventional Radical Initiator. Macromolecules 1995, 28, 7572-7573. [CrossRef]

81. Corrigan, N.; Jung, K.; Moad, G.; Hawker, C.J.; Matyjaszewski, K.; Boyer, C. Reversible-deactivation radical polymerization (Controlled/living radical polymerization): From discovery to materials design and applications. Prog. Polym. Sci. 2020, 111, 101311. [CrossRef]

82. Wu, L.; Glebe, U.; Böker, A. Surface-initiated controlled radical polymerizations from silica nanoparticles, gold nanocrystals, and bionanoparticles. Polym. Chem. 2015, 6, 5143-5184. [CrossRef]

83. Wang, Z.; Yan, J.; Liu, T.; Wei, Q.; Li, S.; Olszewski, M.; Wu, J.; Sobieski, J.; Fantin, M.; Bockstaller, M.R.; et al. Control of Dispersity and Grafting Density of Particle Brushes by Variation of ATRP Catalyst Concentration. ACS Macro Lett. 2019, 8 , 859-864. [CrossRef]

84. Wang, Z.; Lee, J.; Wang, Z.; Zhao, Y.; Yan, J.; Lin, Y.; Li, S.; Liu, T.; Olszewski, M.; Pietrasik, J.; et al. Tunable Assembly of Block Copolymer Tethered Particle Brushes by Surface-Initiated Atom Transfer Radical Polymerization. ACS Macro Lett. 2020, 9 , 806-812. [CrossRef]

85. Farmer, S.C.; Patten, T.E. Photoluminescent Polymer/Quantum Dot Composite Nanoparticles. Chem. Mater. 2001, 13, 3920-3926. [CrossRef]

86. Zhang, L.; Zhou, G.; Sun, B.; Chen, F.; Zhao, M.; Li, T. Tunable Shell Thickness in Silica Nanospheres Functionalized by a Hydrophobic PMMA-PSt Diblock Copolymer Brush via Activators Generated by Electron Transfer for Atom Transfer Radical Polymerization. Macromol. Chem. Phys. 2013, 214, 1602-1611. [CrossRef]

87. Wang, Z.; Fantin, M.; Sobieski, J.; Wang, Z.; Yan, J.; Lee, J.; Liu, T.; Li, S.; Olszewski, M.; Bockstaller, M.R.; et al. Pushing the Limit: Synthesis of SiO 2-g -PMMA/PS Particle Brushes via ATRP with Very Low Concentration of Functionalized SiO $2-\mathrm{Br}$ Nanoparticles. Macromolecules 2019, 52, 8713-8723. [CrossRef]

88. Bayramoglu, G.; Ozalp, V.C.; Oztekin, M.; Arica, M.Y. Rapid and label-free detection of Brucella melitensis in milk and milk products using an aptasensor. Talanta 2019, 200, 263-271. [CrossRef]

89. Bayramoglu, G.; Arica, M.Y. Star type polymer grafted and polyamidoxime modified silica coated-magnetic particles for adsorption of U(VI) ions from solution. Chem. Eng. Res. Des. 2019, 147, 146-159. [CrossRef]

90. Nguyen, D.T.; Phu Nguyen, T.N.; Nguyen, D.C.; Thanh Ho, V.T.; Islam, M.R.; Lim, K.T.; Bach, L.G. A Robust Modification of SiO2 Nanoparticles by Poly(2-hydroxyethylmethacrylate) via Surface-Initiated Atom Transfer Radical Polymerization. Asian J. Chem. 2019, 31, 337-342. [CrossRef]

91. Ma, A.; Zhang, J.; Wang, N.; Bai, L.; Chen, H.; Wang, W.; Yang, H.; Yang, L.; Niu, Y.; Wei, D. Surface-Initiated Metal-Free Photoinduced ATRP of 4-Vinylpyridine from SiO 2 via Visible Light Photocatalysis for Self-Healing Hydrogels. Ind. Eng. Chem. Res. 2018, 57, 17417-17429. [CrossRef]

92. Wu, T.; Zhang, Y.; Wang, X.; Liu, S. Fabrication of hybrid silica nanoparticles densely grafted with thermoresponsive poly(Nisopropylacrylamide) brushes of controlled thickness via surface-initiated atom transfer radical polymerization. Chem. Mater. 2008, 20, 101-109. [CrossRef]

93. Xing, L.; Guo, N.; Zhang, Y.; Zhang, H.; Liu, J. A negatively charged loose nanofiltration membrane by blending with poly (sodium 4-styrene sulfonate) grafted SiO2 via SI-ATRP for dye purification. Sep. Purif. Technol. 2015, 146, 50-59. [CrossRef]

94. Du, Z.; Sun, X.; Tai, X.; Wang, G.; Liu, X. Synthesis of hybrid silica nanoparticles grafted with thermoresponsive poly(ethylene glycol) methyl ether methacrylate via AGET-ATRP. RSC Adv. 2015, 5, 17194-17201. [CrossRef]

95. Saigal, T.; Dong, H.; Matyjaszewski, K.; Tilton, R.D. Pickering Emulsions Stabilized by Nanoparticles with Thermally Responsive Grafted Polymer Brushes. Langmuir 2010, 26, 15200-15209. [CrossRef] [PubMed]

96. Zhou, L.; Yuan, W.; Yuan, J.; Hong, X. Preparation of double-responsive SiO2-g-PDMAEMA nanoparticles via ATRP. Mater. Lett. 2008, 62, 1372-1375. [CrossRef]

97. Pinto, J.C.; Whiting, G.L.; Khodabakhsh, S.; Torre, L.; Rodríguez, A.; Dalgliesh, R.M.; Higgins, A.M.; Andreasen, J.W.; Nielsen, M.M.; Geoghegan, M.; et al. Organic Thin Film Transistors with Polymer Brush Gate Dielectrics Synthesized by Atom Transfer Radical Polymerization. Adv. Funct. Mater. 2008, 18, 36-43. [CrossRef]

98. Hwang, D.H.; Nomura, A.; Kim, J.; Kim, J.H.; Cho, H.; Lee, C.; Ohno, K.; Tsujii, Y. Synthesis and characterization of polystyrene brushes for organic thin film transistors. J. Nanosci. Nanotechnol. 2012, 12, 4137-4141. [CrossRef]

99. Facchetti, A.; Yoon, M.-H.; Marks, T.J. Gate Dielectrics for Organic Field-Effect Transistors: New Opportunities for Organic Electronics. Adv. Mater. 2005, 17, 1705-1725. [CrossRef]

100. Veres, J.; Ogier, S.; Lloyd, G.; de Leeuw, D. Gate Insulators in Organic Field-Effect Transistors. Chem. Mater. 2004, 16, 4543-4555. [CrossRef]

101. Li, L.; Hu, W.; Chi, L.; Fuchs, H. Polymer brush and inorganic oxide hybrid nanodielectrics for high performance organic transistors. J. Phys. Chem. B 2010, 114, 5315-5319. [CrossRef] [PubMed] 
102. Kopeć, M.; Spanjers, J.; Scavo, E.; Ernens, D.; Duvigneau, J.; Julius Vancso, G. Surface-initiated ATRP from polydopamine-modified TiO2 nanoparticles. Eur. Polym. J. 2018, 106, 291-296. [CrossRef]

103. Maeda, S.; Fujita, M.; Idota, N.; Matsukawa, K.; Sugahara, Y. Preparation of Transparent Bulk TiO2/PMMA Hybrids with Improved Refractive Indices via an in Situ Polymerization Process Using TiO2 Nanoparticles Bearing PMMA Chains Grown by Surface-Initiated Atom Transfer Radical Polymerization. ACS Appl. Mater. Interfaces 2016, 8, 34762-34769. [CrossRef]

104. Liu, L.; Chen, H.; Yang, F. Enhancing membrane performance by blending ATRP grafted PMMA-TiO 2 or PMMA-PSBMA-TiO2 in PVDF. Sep. Purif. Technol. 2014, 133, 22-31. [CrossRef]

105. Fan, X.; Lin, L.; Messersmith, P.B. Surface-initiated polymerization from $\mathrm{TiO} 2$ nanoparticle surfaces through a biomimetic initiator: A new route toward polymer-matrix nanocomposites. Compos. Sci. Technol. 2006, 66, 1198-1204. [CrossRef]

106. Cui, W.W.; Tang, D.Y.; Gong, Z.L. Electrospun poly(vinylidene fluoride)/poly(methyl methacrylate) grafted TiO 2 composite nanofibrous membrane as polymer electrolyte for lithium-ion batteries. J. Power Sources 2013, 223, 206-213. [CrossRef]

107. Xia, R.; Ruan, Z.; Zhang, Y.; Zhu, H.; Cao, M.; Chen, P.; Miao, J.; Qian, J. Click polymerization and characterization of TiO2 nanoparticles to one-dimensional nanochains. Chem. Phys. Lett. 2017, 687, 312-316. [CrossRef]

108. Kumar, A.; Bansal, A.; Behera, B.; Jain, S.L.; Ray, S.S. Ternary hybrid polymeric nanocomposites through grafting of polystyrene on graphene oxide-TiO2 by surface initiated atom transfer radical polymerization (SI-ATRP). Mater. Chem. Phys. 2016, 172, 189-196. [CrossRef]

109. Vergnat, V.; Roland, T.; Pourroy, G.; Masson, P. Effect of covalent grafting on mechanical properties of TiO 2/polystyrene composites. Mater. Chem. Phys. 2014, 147, 261-267. [CrossRef]

110. Wang, W.; Cao, H.; Zhu, G.; Wang, P. A facile strategy to modify TiO 2 nanoparticles via surface-initiated ATRP of styrene. J. Polym. Sci. Part A Polym. Chem. 2010, 48, 1782-1790. [CrossRef]

111. Tae Park, J.; Soo Lee, C.; Hun Park, C.; Hak Kim, J. Preparation of TiO2/Ag binary nanocomposite as high-activity visible-lightdriven photocatalyst via graft polymerization. Chem. Phys. Lett. 2017, 685, 119-126. [CrossRef]

112. Park, J.T.; Koh, J.H.; Roh, D.K.; Shul, Y.G.; Kim, J.H. Proton-conducting nanocomposite membranes based on P(VDF-co-CTFE)-gPSSA graft copolymer and TiO2-PSSA nanoparticles. Int. J. Hydrogen Energy 2011, 36, 1820-1827. [CrossRef]

113. Park, J.T.; Koh, J.H.; Seo, J.A.; Cho, Y.S.; Kim, J.H. Synthesis and characterization of TiO 2 / Ag/polymer ternary nanoparticles via surface-initiated atom transfer radical polymerization. Appl. Surf. Sci. 2011, 257, 8301-8306. [CrossRef]

114. Park, J.T.; Koh, J.H.; Koh, J.K.; Kim, J.H. Surface-initiated atom transfer radical polymerization from TiO2 nanoparticles. Appl. Surf. Sci. 2009, 255, 3739-3744. [CrossRef]

115. Gong, Z.; Tang, D.; Guo, Y. The fabrication and self-flocculation effect of hybrid TiO2 nanoparticles grafted with poly(Nisopropylacrylamide) at ambient temperature via surface-initiated atom transfer radical polymerization. J. Mater. Chem. 2012, 22, 16872. [CrossRef]

116. Chen, H.; Pan, S.; Xiong, Y.; Peng, C.; Pang, X.; Li, L.; Xiong, Y.; Xu, W. Preparation of thermo-responsive superhydrophobic TiO 2 /poly(N-isopropylacrylamide) microspheres. Appl. Surf. Sci. 2012, 258, 9505-9509. [CrossRef]

117. Zhang, G.; Lu, S.; Zhang, L.; Meng, Q.; Shen, C.; Zhang, J. Novel polysulfone hybrid ultrafiltration membrane prepared with TiO2-g-HEMA and its antifouling characteristics. J. Memb. Sci. 2013, 436, 163-173. [CrossRef]

118. Krysiak, E.; Wypych-Puszkarz, A.; Krysiak, K.; Nowaczyk, G.; Makrocka-Rydzyk, M.; Jurga, S.; Ulanski, J. Core-shell system based on titanium dioxide with elevated value of dielectric permittivity: Synthesis and characterization. Synth. Met. 2015, 209, 150-157. [CrossRef]

119. Xie, L.; Huang, X.; Wu, C.; Jiang, P. Core-shell structured poly(methyl methacrylate)/BaTiO3 nanocomposites prepared by in situ atom transfer radical polymerization: A route to high dielectric constant materials with the inherent low loss of the base polymer. J. Mater. Chem. 2011, 21, 5897-5906. [CrossRef]

120. You, N.; Zhang, C.; Liang, Y.; Zhang, Q.; Fu, P.; Liu, M.; Zhao, Q.; Cui, Z.; Pang, X. Facile Fabrication of Size-Tunable Core/Shell Ferroelectric/Polymeric Nanoparticles with Tailorable Dielectric Properties via Organocatalyzed Atom Transfer Radical Polymerization Driven by Visible Light. Sci. Rep. 2019, 9, 1869. [CrossRef]

121. Zhang, X.; Zhao, S.; Wang, F.; Ma, Y.; Wang, L.; Chen, D.; Zhao, C.; Yang, W. Improving dielectric properties of Ba$\mathrm{TiO} /$ poly(vinylidene fluoride) composites by employing core-shell structured BaTiO3@Poly(methylmethacrylate) and BaTiO3@Poly(trifluoroethyl methacrylate) nanoparticles. Appl. Surf. Sci. 2017, 403, 71-79. [CrossRef]

122. Bobnar, V.; LeV.stik, A.; Huang, C.; Zhang, Q.M. Intrinsic dielectric properties and charge transport in oligomers of organic semiconductor copper phthalocyanine. Phys. Rev. B 2005, 71, 041202. [CrossRef]

123. Nalwa, H.S.; Dalton, L.R.; Vasudevan, P. Dielectric properties of copper-phthalocyanine polymer. Eur. Polym. J. 1985, 21, 943-947. [CrossRef]

124. Wang, J.; Guan, F.; Cui, L.; Pan, J.; Wang, Q.; Zhu, L. Achieving high electric energy storage in a polymer nanocomposite at low filling ratios using a highly polarizable phthalocyanine interphase. J. Polym. Sci. Part B Polym. Phys. 2014, 52, 1669-1680. [CrossRef]

125. Xie, L.; Huang, X.; Huang, Y.; Yang, K.; Jiang, P. Core@Double-Shell Structured BaTiO 3 -Polymer Nanocomposites with High Dielectric Constant and Low Dielectric Loss for Energy Storage Application. J. Phys. Chem. C 2013, 117, 22525-22537. [CrossRef] 
126. Zhang, X.; Chen, H.; Ma, Y.; Zhao, C.; Yang, W. Preparation and dielectric properties of core-shell structural composites of poly $(1 \mathrm{H}, 1 \mathrm{H}, 2 \mathrm{H}, 2 \mathrm{H}$-perfluorooctyl methacrylate)@BaTiO3 nanoparticles. Appl. Surf. Sci. 2013, 277, 121-127. [CrossRef]

127. Huang, Y.; Huang, X.; Schadler, L.S.; He, J.; Jiang, P. Core@Double-Shell Structured Nanocomposites: A Route to High Dielectric Constant and Low Loss Material. ACS Appl. Mater. Interfaces 2016, 8, 25496-25507. [CrossRef] [PubMed]

128. Cobo Sánchez, C.; Wåhlander, M.; Taylor, N.; Fogelström, L.; Malmström, E. Novel Nanocomposites of Poly(lauryl methacrylate)Grafted Al2O3 Nanoparticles in LDPE. ACS Appl. Mater. Interfaces 2015, 7, 25669-25678. [CrossRef] [PubMed]

129. Grabowski, C.A.; Fillery, S.P.; Koerner, H.; Tchoul, M.; Drummy, L.; Beier, C.W.; Brutchey, R.L.; Durstock, M.F.; Vaia, R.A. Dielectric performance of high permitivity nanocomposites: Impact of polystyrene grafting on BaTiO3 and TiO2. Nanocomposites 2016, 2, 117-124. [CrossRef]

130. Chen, S.; Lv, X.; Han, X.; Luo, H.; Bowen, C.R.; Zhang, D. Significantly improved energy density of BaTiO 3 nanocomposites by accurate interfacial tailoring using a novel rigid-fluoro-polymer. Polym. Chem. 2018, 9, 548-557. [CrossRef]

131. Ma, J.; Azhar, U.; Zong, C.; Zhang, Y.; Xu, A.; Zhai, C.; Zhang, L.; Zhang, S. Core-shell structured PVDF@BT nanoparticles for dielectric materials: A novel composite to prove the dependence of dielectric properties on ferroelectric shell. Mater. Des. 2019, 164, 107556. [CrossRef]

132. Kim, K.; Park, M.S.; Na, Y.; Choi, J.; Jenekhe, S.A.; Kim, F.S. Preparation and application of polystyrene-grafted alumina core-shell nanoparticles for dielectric surface passivation in solution-processed polymer thin film transistors. Org. Electron. 2019, 65, 305-310. [CrossRef]

133. Xie, L.; Huang, X.; Yang, K.; Li, S.; Jiang, P. “Grafting to” route to PVDF-HFP-GMA/BaTiO3 nanocomposites with high dielectric constant and high thermal conductivity for energy storage and thermal management applications. J. Mater. Chem. A 2014, 2, 5244. [CrossRef]

134. Ejaz, M.; Puli, V.S.; Elupula, R.; Adireddy, S.; Riggs, B.C.; Chrisey, D.B.; Grayson, S.M. Core-shell structured poly(glycidyl methacrylate)/BaTiO3 nanocomposites prepared by surface-initiated atom transfer radical polymerization: A novel material for high energy density dielectric storage. J. Polym. Sci. Part A Polym. Chem. 2015, 53, 719-728. [CrossRef]

135. Qiao, Y.; Islam, M.S.; Wang, L.; Yan, Y.; Zhang, J.; Benicewicz, B.C.; Ploehn, H.J.; Tang, C. Thiophene Polymer-Grafted Barium Titanate Nanoparticles toward Nanodielectric Composites. Chem. Mater. 2014, 26, 5319-5326. [CrossRef]

136. Wang, C.; Zhang, J.; Gong, S.; Ren, K. Significantly enhanced breakdown field for core-shell structured poly(vinylidene fluoridehexafluoropropylene)/TiO2 nanocomposites for ultra-high energy density capacitor applications. J. Appl. Phys. 2018, 124, 154103. [CrossRef]

137. Tchoul, M.N.; Fillery, S.P.; Koerner, H.; Drummy, L.F.; Oyerokun, F.T.; Mirau, P.A.; Durstock, M.F.; Vaia, R.A. Assemblies of titanium dioxide-polystyrene hybrid nanoparticles for dielectric applications. Chem. Mater. 2010, 22, 1749-1759. [CrossRef]

138. Crippa, M.; Bianchi, A.; Cristofori, D.; D’Arienzo, M.; Merletti, F.; Morazzoni, F.; Scotti, R.; Simonutti, R. High dielectric constant rutile-polystyrene composite with enhanced percolative threshold. J. Mater. Chem. C 2013, 1, 484-492. [CrossRef]

139. Yang, C.; Marian, C.; Liu, J.; Di, Q.; Xu, M.; Zhang, Y.; Han, W.; Liu, K. Polymer grafted aluminum nanoparticles for percolative composite films with enhanced compatibility. Polymers 2019, 11, 638. [CrossRef]

140. Zhang, G.; Li, Y.; Tang, S.; Thompson, R.D.; Zhu, L. The Role of Field Electron Emission in Polypropylene/Aluminum Nanodielectrics Under High Electric Fields. ACS Appl. Mater. Interfaces 2017, 9, 10106-10119. [CrossRef]

141. Yu, J.; Huo, R.; Wu, C.; Wu, X.; Wang, G.; Jiang, P. Influence of interface structure on dielectric properties of epoxy/alumina nanocomposites. Macromol. Res. 2012, 20, 816-826. [CrossRef]

142. Fredin, L.A.; Li, Z.; Lanagan, M.T.; Ratner, M.A.; Marks, T.J. Substantial recoverable energy storage in percolative metallic aluminum-polypropylene nanocomposites. Adv. Funct. Mater. 2013, 23, 3560-3569. [CrossRef]

143. Chiefari, J.; Chong, Y.K.; Ercole, F.; Krstina, J.; Jeffery, J.; Le, T.P.T.; Mayadunne, R.T.A.; Meijs, G.F.; Moad, C.L.; Moad, G.; et al (Living Free-Radical Polymerization by Reversible Addition-Fragmentation Chain Transfer: The RAFT Process. Macromolecules 1998, 31, 5559-5562. [CrossRef]

144. Goto, A.; Fukuda, T. Kinetics of living radical polymerization. Prog. Polym. Sci. 2004, 29, 329-385. [CrossRef]

145. Fischer, H. The Persistent Radical Effect: A Principle for Selective Radical Reactions and Living Radical Polymerizations. Chem. Rev. 2001, 101, 3581-3610. [CrossRef] [PubMed]

146. Ouchi, M.; Terashima, T.; Sawamoto, M. Transition Metal-Catalyzed Living Radical Polymerization: Toward Perfection in Catalysis and Precision Polymer Synthesis. Chem. Rev. 2009, 109, 4963-5050. [CrossRef]

147. Nicolas, J.; Guillaneuf, Y.; Bertin, D.; Gigmes, D.; Charleux, B. Nitroxide-Mediated Polymerization. In Polymer Science: A Comprehensive Reference; Matyjaszewski, K., Möller, M., Eds.; Elsevier: Amsterdam, The Netherland, 2012; Volume 3, pp. 277-350; ISBN 9780080878621.

148. Moad, G.; Rizzardo, E.; Thang, S.H. Living Radical Polymerization by the RAFT Process-A Third Update. Aust. J. Chem. 2012, 65, 985-1076. [CrossRef]

149. Perrier, S. 50th Anniversary Perspective: RAFT Polymerization-A User Guide. Macromolecules 2017, 50, 7433-7447. [CrossRef]

150. Moad, G.; Rizzardo, E.; Thang, S.H. Radical addition-fragmentation chemistry in polymer synthesis. Polymer (Guildf). 2008, 49, 1079-1131. [CrossRef]

151. Gody, G.; Maschmeyer, T.; Zetterlund, P.B.; Perrier, S. Rapid and quantitative one-pot synthesis of sequence-controlled polymers by radical polymerization. Nat. Commun. 2013, 4, 2505. [CrossRef] 
152. Gody, G.; Maschmeyer, T.; Zetterlund, P.B.; Perrier, S. Pushing the Limit of the RAFT Process: Multiblock Copolymers by One-Pot Rapid Multiple Chain Extensions at Full Monomer Conversion. Macromolecules 2014, 47, 3451-3460. [CrossRef]

153. Chapman, R.; Gormley, A.J.; Herpoldt, K.-L.; Stevens, M.M. Highly Controlled Open Vessel RAFT Polymerizations by Enzyme Degassing. Macromolecules 2014, 47, 8541-8547. [CrossRef]

154. Gody, G.; Barbey, R.; Danial, M.; Perrier, S. Ultrafast RAFT polymerization: Multiblock copolymers within minutes. Polym. Chem. 2015, 6, 1502-1511. [CrossRef]

155. Gody, G.; Rossner, C.; Moraes, J.; Vana, P.; Maschmeyer, T.; Perrier, S. One-Pot RAFT/“Click” Chemistry via Isocyanates: Efficient Synthesis of $\alpha$-End-Functionalized Polymers. J. Am. Chem. Soc. 2012, 134, 12596-12603. [CrossRef]

156. Moraes, J.; Maschmeyer, T.; Perrier, S. "Pseudo-star" Copolymers Formed by a Combination of RAFT Polymerization and Isocyanate-Coupling. Aust. J. Chem. 2011, 64, 1047. [CrossRef]

157. Zhao, Y.; Perrier, S. Synthesis of Well-Defined Homopolymer and Diblock Copolymer Grafted onto Silica Particles by Z-Supported RAFT Polymerization. Macromolecules 2006, 39, 8603-8608. [CrossRef]

158. Stenzel, M.H.; Zhang, L.; Huck, W.T.S. Temperature-Responsive Glycopolymer Brushes Synthesized via RAFT Polymerization Using the Z-group Approach. Macromol. Rapid Commun. 2006, 27, 1121-1126. [CrossRef]

159. Zhu, L.-J.; Zhu, L.-P.; Zhang, P.-B.; Zhu, B.-K.; Xu, Y.-Y. Surface zwitterionicalization of poly(vinylidene fluoride) membranes from the entrapped reactive core-shell silica nanoparticles. J. Colloid Interface Sci. 2016, 468, 110-119. [CrossRef]

160. Le-Masurier, S.P.; Gody, G.; Perrier, S.; Granville, A.M. One-pot polymer brush synthesis via simultaneous isocyanate coupling chemistry and "grafting from" RAFT polymerization. Polym. Chem. 2014, 5, 2816-2823. [CrossRef]

161. Cai, Y.; Peng, W.; Demeshko, S.; Tian, J.; Vana, P. Silica-Coated Magnetite Nanoparticles Carrying a High-Density Polymer Brush Shell of Hydrophilic Polymer. Macromol. Rapid Commun. 2018, 39, 1800226. [CrossRef]

162. Qu, Z.; Hu, F.; Chen, K.; Duan, Z.; Gu, H.; Xu, H. A facile route to the synthesis of spherical poly(acrylic acid) brushes via RAFT polymerization for high-capacity protein immobilization. J. Colloid Interface Sci. 2013, 398, 82-87. [CrossRef] [PubMed]

163. Liu, J.; Zhang, L.; Shi, S.; Chen, S.; Zhou, N.; Zhang, Z.; Cheng, Z.; Zhu, X. A Novel and Universal Route to SiO 2 -Supported Organic/Inorganic Hybrid Noble Metal Nanomaterials via Surface RAFT Polymerization. Langmuir 2010, 26, 14806-14813. [CrossRef]

164. Zhu, L.-J.; Zhu, L.-P.; Jiang, J.-H.; Yi, Z.; Zhao, Y.-F.; Zhu, B.-K.; Xu, Y.-Y. Hydrophilic and anti-fouling polyethersulfone ultrafiltration membranes with poly(2-hydroxyethyl methacrylate) grafted silica nanoparticles as additive. J. Memb. Sci. 2014, 451, 157-168. [CrossRef]

165. Tumnantong, D.; Rempel, G.; Prasassarakich, P. Polyisoprene-Silica Nanoparticles Synthesized via RAFT Emulsifier-Free Emulsion Polymerization Using Water-Soluble Initiators. Polymers 2017, 9, 637. [CrossRef]

166. Bach, L.G.; Quynh, B.T.P.; Thuong, N.T.; Ho, V.T.T. Synthesis and characterization of photoluminescent Eu(III) coordinated with poly(2-hydroxyethyl methacrylate) grafted $\mathrm{SiO} 2$ nanoparticles via surface RAFT polymerization. Mol. Cryst. Liq. Cryst. 2017, 644, 175-182. [CrossRef]

167. Bach, L.G.; Bui, Q.T.P.; Cao, X.T.; Ho, V.T.T.; Lim, K.T. A new approach for synthesis of SiO2/poly(2-hydroxyethyl methacrylate):Tb3+ nanohybrids by combination of surface-initiated raft polymerization and coordination chemistry. Polym. Bull. 2016, 73, 2627-2638. [CrossRef]

168. Huang, G.; Xiong, Z.; Qin, H.; Zhu, J.; Sun, Z.; Zhang, Y.; Peng, X.; Ou, J.; Zou, H. Synthesis of zwitterionic polymer brushes hybrid silica nanoparticles via controlled polymerization for highly efficient enrichment of glycopeptides. Anal. Chim. Acta 2014, 809, 61-68. [CrossRef]

169. Bouharras, F.E.; Raihane, M.; Silly, G.; Totee, C.; Ameduri, B. Core-shell structured poly(vinylidene fluoride)- grafted -BaTiO 3 nanocomposites prepared via reversible addition-fragmentation chain transfer (RAFT) polymerization of VDF for high energy storage capacitors. Polym. Chem. 2019, 10, 891-904. [CrossRef]

170. Qian, K.; Lv, X.; Chen, S.; Luo, H.; Zhang, D. Interfacial engineering tailoring the dielectric behavior and energy density of BaTiO 3 / P(VDF-TrFE-CTFE) nanocomposites by regulating a liquid-crystalline polymer modifier structure. Dalt. Trans. 2018, 47, 12759-12768. [CrossRef]

171. Zhang, D.; Ma, C.; Zhou, X.; Chen, S.; Luo, H.; Bowen, C.R.; Zhou, K. High Performance Capacitors Using BaTiO 3 Nanowires Engineered by Rigid Liquid-crystalline Polymers. J. Phys. Chem. C 2017, 121, 20075-20083. [CrossRef]

172. Cao, X.T.; Showkat, A.M.; Lee, W.-K.; Lim, K.T. Luminescence of Terbium (III) Complexes Incorporated in Carboxylic Acid Functionalized Polystyrene/BaTiO 3 Nanocomposites. Mol. Cryst. Liq. Cryst. 2015, 622, 36-43. [CrossRef]

173. Qiao, Y.; Yin, X.; Wang, L.; Islam, M.S.; Benicewicz, B.C.; Ploehn, H.J.; Tang, C. Bimodal Polymer Brush Core-Shell Barium Titanate Nanoparticles: A Strategy for High-Permittivity Polymer Nanocomposites. Macromolecules 2015, 48, 8998-9006. [CrossRef]

174. Qiao, Y.; Islam, M.S.; Han, K.; Leonhardt, E.; Zhang, J.; Wang, Q.; Ploehn, H.J.; Tang, C. Polymers Containing Highly Polarizable Conjugated Side Chains as High-Performance All-Organic Nanodielectric Materials. Adv. Funct. Mater. 2013, 23, 5638-5646. [CrossRef]

175. Yang, K.; Huang, X.; Huang, Y.; Xie, L.; Jiang, P. Fluoro-Polymer@BaTiO 3 Hybrid Nanoparticles Prepared via RAFT Polymerization: Toward Ferroelectric Polymer Nanocomposites with High Dielectric Constant and Low Dielectric Loss for Energy Storage Application. Chem. Mater. 2013, 25, 2327-2338. [CrossRef] 
176. Yang, K.; Huang, X.; Xie, L.; Wu, C.; Jiang, P.; Tanaka, T. Core-Shell Structured Polystyrene/BaTiO 3 Hybrid Nanodielectrics Prepared by In Situ RAFT Polymerization: A Route to High Dielectric Constant and Low Loss Materials with Weak Frequency Dependence. Macromol. Rapid Commun. 2012, 33, 1921-1926. [CrossRef] [PubMed]

177. Zhang, L.; Khani, M.M.; Krentz, T.M.; Huang, Y.; Zhou, Y.; Benicewicz, B.C.; Nelson, J.K.; Schadler, L.S. Suppression of space charge in crosslinked polyethylene filled with poly(stearyl methacrylate)-grafted SiO 2 nanoparticles. Appl. Phys. Lett. 2017, 110, 132903. [CrossRef]

178. Krentz, T.; Khani, M.M.; Bell, M.; Benicewicz, B.C.; Nelson, J.K.; Zhao, S.; Hillborg, H.; Schadler, L.S. Morphologically dependent alternating-current and direct-current breakdown strength in silica-polypropylene nanocomposites. J. Appl. Polym. Sci. 2017, 134. [CrossRef]

179. Xiong, L.; Liang, H.B.; Wang, R.M.; Pang, Y. The effect of surface modification of TiO2 with diblock copolymers on the properties of epoxy nanocomposites. Polym. Plast. Technol. Eng. 2010, 49, 1483-1488. [CrossRef]

180. Li, C.; Han, J.; Ryu, C.Y.; Benicewicz, B.C. A versatile method to prepare RAFT agent anchored substrates and the preparation of PMMA grafted-nanoparticles. Macromolecules 2006, 39, 3175-3183. [CrossRef]

181. Schadler, L.S.; Kumar, S.K.; Benicewicz, B.C.; Lewis, S.L.; Harton, S.E. Designed Interfaces in Polymer Nanocomposites: A Fundamental Viewpoint. MRS Bull. 2007, 32, 335-340. [CrossRef]

182. Li, Y.; Krentz, T.M.; Wang, L.; Benicewicz, B.C.; Schadler, L.S. Ligand Engineering of Polymer Nanocomposites: From the Simple to the Complex. ACS Appl. Mater. Interfaces 2014, 6, 6005-6021. [CrossRef] [PubMed]

183. Natarajan, B.; Neely, T.; Rungta, A.; Benicewicz, B.C.; Schadler, L.S. Thermomechanical Properties of Bimodal Brush Modified Nanoparticle Composites. Macromolecules 2013, 46, 4909-4918. [CrossRef]

184. Rungta, A.; Natarajan, B.; Neely, T.; Dukes, D.; Schadler, L.S.; Benicewicz, B.C. Grafting Bimodal Polymer Brushes on Nanoparticles Using Controlled Radical Polymerization. Macromolecules 2012, 45, 9303-9311. [CrossRef]

185. Tanaka, T. Dielectric nanocomposites with insulating properties. IEEE Trans. Dielectr. Electr. Insul. 2005, 12, 914-928. [CrossRef]

186. Siddabattuni, S.; Schuman, T.P.; Dogan, F. Dielectric properties of polymer-particle nanocomposites influenced by electronic nature of filler surfaces. ACS Appl. Mater. Interfaces 2013, 5, 1917-1927. [CrossRef]

187. Bell, M.; Krentz, T.; Keith Nelson, J.; Schadler, L.; Wu, K.; Breneman, C.; Zhao, S.; Hillborg, H.; Benicewicz, B. Investigation of dielectric breakdown in silica-epoxy nanocomposites using designed interfaces. J. Colloid Interface Sci. 2017, 495, 130-139. [CrossRef] [PubMed]

188. Zhao, D.; Di Nicola, M.; Khani, M.M.; Jestin, J.; Benicewicz, B.C.; Kumar, S.K. Self-Assembly of Monodisperse versus Bidisperse Polymer-Grafted Nanoparticles. ACS Macro Lett. 2016, 5, 790-795. [CrossRef]

189. Hojjati, B.; Charpentier, P.A. Synthesis of TiO2-polymer nanocomposite in supercritical CO2 via RAFT polymerization. Polymer 2010, 51, 5345-5351. [CrossRef]

190. Hojjati, B.; Charpentier, P.A. Synthesis and kinetics of graft polymerization of methyl methacrylate from the RAFT coordinated surface of nano-TiO2. J. Polym. Sci. Part A Polym. Chem. 2008, 46, 3926-3937. [CrossRef]

191. Gregurec, D.; Politakos, N.; Yate, L.; Moya, S.E. Strontium confinement in polyacrylic acid brushes: A soft nanoarchitectonics approach for the design of titania coatings with enhanced osseointegration. Mol. Syst. Des. Eng. 2019, 4, 421-430. [CrossRef]

192. Hojjati, B.; Sui, R.; Charpentier, P.A. Synthesis of TiO2/PAA nanocomposite by RAFT polymerization. Polymer 2007, 48, 5850-5858. [CrossRef]

193. Rafiei, H.; Abbasian, M.; Yegani, R. Synthesis of well-defined poly(n-vinylpyrrolidone)/n-TiO2 nanocomposites by xanthatemediated radical polymerization. Iran. Polym. J. (Engl. Ed.) 2020. [CrossRef]

194. Abbasian, M.; Masoumi, B.; Masoudi, A.; Rashidzadeh, B. Synthesis and Characterization of Poly Chloromethylstyrene TiO2Nanocomposite Through a Simple Method via Reversible Addition-Fragmentation Transfer Polymerization. Polym. Plast. Technol. Eng. 2014, 53, 1150-1159. [CrossRef]

195. Che, X.C.; Jin, Y.Z.; Lee, Y.S. Preparation of nano-TiO2/polyurethane emulsions via in situ RAFT polymerization. Prog. Org. Coatings 2010, 69, 534-538. [CrossRef]

196. Xiong, L.; Wang, R.; Liang, H.; Pang, Y.; Guan, J. Synthesis and characterization of poly(methyl methacrylate)-b-polystyrene/ $\mathrm{TiO} 2$ nanocomposites via reversible addition-fragmentation chain transfer polymerization. J. Macromol. Sci. Part A Pure Appl. Chem. 2010, 47, 903-908. [CrossRef]

197. Zhu, M.; Huang, X.; Yang, K.; Zhai, X.; Zhang, J.; He, J.; Jiang, P. Energy Storage in Ferroelectric Polymer Nanocomposites Filled with Core-Shell Structured Polymer@BaTiO3 Nanoparticles: Understanding the Role of Polymer Shells in the Interfacial Regions. ACS Appl. Mater. Interfaces 2014, 6, 19644-19654. [CrossRef] [PubMed]

198. Georges, M.K.; Veregin, R.P.N.; Kazmaier, P.M.; Hamer, G.K. Narrow molecular weight resins by a free-radical polymerization process. Macromolecules 1993, 26, 2987-2988. [CrossRef]

199. Goto, A.; Fukuda, T. Kinetic Study on Nitroxide-Mediated Free Radical Polymerization of tert -Butyl Acrylate. Macromolecules 1999, 32, 618-623. [CrossRef]

200. Guillaneuf, Y.; Gigmes, D.; Marque, S.R.A.; Astolfi, P.; Greci, L.; Tordo, P.; Bertin, D. First Effective Nitroxide-Mediated Polymerization of Methyl Methacrylate. Macromolecules 2007, 40, 3108-3114. [CrossRef] 
201. Nicolas, J.; Charleux, B.; Guerret, O.; Magnet, S. Nitroxide-Mediated Controlled Free-Radical Emulsion Polymerization of Styrene andn-Butyl Acrylate with a Water-Soluble Alkoxyamine as Initiator. Angew. Chemie 2004, 116, 6312-6315. [CrossRef]

202. Couvreur, L.; Lefay, C.; Belleney, J.; Charleux, B.; Guerret, O.; Magnet, S. First Nitroxide-Mediated Controlled Free-Radical Polymerization of Acrylic Acid. Macromolecules 2003, 36, 8260-8267. [CrossRef]

203. Deleuze, C.; Delville, M.H.; Pellerin, V.; Derail, C.; Billon, L. Hybrid Core@Soft Shell Particles as Adhesive Elementary Building Blocks for Colloidal Crystals. Macromolecules 2009, 42, 5303-5309. [CrossRef]

204. Parvole, J.; Ahrens, L.; Blas, H.; Vinas, J.; Boissière, C.; Sanchez, C.; Save, M.; Charleux, B. Grafting polymer chains bearing an $\mathrm{N}$-succinimidyl activated ester end-group onto primary amine-coated silica particles and application of a simple, one-step approach via nitroxide-mediated controlled/living free-radical polymerization. J. Polym. Sci. Part A Polym. Chem. 2010, 48, 173-185. [CrossRef]

205. Ostaci, R.; Celle, C.; Seytre, G.; Beyou, E.; Chapel, J.; Drockenmuller, E. Influence of nitroxide structure on polystyrene brushes "grafted-from" silicon wafers. J. Polym. Sci. Part A Polym. Chem. 2008, 46, 3367-3374. [CrossRef]

206. Benoit, D.; Grimaldi, S.; Robin, S.; Finet, J.-P.; Tordo, P.; Gnanou, Y. Kinetics and Mechanism of Controlled Free-Radical Polymerization of Styrene and $\mathrm{n}$-Butyl Acrylate in the Presence of an Acyclic $\beta$-Phosphonylated Nitroxide. J. Am. Chem. Soc. 2000, 122, 5929-5939. [CrossRef]

207. Pitliya, P.; Butcher, R.J.; Karim, A.; Hudrlik, P.F.; Hudrlik, A.M.; Raghavan, D. 3-[1-(4-Bromophenyl)ethoxy]-2,2,5-trimethyl-4phenyl-3-azahexane. Acta Crystallogr. Sect. E Struct. Reports Online 2013, 69, o1792-o1793. [CrossRef]

208. Ni, G.; Yang, W.; Bo, L.; Guo, H.; Zhang, W.; Gao, J. Preparation of polystyrene/SiO2 nanocomposites by surface-initiated nitroxide-mediated radical polymerization. Chinese Sci. Bull. 2006, 51, 1644-1647. [CrossRef]

209. Matsuno, R.; Otsuka, H.; Takahara, A. Polystyrene-grafted titanium oxide nanoparticles prepared through surface-initiated nitroxide-mediated radical polymerization and their application to polymer hybrid thin films. Soft Matter 2006, 2, $415-421$. [CrossRef]

210. Abbasian, M.; Khakpour Aali, N. Nitroxide-Mediated Radical Polymerization of Styrene Initiated from the Surface of Titanium Oxide Nanoparticles. J. Nanostructures 2016, 6, 38-45. [CrossRef]

211. Jaymand, M. Synthesis and characterization of novel type poly (4-chloromethyl styrene-grft-4-vinylpyridine)/TiO2 nanocomposite via nitroxide-mediated radical polymerization. Polymer 2011, 52, 4760-4769. [CrossRef]

212. Lee, Y.J. Preparation of Poly(4-hydroxystyrene) Based Functional Block Copolymer Through Living Radical Polymerization and Its Nanocomposite with BaTiO3 for Dielectric Material. J. Nanosci. Nanotechnol. 2009, 9. [CrossRef]

213. Woo, J.H.; Park, M.; Lee, S.-S.; Hong, S.C. Preparation of Functional Polystyrene Copolymers Through Nitroxide Mediated Polymerization and Their Applications as Surface Modifiers for BaTiO3 Nanoparticles. J. Nanosci. Nanotechnol. 2009, 9, 1872-1880. [CrossRef] [PubMed]

214. Mai, T.B.; Tran, T.N.; Rafiqul Islam, M.; Park, J.M.; Lim, K.T. Covalent functionalization of silica nanoparticles with poly(Nisopropylacrylamide) employing thiol-ene chemistry and activator regenerated by electron transfer ATRP protocol. J. Mater. Sci. 2014, 49, 1519-1526. [CrossRef]

215. Han, M.S.; Zhang, X.Y.; Li, L.; Peng, C.; Bao, L.; Ou, E.C.; Xiong, Y.Q.; Xu, W.J. Dual-switchable surfaces between hydrophobic and superhydrophobic fabricated by the combination of click chemistry and RAFT. Express Polym. Lett. 2014, 8, 528-542. [CrossRef]

216. Guo, C.; Wang, B.; Shan, J. Preparation of Thermosensitive Hollow Imprinted Microspheres via Combining Distillation Precipitation Polymerization and Thiol-ene Click Chemistry. Chinese J. Chem. 2015, 33, 225-234. [CrossRef]

217. Li, G.L.; Xu, L.Q.; Tang, X.; Neoh, K.G.; Kang, E.T. Hairy Hollow Microspheres of Fluorescent Shell and Temperature-Responsive Brushes via Combined Distillation-Precipitation Polymerization and Thiol-ene Click Chemistry. Macromolecules 2010, 43, 5797-5803. [CrossRef]

218. Zhang, Q.; Yang, S.; Zhu, T.; Oh, J.K.; Li, P. Soft-nanocoupling between silica and gold nanoparticles based on block copolymer. React. Funct. Polym. 2017, 110, 30-37. [CrossRef]

219. Lee, S.; Jang, M.; Yang, H. Optimized Grafting Density of End-Functionalized Polymers to Polar Dielectric Surfaces for SolutionProcessed Organic Field-Effect Transistors. ACS Appl. Mater. Interfaces 2014, 6, 20444-20451. [CrossRef] [PubMed]

220. Maliakal, A.; Katz, H.; Cotts, P.M.; Subramoney, S.; Mirau, P. Inorganic Oxide Core, Polymer Shell Nanocomposite as a High K Gate Dielectric for Flexible Electronics Applications. J. Am. Chem. Soc. 2005, 127, 14655-14662. [CrossRef]

221. Hailu, S.T.; Samant, S.; Grabowski, C.; Durstock, M.; Karim, A.; Raghavan, D. Synthesis of highly dispersed, block copolymergrafted TiO2 nanoparticles within neat block copolymer films. J. Polym. Sci. Part A Polym. Chem. 2015, 53, 468-478. [CrossRef]

222. Hailu, S.T.; Samant, S.; Grabowski, C.; Durstock, M.; Karim, A.; Raghavan, D. Dielectric Study of PMMA-b-PS -g-TiO2/PS-PMMA BCP Nanocomposite Films. Unpublished data.

223. Obata, M.; Yamai, K.; Takahashi, M.; Ueno, S.; Ogura, H.; Egami, Y. Synthesis of an oxygen-permeable block copolymer with catechol groups and its application in polymer-ceramic pressure-sensitive paint. Polymer 2020, 191, 122281. [CrossRef]

224. Klaysri, R.; Wichaidit, S.; Piticharoenphun, S.; Mekasuwandumrong, O.; Praserthdam, P. Synthesis of TiO2-grafted onto PMMA film via ATRP: Using monomer as a coupling agent and reusability in photocatalytic application. Mater. Res. Bull. 2016, 83, 640-648. [CrossRef]

225. Yang, K.; Huang, X.; Zhu, M.; Xie, L.; Tanaka, T.; Jiang, P. Combining RAFT Polymerization and Thiol-Ene Click Reaction for Core-Shell Structured Polymer@BaTiO3 Nanodielectrics with High Dielectric Constant, Low Dielectric Loss, and High Energy Storage Capability. ACS Appl. Mater. Interfaces 2014, 6, 1812-1822. [CrossRef] 
226. Bourgeat-Lami, E.; Lang, J. Encapsulation of Inorganic Particles by Dispersion Polymerization in Polar Media. J. Colloid Interface Sci. 1998, 197, 293-308. [CrossRef] [PubMed]

227. Guo, J.; Zhang, H.; Li, C.; Zang, L.; Luo, J. In situ synthesis of poly(methyl methacrylate)/SiO 2 hybrid nanocomposites via grafting onto strategy based on UV irradiation in the presence of iron aqueous solution. J. Nanomater. 2012, 2012. [CrossRef]

228. Landfester, K. Synthesis of colloidal particles in miniemulsions. Annu. Rev. Mater. Res. 2006, 36, 231-279. [CrossRef]

229. Tang, E.; Dong, S. Preparation of styrene polymer/ZnO nanocomposite latex via miniemulsion polymerization and its antibacterial property. Colloid Polym. Sci. 2009, 287, 1025-1032. [CrossRef]

230. Morales-Acosta, M.D.; Alvarado-Beltrán, C.G.; Quevedo-López, M.A.; Gnade, B.E.; Mendoza-Galván, A.; Ramírez-Bon, R. Adjustable structural, optical and dielectric characteristics in sol-gel PMMA-SiO2 hybrid films. J. Non. Cryst. Solids 2013, 362, 124-135. [CrossRef]

231. Alvarado-Beltrán, C.G.; Almaral-Sánchez, J.L.; Mejia, I.; Quevedo-López, M.A.; Ramirez-Bon, R. Sol-Gel PMMA-ZrO 2 Hybrid Layers as Gate Dielectric for Low-Temperature ZnO-Based Thin-Film Transistors. ACS Omega 2017, 2, 6968-6974. [CrossRef]

232. Morales-Acosta, M.D.; Quevedo-López, M.A.; Ramírez-Bon, R. PMMA-SiO2 hybrid films as gate dielectric for ZnO based thin-film transistors. Mater. Chem. Phys. 2014, 146, 380-388. [CrossRef]

233. Alvarado-Beltrán, C.G.; Almaral-Sánchez, J.L.; Ramírez-Bon, R. Synthesis and properties of PMMA-ZrO 2 organic-inorganic hybrid films. J. Appl. Polym. Sci. 2015, 132, n. [CrossRef]

234. Alvarado-Beltrán, C.G.; Almaral-Sánchez, J.L.; Quevedo-López, M.A.; Ramirez-Bon, R. Dielectric Gate Applications of PMMATiO2 Hybrid Films in ZnO-Based Thin Film Transistors. Int. J. Electrochem. Sci 2015, 10, 4068-4082.

235. Sánchez-Ahumada, D.; Verastica-Ward, L.J.; Gálvez-López, M.F.; Castro-Beltrán, A.; Ramirez-Bon, R.; Alvarado-Beltrán, C.G. Low-temperature synthesis and physical characteristics of PS TiO2 hybrid films for transparent dielectric gate applications. Polymer 2019, 172, 170-177. [CrossRef]

236. Kandulna, R.; Choudhary, R.B.; Singh, R.; Purty, B. PMMA-TiO2 based polymeric nanocomposite material for electron transport layer in OLED application. J. Mater. Sci. Mater. Electron. 2018, 29, 5893-5907. [CrossRef]

237. Zhou, Y.; Liu, Q.; Chen, F.; Zhao, Y.; Sun, S.; Guo, J.; Yang, Y.; Xu, J. Significantly enhanced energy storage in core-shell structured poly(vinylidene fluoride-co-chlorotrifluoroethylene)/BaTiO3@polyurea nanocomposite films. J. Mater. Sci. 2020, 55, 11296-11309. [CrossRef]

238. Pang, X.; Zhao, L.; Han, W.; Xin, X.; Lin, Z. A general and robust strategy for the synthesis of nearly monodisperse colloidal nanocrystals. Nat. Nanotechnol. 2013, 8, 426-431. [CrossRef]

239. Müllner, M.; Yuan, J.; Weiss, S.; Walther, A.; Förtsch, M.; Drechsler, M.; Müller, A.H.E. Water-Soluble Organo-Silica Hybrid Nanotubes Templated by Cylindrical Polymer Brushes. J. Am. Chem. Soc. 2010, 132, 16587-16592. [CrossRef]

240. Zheng, Z.; Daniel, A.; Yu, W.; Weber, B.; Ling, J.; Müller, A.H.E. Rare-Earth Metal Cations Incorporated Silica Hybrid Nanoparticles Templated by Cylindrical Polymer Brushes. Chem. Mater. 2013, 25, 4585-4594. [CrossRef]

241. Müllner, M.; Lunkenbein, T.; Breu, J.; Caruso, F.; Müller, A.H.E. Template-Directed Synthesis of Silica Nanowires and Nanotubes from Cylindrical Core-Shell Polymer Brushes. Chem. Mater. 2012, 24, 1802-1810. [CrossRef]

242. Yuan, J.; Lu, Y.; Schacher, F.; Lunkenbein, T.; Weiss, S.; Schmalz, H.; Müller, A.H.E. Template-Directed Synthesis of Hybrid Titania Nanowires within Core-Shell Bishydrophilic Cylindrical Polymer Brushes. Chem. Mater. 2009, 21, 4146-4154. [CrossRef]

243. Yuan, J.; Schacher, F.; Drechsler, M.; Hanisch, A.; Lu, Y.; Ballauff, M.; Müller, A.H.E. Stimuli-Responsive Organosilica Hybrid Nanowires Decorated with Metal Nanoparticles. Chem. Mater. 2010, 22, 2626-2634. [CrossRef]

244. Xu, H.; Xu, Y.; Pang, X.; He, Y.; Jung, J.; Xia, H.; Lin, Z. A general route to nanocrystal kebabs periodically assembled on stretched flexible polymer shish. Sci. Adv. 2015, 1, 1-12. [CrossRef] [PubMed]

245. He, M.; Pang, X.; Liu, X.; Jiang, B.; He, Y.; Snaith, H.; Lin, Z. Monodisperse Dual-Functional Upconversion Nanoparticles Enabled Near-Infrared Organolead Halide PeroV·skite Solar Cells. Angew. Chemie Int. Ed. 2016, 55, 4280-4284. [CrossRef] [PubMed]

246. Liu, Y.; Wang, J.; Zhang, M.; Li, H.; Lin, Z. Polymer-Ligated Nanocrystals Enabled by Nonlinear Block Copolymer Nanoreactors: Synthesis, Properties, and Applications. ACS Nano 2020, 14, 12491-12521. [CrossRef]

247. Xie, G.; Ding, H.; Daniel, W.F.M.; Wang, Z.; Pietrasik, J.; Sheiko, S.S.; Matyjaszewski, K. Preparation of titania nanoparticles with tunable anisotropy and branched structures from core-shell molecular bottlebrushes. Polymer 2016, 98, 481-486. [CrossRef]

248. Müllner, M.; Lunkenbein, T.; Schieder, M.; Gröschel, A.H.; Miyajima, N.; Förtsch, M.; Breu, J.; Caruso, F.; Müller, A.H.E. TemplateDirected Mild Synthesis of Anatase Hybrid Nanotubes within Cylindrical Core-Shell-Corona Polymer Brushes. Macromolecules 2012, 45, 6981-6988. [CrossRef]

249. Yuan, J.; Xu, Y.; Walther, A.; Bolisetty, S.; Schumacher, M.; Schmalz, H.; Ballauff, M.; Müller, A.H.E. Water-soluble organo-silica hybrid nanowires. Nat. Mater. 2008, 7, 718-722. [CrossRef]

250. Wang, H.; Liu, Y.; Li, M.; Huang, H.; Xu, H.M.; Hong, R.J.; Shen, H. Multifunctional TiO2 nanowires-modified nanoparticles bilayer film for 3D dye-sensitized solar cells. Optoelectron. Adv. Mater. Rapid Commun. 2010, 4, 1166-1169. [CrossRef]

251. Budzalek, K.; Ding, H.; Janasz, L.; Wypych-Puszkarz, A.; Cetinkaya, O.; Pietrasik, J.; Kozanecki, M.; Ulanski, J.; Matyjaszewski, K. Star polymer-TiO2 nanohybrids to effectively modify the surface of PMMA dielectric layers for solution processable OFETs. J. Mater. Chem. C 2021, 9, 1269-1278. [CrossRef] 
252. Pang, X.; Zhao, L.; Akinc, M.; Kim, J.K.; Lin, Z. Novel Amphiphilic Multi-Arm, Star-Like Block Copolymers as Unimolecular Micelles. Macromolecules 2011, 44, 3746-3752. [CrossRef]

253. Guo, H.Z.; Mudryk, Y.; Ahmad, M.I.; Pang, X.C.; Zhao, L.; Akinc, M.; Pecharsky, V.K.; Bowler, N.; Lin, Z.Q.; Tan, X. Structure evolution and dielectric behavior of polystyrene-capped barium titanate nanoparticles. J. Mater. Chem. 2012. [CrossRef]

254. Pang, X.; He, Y.; Jiang, B.; Iocozzia, J.; Zhao, L.; Guo, H.; Liu, J.; Akinc, M.; Bowler, N.; Tan, X.; et al. Block copolymer/ferroelectric nanoparticle nanocomposites. Nanoscale 2013, 5, 8695. [CrossRef]

255. Bates, C.M.; Bates, F.S. 50th Anniversary Perspective: Block Polymers-Pure Potential. Macromolecules 2017, 50, 3-22. [CrossRef]

256. Samant, S.P.; Grabowski, C.A.; Kisslinger, K.; Yager, K.G.; Yuan, G.; Satija, S.K.; Durstock, M.F.; Raghavan, D.; Karim, A. Directed Self-Assembly of Block Copolymers for High Breakdown Strength Polymer Film Capacitors. ACS Appl. Mater. Interfaces 2016, 8, 7966-7976. [CrossRef] [PubMed]

257. Samant, S.; Hailu, S.; Singh, M.; Pradhan, N.; Yager, K.; Al-Enizi, A.M.; Raghavan, D.; Karim, A. Alignment frustration in block copolymer films with block copolymer grafted TiO2 nanoparticles under soft-shear cold zone annealing. Polym. Adv. Technol. 2021, 32, 2052-2060. [CrossRef] 